\title{
Large Eddy Simulations of Severe Convection Induced Turbulence
}

\author{
Nash'at Ahmad*, Fred Proctor ${ }^{\dagger}$ \\ NASA Langley Research Center, Hampton, Virginia, 23681
}

\begin{abstract}
Convective storms can pose a serious risk to aviation operations since they are often accompanied by turbulence, heavy rain, hail, icing, lightning, strong winds, and poor visibility. They can cause major delays in air traffic due to the re-routing of flights, and by disrupting operations at the airports in the vicinity of the storm system. In this study, the Terminal Area Simulation System is used to simulate five different convective events ranging from a mesoscale convective system to isolated storms. The occurrence of convection induced turbulence is analyzed from these simulations. The validation of model results with the radar data and other observations is reported and an aircraft-centric turbulence hazard metric calculated for each case is discussed. The turbulence analysis showed that large pockets of significant turbulence hazard can be found in regions of low radar reflectivity. Moderate and severe turbulence was often found in building cumulus turrets and overshooting tops.
\end{abstract}

\section{Nomenclature}

$\begin{array}{ll}d B Z & =\text { decibels of radar reflectivity, } Z \\ \text { MSL } & =\text { Mean Sea Level } \\ \text { NEXRAD } & =\text { Next Generation Radar } \\ g & =\text { acceleration due to earth's gravity } \\ P & =\text { atmospheric pressure } \\ w & =\text { vertical component of velocity } \\ T & =\text { atmospheric temperature } \\ x & =\text { Cartesian coordinate in east direction } \\ y & =\text { Cartesian coordinate in north direction } \\ z & =\text { Cartesian coordinate in vertical direction, altitude above ground } \\ \Delta n & =\text { aircraft's normal load acceleration } \\ \Delta x & =\text { grid size along } x \text {-coordinate } \\ \Delta y & =\text { grid size along } y \text {-coordinate } \\ \Delta z & =\text { grid size along } z \text {-coordinate } \\ L_{\mathrm{x}} & =\text { averaging interval along } x \text {-direction } \\ L_{\mathrm{y}} & =\text { variance of vertical velocity } \\ \sigma_{\mathrm{w}}{ }^{2} & =\text { root mean square of aircraft's normal load acceleration } \\ \sigma_{\Delta \mathrm{n}} & \end{array}$

\section{Introduction}

ircraft encounters with turbulence are the leading cause of in-flight injuries (Tyrvanas 2003), and on a few A loccasions have resulted in passenger and crew fatalities. According to a National Transportation and Safety Board (NTSB) report posted on the internet, there were 19,562 aircraft accidents between 1994 and 2003 and weather was a factor in approximately $21 \%$ of these accidents. In the Federal Aviation Regulations (FAR) Part 121 (Air Carrier Operations) category, seventy four percent of the weather related accidents were due to turbulence encounters (http://www.asias.faa.gov/aviation_studies/weather_study/studyindex.html). A substantial number of these turbulence encounters was likely due to convection induced turbulence (CIT). Studies have shown that most

\footnotetext{
${ }^{*}$ Research Aerospace Engineer, NASA, Hampton, Virginia. Senior Member, AIAA.

${ }^{\dagger}$ Senior Research Scientist, NASA, Hampton, Virginia. Senior Member, AIAA.
} 
of the injuries were caused by sudden and unexpected encounters with turbulence that occurred within or in proximity to convective activity (Kaplan 2005). Encounters with severe CIT are usually brief, lasting several seconds to a few minutes. Severe encounters may occur as aircraft attempt to navigate around high radar reflectivity regions or when cells rise from below the flight path, especially when visibility is poor.

In the fall of 2000 and the spring of 2002, two flight campaigns were conducted by the National Aeronautics and Space Administration (NASA) to test the feasibility of a radar-based airborne turbulence detection system. NASA Langley Research Center's B-757 research aircraft was flown into regions of convectively induced turbulence. Turbulence encounters were typically less than 30 s in duration and coincided with the time spent within the cloud (Hamilton and Proctor 2002; Hamilton and Proctor 2006). Furthermore, the events occurred outside of moderate and high reflectivity regions $(>35 \mathrm{dBZ})$ which were avoided during the flight experiments. Strong turbulence encounters occurred with radar reflectivity factors as low as $0 d B Z$ and no correlation was apparent between turbulence intensity and the radar reflectivity factor (RRF).

In commercial aircraft encounters with CIT, onboard weather radar may fail to detect regions of low RRF, and the incidents are therefore classified as encounters with clear air turbulence (CAT). For example, on 15 July 2010, a Delta Airlines' Boeing 767-300 encountered turbulence 250nmi north-northwest of Guam while at 36,000ft. The onboard weather radar indicated nothing prior to the incident. During the encounter, the aircraft underwent vertical accelerations between $+1.5 \mathrm{~g}$ and $-0.3 \mathrm{~g}$ for approximately $5 \mathrm{~s}$. A flight attendant walking down the aisle fell down and fractured her ankle. The investigation into the incident concluded that the probable cause of the accident was an inadvertent encounter with clear air turbulence (NTSB Identification: DCA10FA076). This conclusion is suspect since the crew reported scattered cloud build ups around the aircraft at the time of the incident, and synoptic weather conditions did not support the likelihood of CAT.

Simulations with the Terminal Area Simulation System (TASS) have been used in the past for the development and testing of algorithms used by airborne turbulence detection systems and in defining turbulence hazard in terms of aircraft-centric metrics (Hamilton and Proctor 2006). These simulations also provide a detailed insight into the formation and evolution of convective systems. In the following sections, the TASS, the Weather Research and Forecast (WRF) mesoscale model, and the turbulence hazard metric used in this study are briefly described. The paper examines five severe convective events simulated with TASS. The simulation results are compared with the Next Generation Radar (NEXRAD) data (http://www.roc.noaa.gov/WSR88D/) and other observations. Aircraftcentric turbulence characteristics associated with each convective event are also discussed.

\section{Terminal Area Simulation System (TASS)}

TASS is a state-of-the-art, cloud-resolving, large eddy simulation atmospheric flow model (Proctor 1987, 1996, 2002; Proctor et al. 2002). TASS computes the primitive variables non-hydrostatic equations in three dimensions and is capable of resolving flows at multiple spatial (grid resolutions varying from less than $1 \mathrm{~m}$ to $2 \mathrm{~km}$ in the horizontal) and temporal scales (few seconds in the case of turbulence eddies to hours for long-lived convective phenomena). The model solves prognostic equations for potential temperature, water vapor, cloud droplets, ice crystals, rain, snow and hail, and includes a microphysics package for cloud and precipitation development (Proctor 1987). Subgrid scale diffusion is parameterized via a Smagorinsky-type turbulence closure (Smagorinsky 1963) and surface layer processes are computed based on the Monin-Obukhov similarity theory (Stull 1997). The TASS model equations are discretized using quadratic-conservative fourth-order finite-differences in space for the calculation of momentum and pressure fields (Proctor 1996) and the third-order Leonard scheme (Leonard 1995) is used to calculate the transport of potential temperature and water vapor. A Monotone Upstream-centered Scheme for Conservation Laws (MUSCL)-type scheme after van Leer (van Leer 1979; Ahmad and Proctor 2011) has also been implemented in TASS for the transport of water substance variables. The TASS computational mesh uses the Arakawa C-grid staggering (Arakawa and Lamb 1977) for specifying velocities and thermodynamic quantities. The Klemp-Wilhelmson time-splitting scheme (Klemp and Wilhelmson 1978) is used for computational efficiency in which the higher-frequency terms are integrated by enforcing the CFL criteria to take into account sound wave propagation due to compressibility effects. The remaining terms are integrated using a larger time step that is appropriate for anelastic and incompressible flows. Nonreflecting Orlanski boundary conditions (Orlanski 1976) are imposed on open/outflow lateral boundaries. Options also exist for periodic lateral boundary conditions. A sixthorder filter is used to damp-out spurious oscillations in the velocity field that may arise due to the use of centereddifferencing of momentum and pressure terms. Filter and sponge conditions (Perkey and Kreitzberg 1976) are applied to the top four levels to minimize flow interactions and gravity wave reflections with the closed top boundary. The model code is written in FORTRAN and has been fully parallelized for distributed computing 
platforms using the Message Passing Interface (MPI). Excellent scalability and vectorization has been demonstrated on high-end supercomputing platforms such as NASA's SGI Altix cluster.

\section{Initialization of TASS Simulations}

Two steps were needed for achieving high resolution simulations of each of the five cases described in this paper. In the first step, a numerical weather prediction model was run in order to obtain representative environmental conditions. In the second step, the environmental conditions were used as initial conditions in TASS to simulate the detailed structure and evolution of the convective event. The environmental conditions were obtained with the National Center for Atmospheric Research's (NCAR) Weather Research and Forecast (WRF) model (Klemp et al. 2000). The WRF model has been developed by NCAR with help from various partners in academia and government. WRF is a mesoscale weather prediction model with governing equations for the timedependent, three-dimensional, nonhydrostatic, fully compressible Navier-Stokes equations. In the vertical, WRF uses a terrain-following pressure formulation, where the top of the domain is a constant pressure surface. The model grid structure is based on Arakawa C-grid staggering (Arakawa and Lamb 1977). Both horizontal and vertical advection terms can be discretized anywhere from second- to sixth-order spatial accuracy. Fifth-order upwind differencing in the horizontal direction and third-order upwind differencing in the vertical direction are recommended by the developers of the WRF model. The time integration is done using an explicit third-order Runge-Kutta time marching scheme, with smaller time steps for acoustic and gravity wave modes. Extensive physics packages for modeling the boundary layer turbulence, cumulus parameterizations, cloud microphysics, radiation physics and surface layer interactions are included in the model distribution. High resolution terrain and other land use datasets are part of the standard WRF distribution. Numerical forecasts were conducted with WRF to provide initial soundings for each of the five cases described in this paper. The initial environment in TASS is assumed horizontally homogeneous, and varies only in the vertical condition in accordance with the sounding extracted from the WRF simulation. Convection with cloud and precipitation development in TASS is triggered by imposing an artificial bubble of warm air. Three-dimensional velocity, thermodynamic, and moisture fields evolve in the TASS simulation as the convection interacts with the environmental fields.

\section{Flight Turbulence Hazard Metric}

The preferred aircraft turbulence hazard metric (Bowles and Buck 2009; Hamilton and Proctor 2006; Proctor and Hamilton 2005) is a five-second root mean square of the aircraft's normal load accelerations $\left(\sigma_{\Delta \mathrm{n}}\right)$. This metric is preferred because:

1) It is airplane centric

2) The metric is easy to calculate

3) It statistically quantifies the sharp bumps and accelerations that passengers feel when flying in an aircraft

4) And it is understood by the airplane operators

For a given turbulence event, the RMS of normal load accelerations $\left(\sigma_{\Delta \mathrm{n}}\right)$ is strongly correlated with the peak normal load $(|\Delta n|)$. This correlation is shown in Figure 1. Since the relationship of the peak normal load $(|\Delta n|)$ with the root mean square of normal load accelerations is known; the hazard levels can be assigned. The turbulence metric thresholds are subjective, but for warning pilots and dispatchers they can be categorized as follows (Bowles and Buck 2009):

$$
\begin{array}{ll}
\sigma_{\Delta n} \leq 0.1 \mathrm{~g} & \text { Light Turbulence } \\
0.1<\sigma_{\Delta n} \leq 0.2 \mathrm{~g} & \text { Moderate Turbulence } \\
0.2 \leq \sigma_{\Delta n}<0.3 \mathrm{~g} & \text { Moderate to Severe Turbulence } \\
0.3 \leq \sigma_{\Delta n}<0.6 \mathrm{~g} & \text { Severe Turbulence } \\
0.6 \leq \sigma_{\Delta n} & \text { Extreme Turbulence }
\end{array}
$$

The NTSB accident reconstructions shown in Figure 1 have values greater than $0.35 g$ root mean square normal load acceleration $\left(\sigma_{\Delta \mathrm{n}}\right)$ or $1 \mathrm{~g}$ peak normal load $(|\Delta n|)$. Since aircraft response is most affected by the along-track gradients in vertical velocity, the aircraft normal loads can be estimated from aircraft flight dynamics models. A more general algorithm that can easily be applied to large data sets has been used by Proctor et al. (2002a, 2002b) and Hamilton and Proctor (2003). This method relates aircraft RMS normal load acceleration to the variance in 
vertical velocity computed with a $1 \mathrm{~km} \times 1 \mathrm{~km}$ moving box. The $\sigma_{\mathrm{w}}$ fields can be computed for any horizontal plane by using a moving average:

$$
\sigma_{w}(x, y)=\left[\frac{1}{L_{x} L_{y}} \int_{x-\frac{L_{x}}{2}}^{x+\frac{L_{x}}{2}} \int_{y-\frac{L_{y}}{2}}^{y+\frac{L_{y}}{2}}\left\{w\left(x^{\prime}, y^{\prime}\right)-\bar{w}(x, y)\right\}^{2} d x^{\prime} d y^{\prime}\right]^{\frac{1}{2}}
$$

where, $L_{x}$ and $L_{y}$, are the averaging intervals along the $x$ and $y$ coordinates respectively. The average vertical wind $\bar{w}$, is computed from the vertical wind, $w$, as follows:

$$
\bar{w}(x, y)=\frac{1}{L_{x} L_{y}} \int_{x-\frac{L_{x}}{2}}^{x+\frac{L_{x}}{2}} \int_{y-\frac{L_{y}}{2}}^{y+\frac{L_{y}}{2}} w\left(x^{\prime}, y^{\prime}\right) d x^{\prime} d y^{\prime}
$$

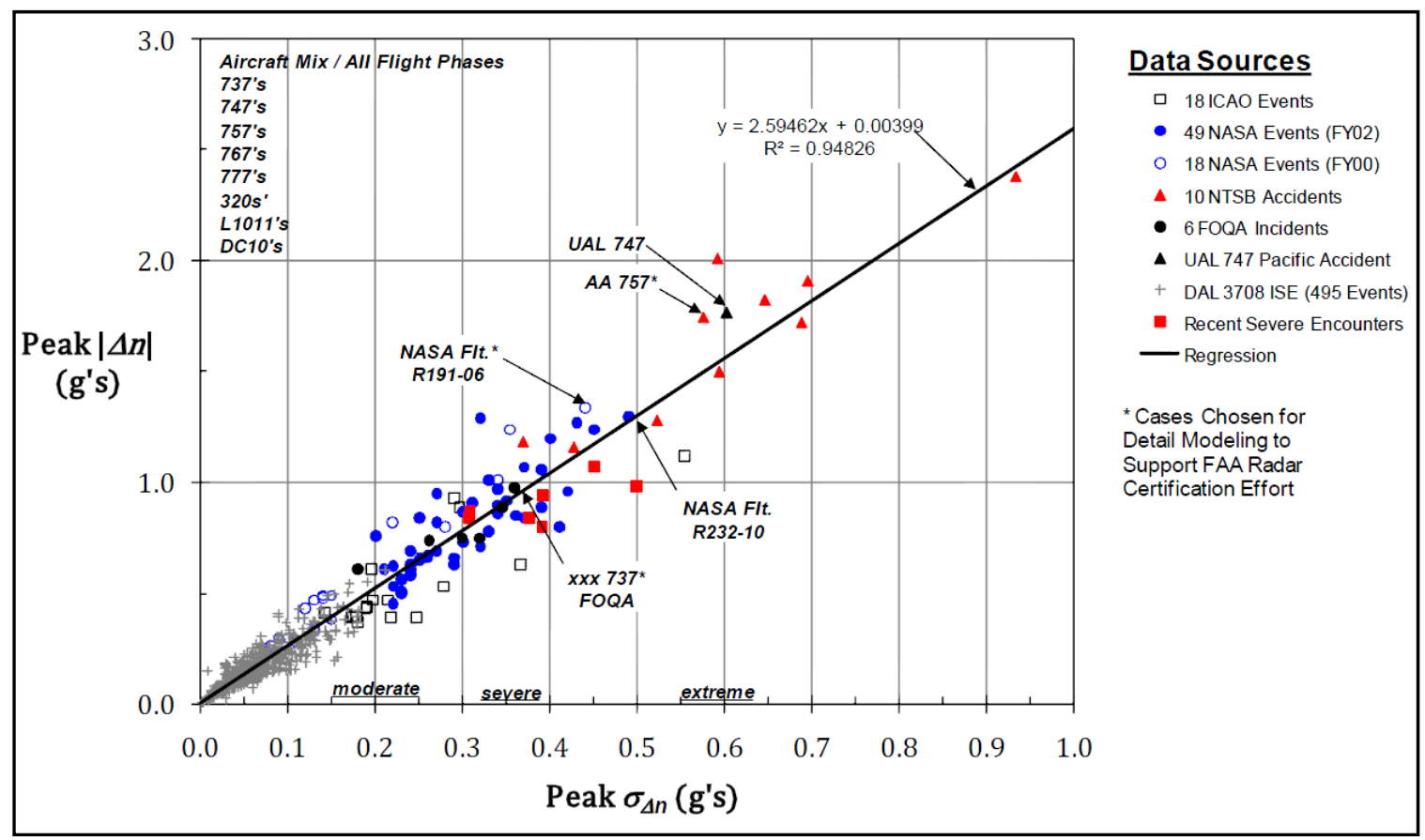

Figure 1. Relationship between the peak normal load $(\Delta n)$ and the root mean square of normal load acceleration $\left(\sigma_{\Delta \mathrm{n}}\right)$ assuming a 5 second window. The dataset is constructed from measurements for 606 turbulence encounters (Bowles and Buck 2009).

The value for the averaging interval, $L_{\mathrm{x}}=L_{\mathrm{y}}=1 \mathrm{~km}$, is chosen which roughly corresponds to a five second averaging period for a commercial aircraft flying at cruise speeds. Turbulence intensities, $\sigma_{\Delta \mathrm{n}}$ are estimated from $\sigma_{\mathrm{w}}$ using the following relationship developed by Bowles and Buck (2009):

$$
\sigma_{\Delta n}(x, y)=\sigma_{w}(x, y)(a(z)-b(z) \log (l))\left(\frac{180}{W}\right)\left(\frac{V}{V_{n}(z)}\right) \times 1.09
$$


where, $V$ is the aircraft's true airspeed and $W$ is the aircraft weight in klbs. The turbulence length scale, $l$ is set to $500 \mathrm{~m}$. The accuracy of Eq. (3) has been verified from NASA B-757's in situ flight data. The parameters $a(z)$ and $b(z)$ are designed for different aircraft types and calculated from look-up tables. $a(z)$ is defined by the following equation:

$$
a(z)=c_{1}+c_{2} z+c_{3} z^{2}+c_{4} z^{3}+c_{5} z^{4}+c_{6} z^{5}+c_{7} z^{6}
$$

where, for a Boeing 757, the constants, $c_{1}, c_{2}, c_{3}, c_{4}, c_{5}, c_{6}$, and $c_{7}$ are as follows (Bowles and Buck 2009):

$$
\begin{aligned}
& c_{1}=0.1367 \mathrm{~s}^{-1} \\
& c_{2}=-4.759443 \times 10^{-5} \mathrm{~m}^{-1} \mathrm{~s}^{-1} \\
& c_{3}=3.453818 \times 10^{-8} \mathrm{~m}^{-2} \mathrm{~s}^{-1} \\
& c_{4}=-1.031272 \times 10^{-11} \mathrm{~m}^{-3} \mathrm{~s}^{-1} \\
& c_{5}=1.457209 \times 10^{-15} \mathrm{~m}^{-4} \mathrm{~s}^{-1} \\
& c_{6}=-9.709422 \times 10^{-22} \mathrm{~m}^{-5} \mathrm{~s}^{-1} \\
& c_{7}=2.448279 \times 10^{-24} \mathrm{~m}^{-6} \mathrm{~s}^{-1}
\end{aligned}
$$

The parameter $b(z)$ is defined by the following equation:

$$
b(z)=c_{1}+c_{2} z+c_{3} z^{2}+c_{4} z^{3}+c_{5} z^{4}+c_{6} z^{5}
$$

where, for a Boeing 757 the constants, $c_{1}, c_{2}, c_{3}, c_{4}, c_{5}$, and $c_{6}$ are as follows (Bowles and Buck 2009):

$$
\begin{aligned}
& c_{1}=-0.0179545 \mathrm{~s}^{-1} \\
& c_{2}=3.996083 \times 10^{-5} \mathrm{~m}^{-1} \mathrm{~s}^{-1} \\
& c_{3}=-1.243271 \times 10^{-8} \mathrm{~m}^{-2} \mathrm{~s}^{-1} \\
& c_{4}=1.760674 \times 10^{-12} \mathrm{~m}^{-3} \mathrm{~s}^{-1} \\
& c_{5}=-1.153713 \times 10^{-16} \mathrm{~m}^{-4} \mathrm{~s}^{-1} \\
& c_{6}=2.807013 \times 10^{-21} \mathrm{~m}^{-5} \mathrm{~s}^{-1}
\end{aligned}
$$

The parameter $V_{n}(z)$ is calculated as follows:

$$
V_{n}(z)= \begin{cases}232.21 \mathrm{~ms}^{-1} & \text { if } z>9.1 \mathrm{~km} \\ c_{1}+c_{2} z+c_{3} z^{2} & \text { if } 3 \mathrm{~km} \leq \mathrm{z} \leq 9.1 \mathrm{~km}\end{cases}
$$

where, for a Boeing 757 the constants, $c_{1}, c_{2}$, and $c_{3}$ are as follows (Bowles and Buck 2009):

$$
\begin{aligned}
& c_{1}=150.1493 \mathrm{~ms}^{-1} \\
& c_{2}=6.2023 \times 10^{-3} \mathrm{~s}^{-1} \\
& c_{3}=3.0298 \times 10^{-7} \mathrm{~m}^{-1} \mathrm{~s}^{-1}
\end{aligned}
$$

The algorithms described above are valid for mesh resolution on the order of $100 \mathrm{~m}$ or less. Simulations of large convective systems at such high mesh resolutions require significant computing resources and very efficient codes. The simulations presented in this paper were run with mesh resolution of $100 \mathrm{~m}$ or less in order to take into account the turbulence scales that affect the aircraft response (Proctor et al. 2002). 


\section{Results}

In this section, the results of five TASS simulations are discussed in detail. The events ranged from a large mesoscale convective system, to a supercell hailstorm and small isolated convective cells (Table 1). The simulation results are compared with NEXRAD data and other surface observations. Aircraft-centric turbulence characteristics for each case are also presented.

Table 1: TASS Simulations

\begin{tabular}{|c|l|c|c|}
\hline Case & \multicolumn{1}{|c|}{ Event Type } & Location & $\Delta \mathbf{x}(\mathbf{m})$ \\
\hline A & Mesoscale Convective System & Minnesota & 100 \\
\hline B & Single Cell Tropical Maritime & Southwest of Puerto Rico & 60 \\
\hline C & Supercell Midwestern & Indiana & 100 \\
\hline D & Multicell Tropical Maritime & Northwestern Puerto Rico & 80 \\
\hline E & Multicell Midwestern & Illinois & 80 \\
\hline
\end{tabular}

\section{A. Mesoscale Convective System (17 July 2008)}

A Mesoscale Convective System (MCS) is an organized collection of several thunderstorms that can maintain its strength for several hours (Ashley 2003). There is no restriction on the shape of an MCS which can be elongated like a squall line or round/oval shaped like a Mesoscale Convective Complex (MCC). Maddox (1980) formally defined an MCC as an MCS with the following characteristics based on infrared satellite images (definition taken from the AMS glossary):

- Size: Area of cloud top defined by an infrared derived temperature of $-32^{\circ} \mathrm{C}$ or less: $100,000 \mathrm{~km}^{2}$ or more (slightly smaller than the state of Ohio), and area of cloud top with temperature of $-52^{\circ} \mathrm{C}$ or less: $50,000 \mathrm{~km}^{2}$ or more.

- Duration: Size criteria must be met for at least 6 hours - Peak storm intensity normally at night.

- Eccentricity: Minor/major axis at least 0.7.

- Any large system of organized thunderstorms which does not meet the strict criteria of Maddox is generally characterized as an MCS.

Due to their extensive size, MCS/MCC's are difficult to simulate with an explicit cloud model. Past studies have examined MCS/MCC's and their environment with mesoscale models (e.g., Zhang and Fritsch 1988). These studies usually assume grid sizes of several kilometers or more; and therefore, cannot explicitly resolve the MCS/MCC's convective updrafts. The objective of this case was to simulate the most active parts of an MCS using TASS. The challenge was to maintain a sufficiently fine grid resolution in order to resolve the cumulus thermals and other important scales of motion within a computational domain large enough to encompass most of the MCS/MCC.

Observations indicated that on 17 July 2008, a large system of thunderstorms moved eastward from Nebraska to southern Minnesota, northern Iowa and Wisconsin. The infrared imagery from GOES-E shows consistent temperatures below $-32^{\circ} \mathrm{C}$ over a large area (Figure 2) indicative of intense convection. The system moved generally eastward at approximately $17 \mathrm{~m} / \mathrm{s}$. The infrared imagery from GOES-E satellite shows that this system persisted for more than eight hours. Figure 3 shows the same system at 1500UTC with a clearly defined outflow boundary which is due to high pressure near the surface at the center of the MCS. The system produced large amounts of rainfall and hail $(25 \mathrm{~mm}$ diameter hail observed near Wasesa between 1430UTC-1500UTC and $18 \mathrm{~mm}$ hail observed at Blue Earth around 1536UTC) over southern Minnesota.

Wind gusts as high as $22 \mathrm{~m} / \mathrm{s}(50 \mathrm{mph})$ were measured at Freeborn, Minnesota and an EF0-tornado was reported at Amboy around 1655UTC. The structure of the low-level radar reflectivity field of the MCS was characterized by 1) a comma shaped line of strong convective cells extending southwest along the southern boundary of the system (approaching the Iowa-Minnesota boarder); 2) small clusters of convective cells located along the northern periphery of the system; 3) a line of convective cells extending southeastward and eastward within the southeastern 
portion of the system; and 4) a broad area of light rain covering the central region of the system (see Figure 4). Satellite photographs indicated that the MCS had an extensive, eastward spreading anvil (Figures 2 and 3).

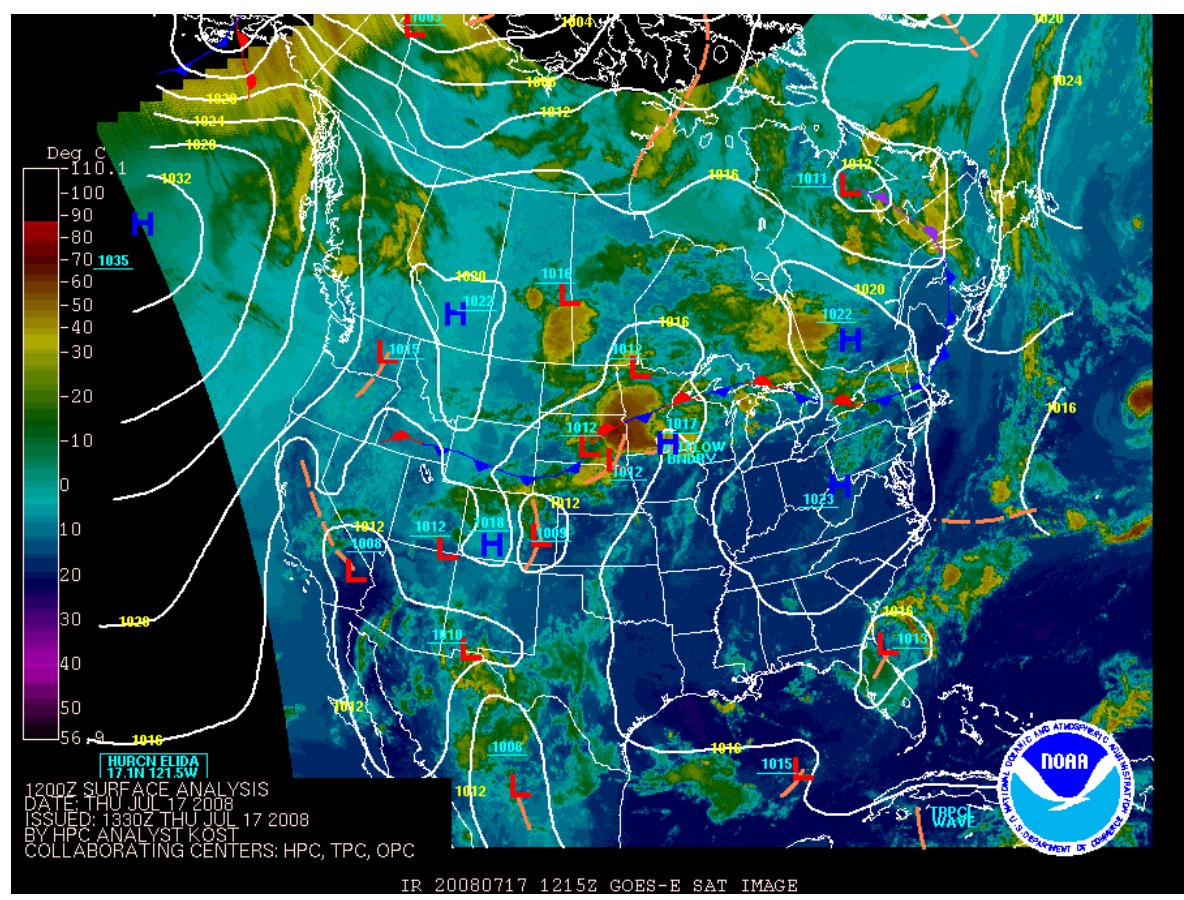

Figure 2. Surface weather map for the continental United States overlaid with GOES-E IR imagery at 1200UTC on 17 July 2008. Colder temperatures indicate higher cloud tops. Source: National Centers for Environmental Prediction (NCEP).

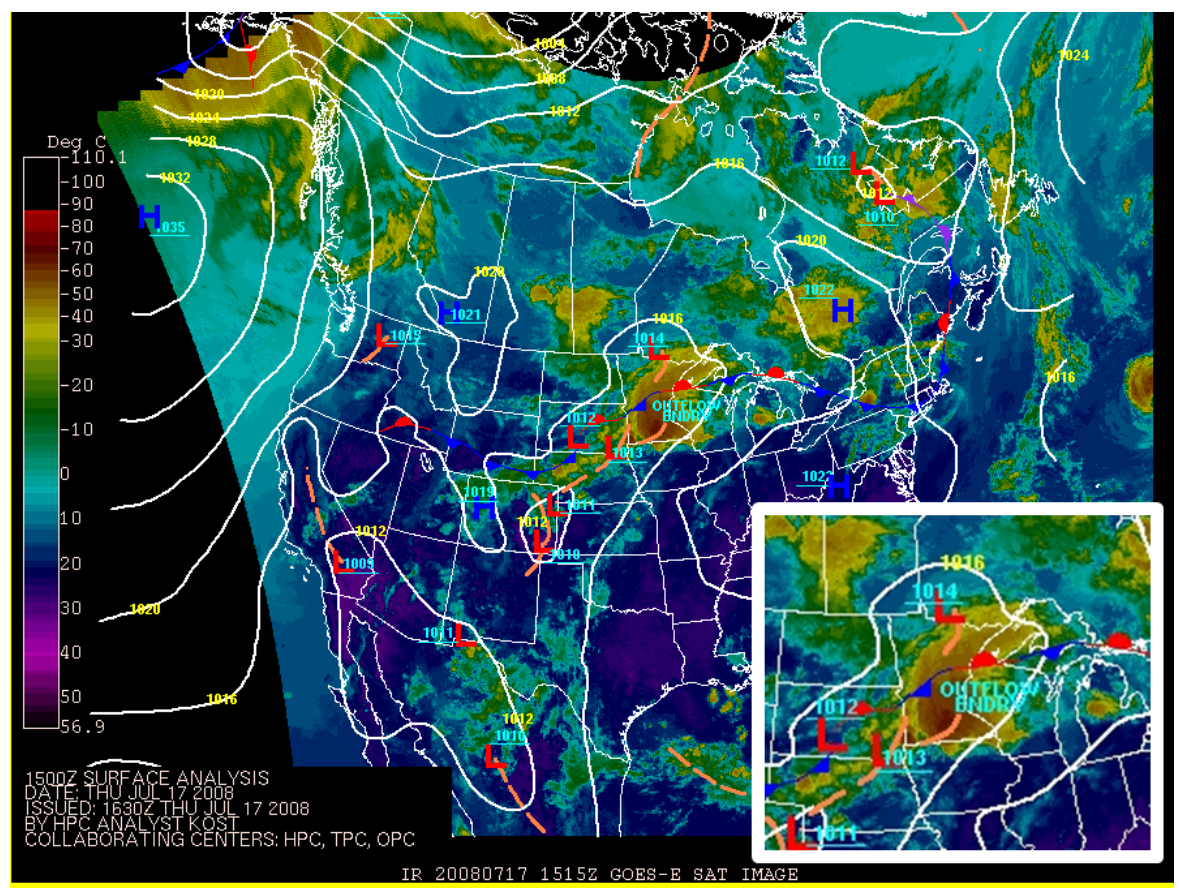

Figure 3. Surface weather map for the continental United States overlaid with GOES-E IR imagery at 10:00 AM CST (1500UTC) on 17 July 2008. A zoomed view of the area covering Minnesota is shown in the inset. Source: National Centers for Environmental Prediction (NCEP). 


\section{Simulation Setup}

The TASS computational domain was set to $100 \mathrm{~km} \times 100 \mathrm{~km}$ in the horizontal with a vertical depth of $17 \mathrm{~km}$. Figure 4 shows the TASS model domain relative to the storm system over Minnesota. Since a long simulation time over a large domain was needed, the simulation was divided into two phases. In the first phase, a moderately coarse mesh with a grid size of $200 \mathrm{~m}$ in all coordinate directions was used and the simulation was carried out until an MCS became established. After two hours and ten minutes of simulation time, the simulation was re-started with a regridded mesh with $100 \mathrm{~m}$ grid resolution, thus doubling the grid points in each of the three coordinate directions. This re-gridding accomplished two objectives: 1) reduced the required computer resources (both CPU and disk space), and 2) accelerated the data post-processing. The re-gridding was based on the algorithms (Clark and Farley 1984) that preserved accuracy and conservation of mass and energy. Comparison of interpolated fields between the $200 \mathrm{~m}$ and $100 \mathrm{~m}$ grids at the time of refinement verified that the interpolation retained the overall structure of the system. The re-gridded simulation was run for an additional $1 \mathrm{hr}$ and $15 \mathrm{~min}$ to capture the evolution of the MCS in time. In both phases of the simulation, the model domain was allowed to translate with the MCS, thus relaxing the need for a much larger computational domain.

The environmental conditions for TASS were initialized using a forecast sounding from the Weather Research and Forecast (WRF) model. The WRF outer most domain was bounded between $126.38^{\circ} \mathrm{W}$ and $69.72^{\circ} \mathrm{W}$ in the longitude and $21.59^{\circ} \mathrm{N}$ and $56.71^{\circ} \mathrm{N}$ in the latitude. The middle domain was bounded between $111.65^{\circ} \mathrm{W}$ and $77.72^{\circ} \mathrm{W}$ in the longitude and $34.54^{\circ} \mathrm{N}$ and $54.07^{\circ} \mathrm{N}$ in the latitude. The innermost domain was bounded between $100.02^{\circ} \mathrm{W}$ and $89.83^{\circ} \mathrm{W}$ in the longitude and $41.91^{\circ} \mathrm{N}$ and $48.30^{\circ} \mathrm{N}$. The WRF outer-most domain had a horizontal grid resolution of $40 \mathrm{~km}$ in the horizontal and the two nested domains had horizontal resolutions of $13.33 \mathrm{~km}$ and $4.44 \mathrm{~km}$ respectively. Figure 5 shows the WRF computational domain with higher-resolution inner nests and the terrain heights for the inner-most nest. The simulation was initialized using North American Regional Reanalysis (NARR) data from the National Climate Data Center (NCDC) for 17 July 2008 at 1200UTC. See Mesinger et al. (2006) for details on the NARR model.

The TASS input sounding (see Figure 6) was extracted from southern Minnesota for 1500UTC WRF forecast. The low levels of the sounding were modified to agree with observed cloud base heights. The environment may be characterized as unstable and moist with winds mostly from the west. The strongest winds were about $28 \mathrm{~m} / \mathrm{s}$ (55kts) and located near the tropopause. The freezing level was at $4100 \mathrm{~m}$ AGL. No horizontal variation is assumed in the TASS initial conditions. Convection with cloud and precipitation development was triggered in TASS by imposing an artificial bubble of warm air. Three-dimensional fields evolved as convection interacted with the environmental fields.

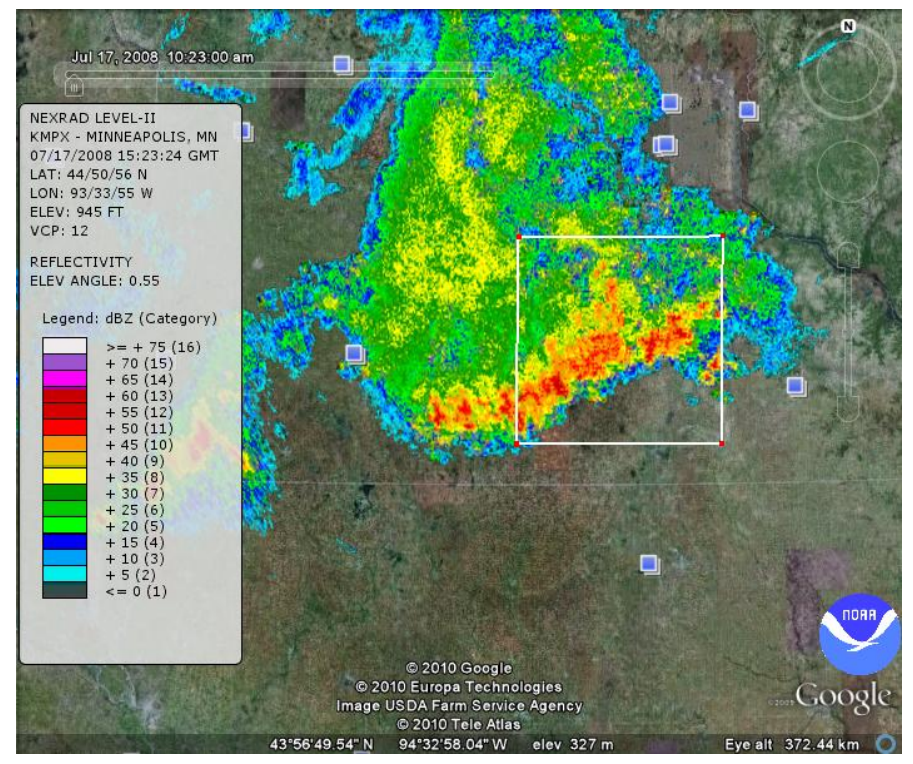

Figure 4. Minneapolis NEXRAD $\left(0.55^{\circ}\right.$ scan $)$ image at 1523UTC. NEXRAD Station ID is KMPX. The white square shows the approximate location of the TASS $100 \mathrm{~km} \times 100 \mathrm{~km}$ model domain. 



Figure 5. The left panel shows the WRF computational domain with higher resolution nests and the right panel shows the terrain contours for the inner most computational domain. The terrain maximum value in the plot is $846.13 m$ and the minimum value is $175.97 m$.

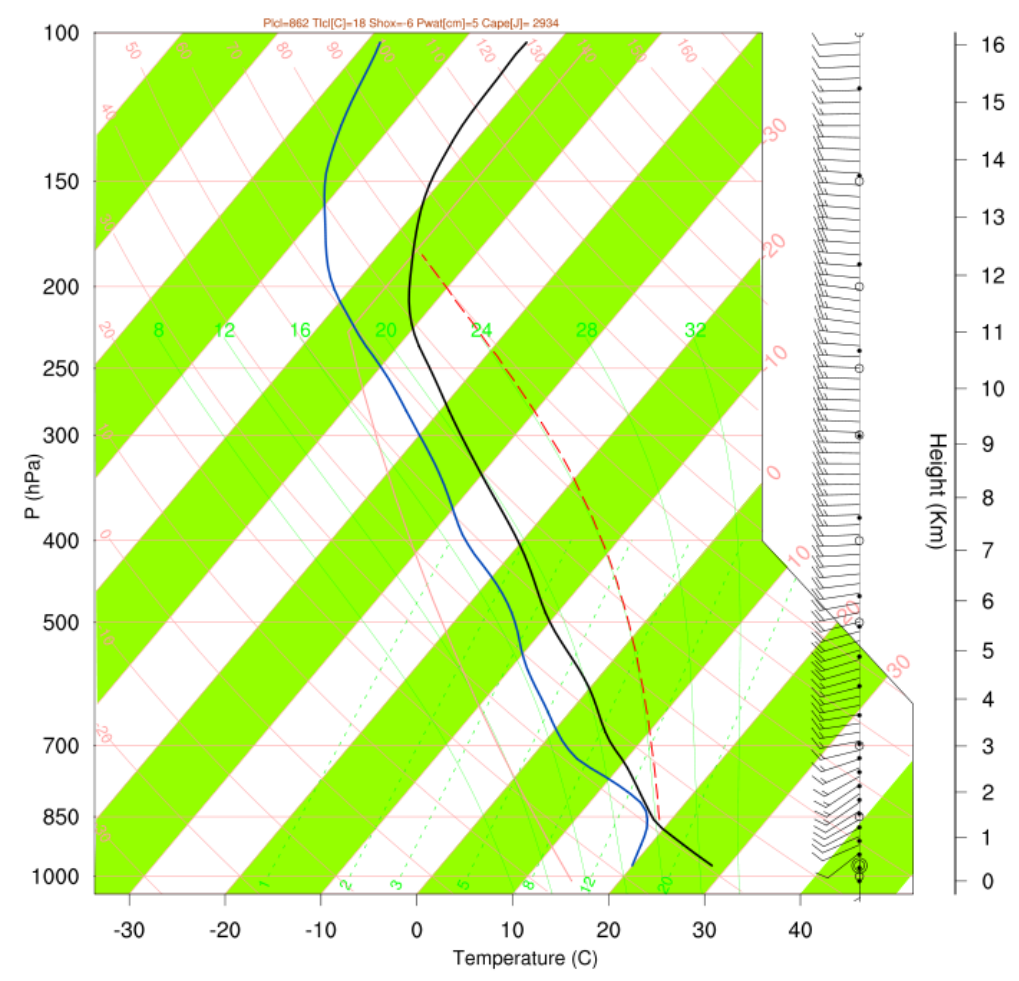

Figure 6. Skew-T chart of atmospheric sounding representing the environment for the Minnesota MCS. Shown are temperature, dewpoint, and horizontal wind velocity as a function of atmospheric pressure for southern Minnesota. 


\section{Validation and Analysis of Simulation}

A matching of the model time with UTC time shows that the simulation is best representative of conditions: corresponding UTC time $=$ simulation time $+14: 43$; e.g., the TASS fine-grid results at 30min corresponds to 1514UTC. This was done with the aid of NEXRAD Level 2 data. A brief description of the NEXRAD products is given in Appendix A. In space, the TASS $x$-coordinate of $x=26,855 \mathrm{~m}$ corresponds to $93.77^{\circ} \mathrm{W}$ longitude, and the $y$-coordinate of $y=8,864 m$ corresponds to $44.22^{\circ} \mathrm{N}$ latitude. TASS simulation results were compared with the NEXRAD observations at Minneapolis (Table 2) and other surface observations. Similarities between the observations and simulation include a persistent MCS with many deep and active cells (updrafts) along its southern periphery. Other cells near center and northern regions can also be seen in both the observed data and simulation. Multiple updrafts fed the system with a large anvil spreading to the east. Hail developed in the simulation and was observed in the actual MCS at three different locations (see Table 3). The simulated and the observed storm tops obtained similar elevations of $15.5 \mathrm{~km}$ AGL $(52,000 \mathrm{ft} \mathrm{MSL})$. Maximum accumulated precipitation from the model was $39.6 \mathrm{~mm}(1.56 \mathrm{in})$ and the maximum accumulated precipitation estimated from NEXRAD radar was between $38 \mathrm{~mm}(1.5 \mathrm{in})$ and $63.5 \mathrm{~mm}(2.5 \mathrm{in})$. Observed Storm movement was around $17.5 \mathrm{~m} / \mathrm{s}$ from the west and the simulated was about $16.5 \mathrm{~m} / \mathrm{s}$ from the west. At storm mid-levels, a ridge of moderate reflectivity extends south eastward from the center of the system which can be seen on both the observed data and the simulation results. The simulated peak surface wind speed was approximately $30 \mathrm{~m} / \mathrm{s}(67 \mathrm{mph})$ compared with the peak measured surface wind of $22.35 \mathrm{~m} / \mathrm{s}$ (50mph) recorded at Freeborn. The simulation differs from observations in system size. The observed system is larger than the modeled system (which was limited by the $100 \mathrm{~km} \times 100 \mathrm{~km}$ domain). Also, the simulation did not generate cells along the eastern southern boundary that extend to the southeast along a cold front. A depiction of the simulated convective cloud is shown in Figures 7-8. Overshooting tops and broad eastward spreading anvil are apparent. Clusters of convective cells feeding the anvil are also apparent.

Table 2: NEXRAD Station Data

\begin{tabular}{|c|c|}
\hline Station ID & KMPX \\
\hline Location & Minneapolis, MN \\
\hline Latitude & $44^{\circ} 50^{\prime} 56^{\prime} \mathrm{N}$ \\
\hline Longitude & $93^{\circ} 33^{\prime} 55^{\prime} \mathrm{W}$ \\
\hline Elevation (MSL) & $288 \mathrm{~m}(945 \mathrm{ft})$ \\
\hline
\end{tabular}

Table 3: Model Comparison with Observations

\begin{tabular}{|c|c|c|}
\hline Variable & TASS & Observed \\
\hline Orientation of MCS Propagation & West to East & West to East \\
\hline Peak Storm Tops (AGL) & $15.5 \mathrm{~km}$ & $15.5 \mathrm{~km}$ \\
\hline Storm Motion (from) & $16.5 \mathrm{~m} / \mathrm{s}(\mathrm{west})$ & $17.5 \mathrm{~m} / \mathrm{s}($ west) \\
\hline Maximum accumulated Precipitation & $39.6 \mathrm{~mm}(1.56 \mathrm{in})$ & $38 \mathrm{~mm}-61 \mathrm{~mm}(1.5 \mathrm{in}-2.4 \mathrm{in})^{*}$ \\
\hline Maximum Radar Reflectivity & $73 \mathrm{dBZ}$ & $68 \mathrm{dBZ}$ \\
\hline Peak Hail Size (diameter) & $\begin{array}{c}14 \mathrm{~mm} \\
9 \mathrm{~mm} \text { continuous }\end{array}$ & $\begin{array}{c}25 \mathrm{~mm} \text { observed near Wasera between } \\
1430 \mathrm{UTC}-1500 \mathrm{UTC}\end{array}$ \\
$\begin{array}{c}18 \mathrm{~mm} \text { observed at Blue Earth (1536UTC) } \\
\text { and Freeborn (1600UTC) }\end{array}$ \\
\hline Peak Surface Gust & $30 \mathrm{~m} / \mathrm{s}$ & $\begin{array}{c}22 \mathrm{~m} / \mathrm{s} \text { recorded at Freeborn (1600UTC) } \\
\text { Trees reported down at other locations }\end{array}$ \\
\hline
\end{tabular}

*Estimated from NEXRAD data.

A composite of TASS RRF between the surface and $5 \mathrm{~km}$ is compared with the observed NEXRAD fields in Figures 9-10. The TASS radar reflectivity field (RRF) is computed within each grid cell from the size distribution of hydrometeors, but does not account for size and geometry of the radar beam. Both simulation and NEXRAD show the southwestern line of strong convective cells that is generated along the cooler downdrafts of air exiting the southern flank of the MCS. Cells near the center of the MCS are stronger and more persistent in TASS than those in the NEXRAD data. As noted earlier, the simulation does not capture the broken cells on the east side of the MCS. 


\section{Turbulence}

To define the turbulence characteristics, turbulence hazard fields were generated according to Eqs. (1)-(3) assuming an in-flight Boeing 737-300 with a weight of 100klbs. The turbulence hazard is dependent upon aircraft type, with lighter aircraft generating stronger loads than heavy aircraft when encountering the same turbulence field. The simulated radar reflectivity factor and the turbulence intensity are shown at an elevation of 9.4km AGL $(\sim 32,000 \mathrm{ft}$ MSL) in Figures 11-12. These fields are at a level slicing through the anvil, but well below the storm tops. First note, that radar reflectivity greater than $5 \mathrm{dBZ}$ covers a broad area that is $\sim 50 \mathrm{~km}$ wide and almost $100 \mathrm{~km}$ long. Relatively small areas of radar reflectivity exceeding $30 \mathrm{dBZ}$ are present, and are associated with vigorous convective cells. Turbulence with RMS normal load acceleration exceeding $0.1 \mathrm{~g}$ occurs within and in proximity to the higher reflectivity regions. However, spots with moderate to severe turbulence can be found within the low reflectivity regions of the MCS. Peak values of the RMS normal load acceleration at this altitude are in excess of $0.4 \mathrm{~g}$. The figures also show the presence of many pockets of hazardous turbulence. Based on estimates appropriate for a Boeing 737-300 in-flight with a weight of 100klbs, the normal accelerations due to turbulence would have exceeded $0.6 \mathrm{~g}$ RMS of the normal load acceleration or $1.8 \mathrm{~g}$ peak normal load in these pockets.

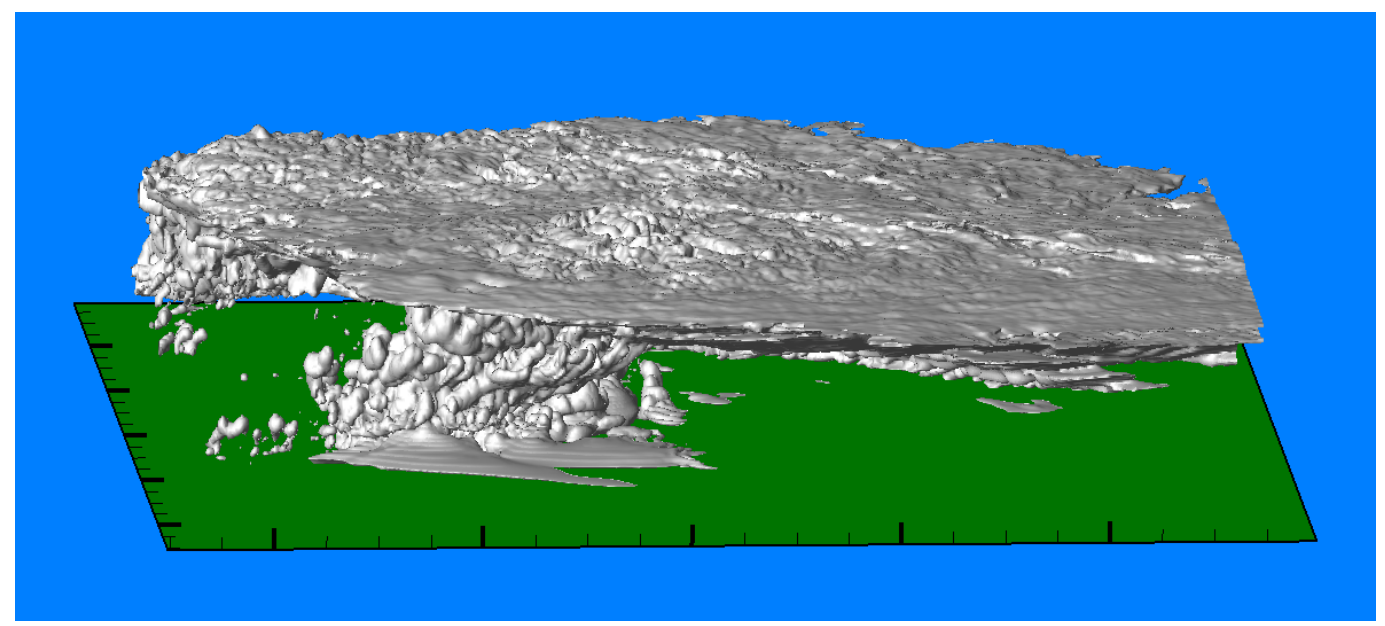

Figure 7. TASS simulated cloud field at time $=15 \mathrm{~min}$ into the simulation. The view is from the south. Every other point in $x-y$ - and $z$-direction is plotted. The simulation domain was bounded within a $100 \mathrm{~km} \times 100 \mathrm{~km} \mathrm{x}$ $17 \mathrm{~km}$ domain. Mesh resolution was set to $\Delta x=\Delta y=\Delta z=100 \mathrm{~m}$.

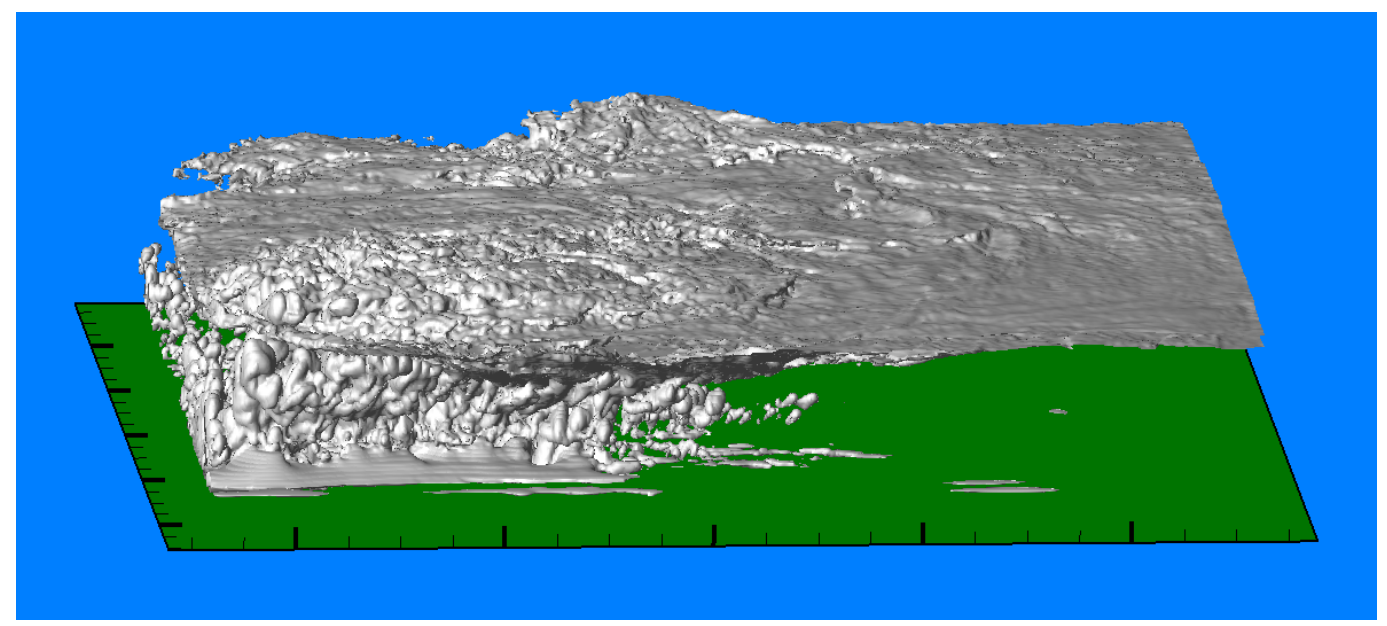

Figure 8. TASS simulated cloud field at time $=75 \mathrm{~min}$ into the simulation. The view is from the south. Every other point in $x-y$-and z-direction is plotted. The simulation domain was bounded within a $100 \mathrm{~km} x 100 \mathrm{~km} \mathrm{x}$ $17 \mathrm{~km}$ domain. Mesh resolution was set to $\Delta x=\Delta y=\Delta z=100 \mathrm{~m}$. 

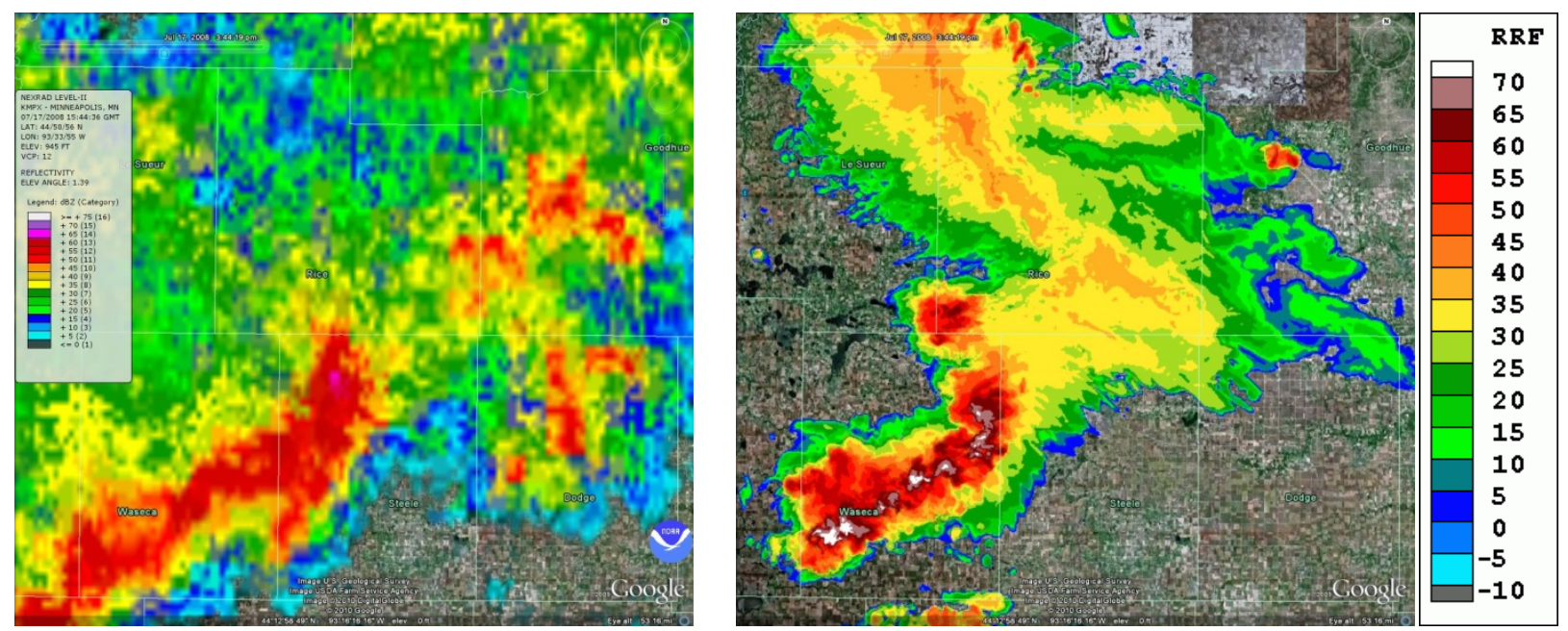

Figure 9. Comparison of the KMPX NEXRAD $1.39^{\circ}$ scan (left) with TASS low-level composite Radar Reflectivity Factor (right). Each panel depicts $100 \mathrm{~km} \times 100 \mathrm{~km}$ area. NEXRAD is at 1544UTC and TASS data is at time $=60 \mathrm{~min}$ into the simulation.


Figure 10. Comparison of the KMPX NEXRAD $1.39^{\circ}$ scan (left) with TASS low-level composite Radar Reflectivity Factor (right). Each panel depicts $100 \mathrm{~km} \times 100 \mathrm{~km}$ area. NEXRAD is at 1557UTC and TASS data is at time $=75 \mathrm{~min}$ into the simulation. 

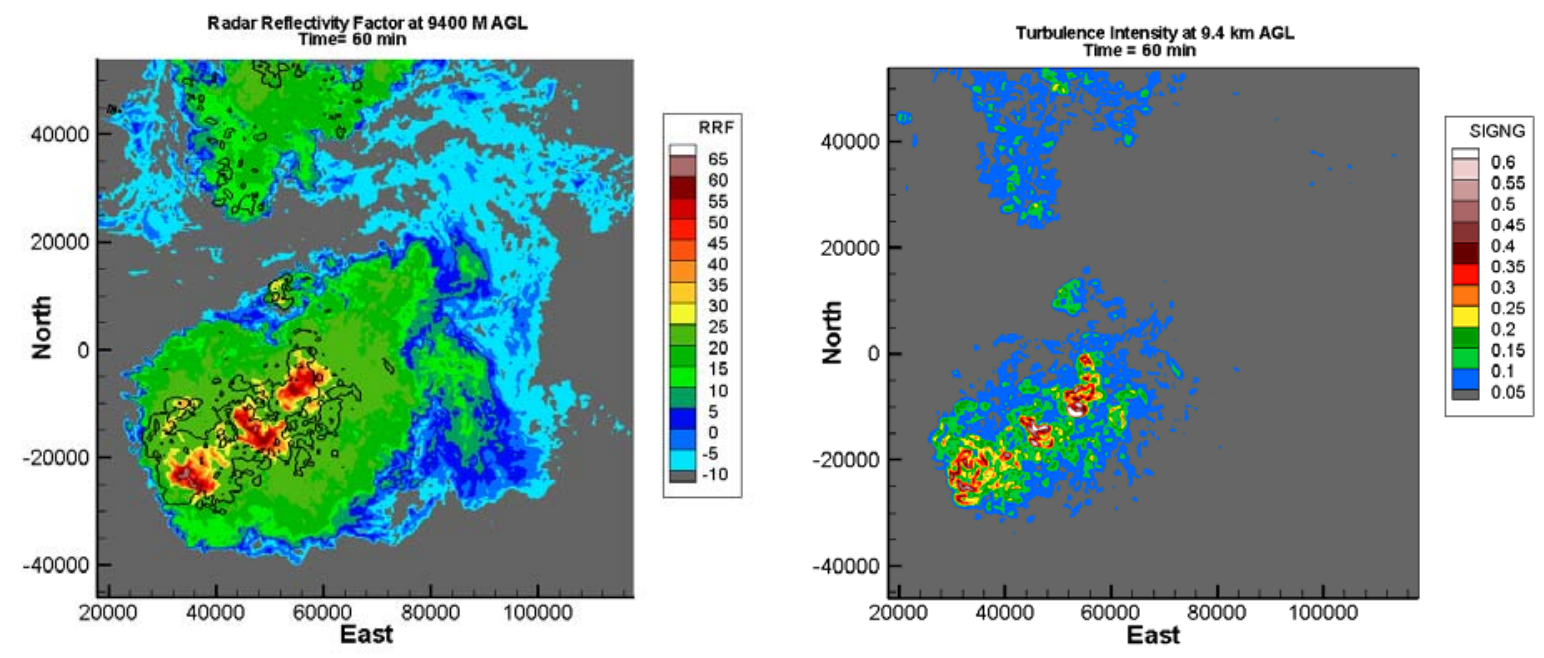

Figure 11. Radar reflectivity field and the root mean square of the normal load acceleration $\left(\sigma_{\Delta \mathrm{n}}\right)$ computed from simulation at $60 \mathrm{~min}$ for an altitude of $9.4 \mathrm{~km}$ AGL $\left(\sim 32,000 \mathrm{ft}\right.$ MSL). The $0.1 \mathrm{~g} \sigma_{\Delta \mathrm{n}}$ contour is also depicted on radar reflectivity plot. Turbulence characteristics are based on data for an in-flight B737-300 with a weight of $100 \mathrm{klbs}$. Axis coordinates are in meters. The simulation domain was bounded within a $100 \mathrm{~km} \times 100 \mathrm{~km} \times 17 \mathrm{~km}$ domain. Mesh resolution was set to $\Delta x=\Delta y=\Delta z=100 \mathrm{~m}$.
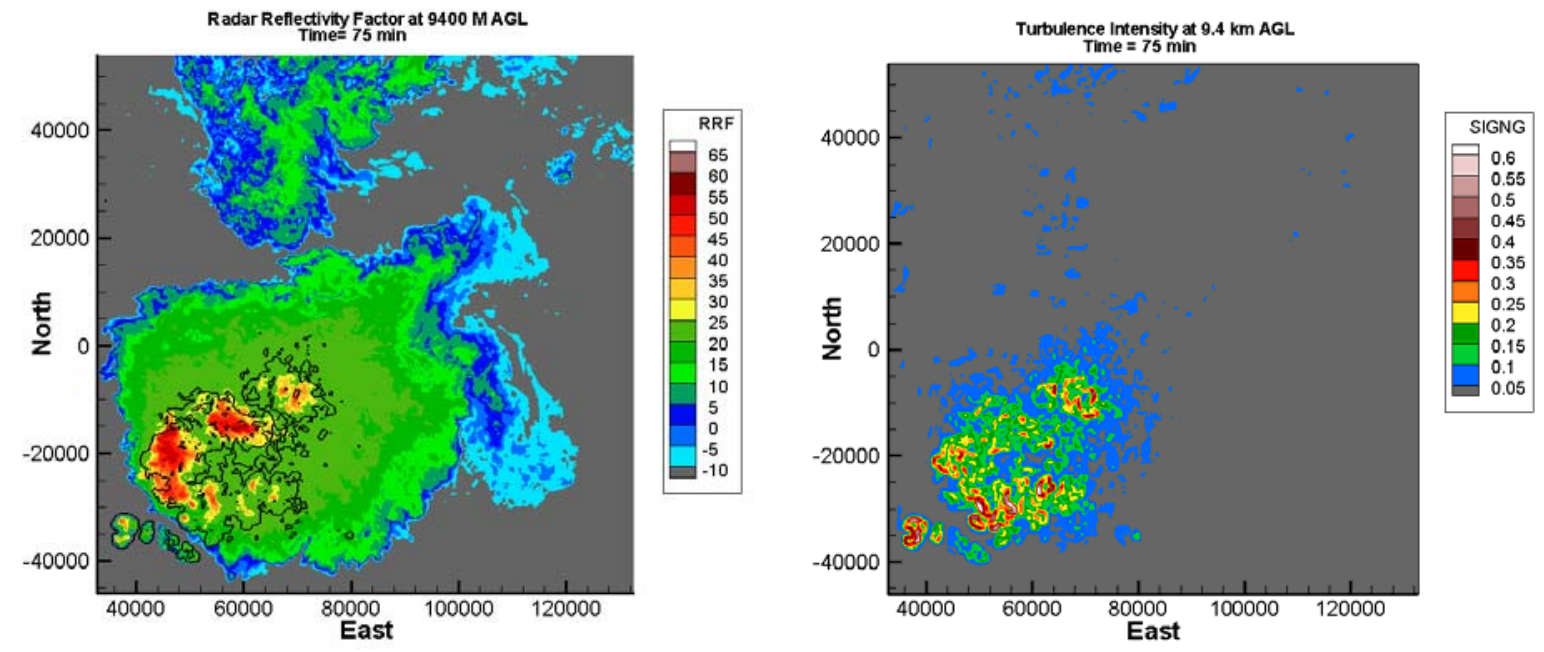

Figure 12. Radar reflectivity field and the root mean square of the normal load acceleration $\left(\sigma_{\Delta \mathrm{n}}\right)$ computed from simulation at $75 \mathrm{~min}$ for an altitude of $9.4 \mathrm{~km}$ AGL $\left(\sim 32,000 \mathrm{ft}\right.$ MSL). The $0.1 \mathrm{~g} \sigma_{\Delta \mathrm{n}}$ contour is also depicted on radar reflectivity plot. Turbulence characteristics are based on data for an in-flight B737-300 with a weight of $100 \mathrm{klbs}$. Axis coordinates are in meters. The simulation domain was bounded within a $100 \mathrm{~km} \times 100 \mathrm{~km} \times 17 \mathrm{~km}$ domain. Mesh resolution was set to $\Delta x=\Delta y=\Delta z=100 \mathrm{~m}$. 


\section{B. Maritime Convection Induced Turbulence (3 August 2009)}

Isolated convective systems over ocean pose a serious turbulence hazard risk to aviation operations. Encounters with such systems are usually sudden and unexpected. In NASA's Fall-2000 flight experiments, it was found that severe turbulence was often within overshooting tops and in growing cumulus turrets. Hamilton and Proctor (2002) reported that such encounters can occur in regions of low radar reflectivity values (peak values ranging from $8 d B Z$ to 33dBZ). These small RRF values are difficult to detect by ground as well as airborne sensors. A likely example of such an encounter was reported on 3 August 2009, when the Continental Airlines Flight 128 encountered turbulence approximately 67 nautical miles north of Bavaro, Dominican Republic. The aircraft was a Boeing 767224 flying at an altitude of $10.97 \mathrm{~km}(36,000 \mathrm{ft})$. The NTSB incident report (NTSB ID: DCA09IA071) suggested that isolated and short-lived cumulus congestus to cumulonimbus clouds were developing near the flight path of the airplane. The flight had originated from Rio de Janeiro, Brazil and was bound for Houston, Texas but had to be diverted to Miami International Airport due to injuries to the passengers and crew members. Thirty three passengers and five flight attendants required medical attention as a result of this turbulence encounter.

In this section, the simulation of a small and isolated tropical maritime convective event that developed south of Puerto Rico is examined. The storm formed off-shore and remained over water during its lifecycle. Throughout its lifecycle the storm remained within 60 nautical miles of the NEXRAD radar site at San Juan, Puerto Rico (station ID TJUA), and thus the event had reasonable coverage from ground-based radar. The NEXRAD station coordinates and elevation are given in Table 4. On 3 August 2009, scattered convective cells were observed by the San Juan NEXRAD radar in the vicinity of Puerto Rico. The streamlines at the $850 \mathrm{mb}$ pressure level (Figure 13) from the North American Regional Reanalysis show that the flow was primarily easterly around 0900UTC.

The convective-cell selected for TASS simulation was identified from the NEXRAD Level 3 data at 0819UTC. The storm started to weaken and dissipate around 0935UTC. The observed storm moved from the east and developed a slight tilt towards the north with time. The average speed of the storm was $6.88 \mathrm{~m} / \mathrm{s}(13.4 \mathrm{kts})$ at 96 degrees. The observed echo tops and radar reflectivity at different elevation angles are shown in Figure 14. Echo tops as high as $12.3 \mathrm{~km}(>40,000 \mathrm{ft}$ ) were observed by the NEXRAD radar. No probability of hail was reported for the storm in the NEXRAD hail index. Radar reflectivity with values greater than $50 \mathrm{dBZ}$ was observed at low levels, which is indicative of heavy rainfall at that time. A vertical cross section of the NEXRAD data is shown in Figure 15. The details on storm trajectory, strength and precipitation are given in Table 5. All of the data in Table 5 was obtained from NEXRAD Level 3 output except the echo tops which, were estimated by analyzing the Level 2 NEXRAD data. A description of the NEXRAD data in Table 5 is given in Appendix A.

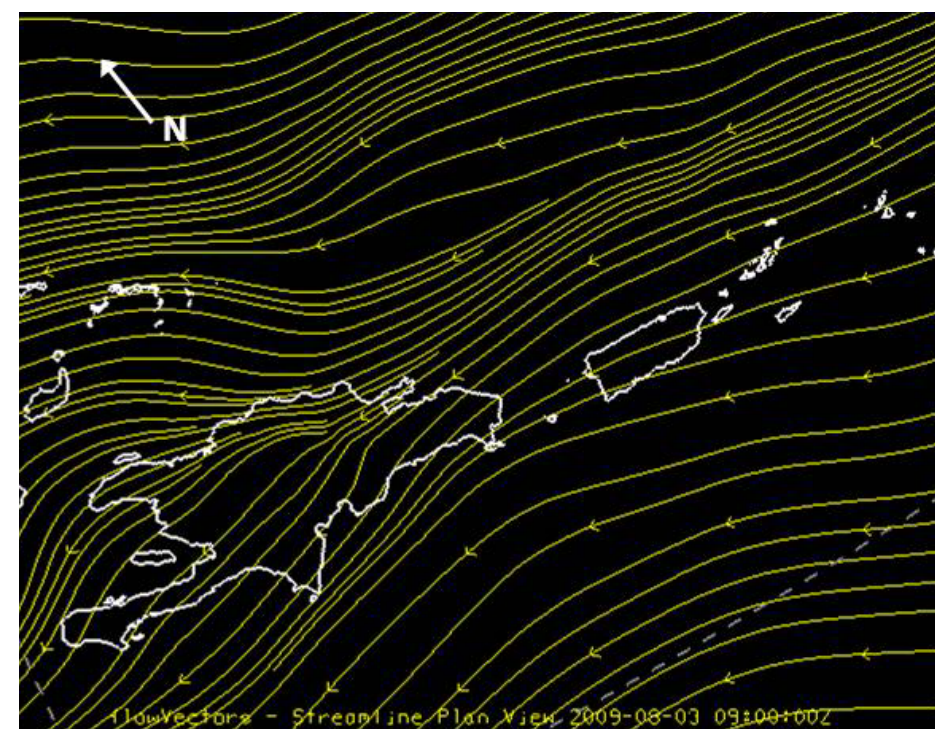

Figure 13. Streamlines at $850 \mathrm{mb}$ pressure level on 3 August 2009 at $0900 \mathrm{UTC}$. The data was obtained from the North American Regional Reanalysis (NARR) available from the National Climate Data Center (NCDC). 


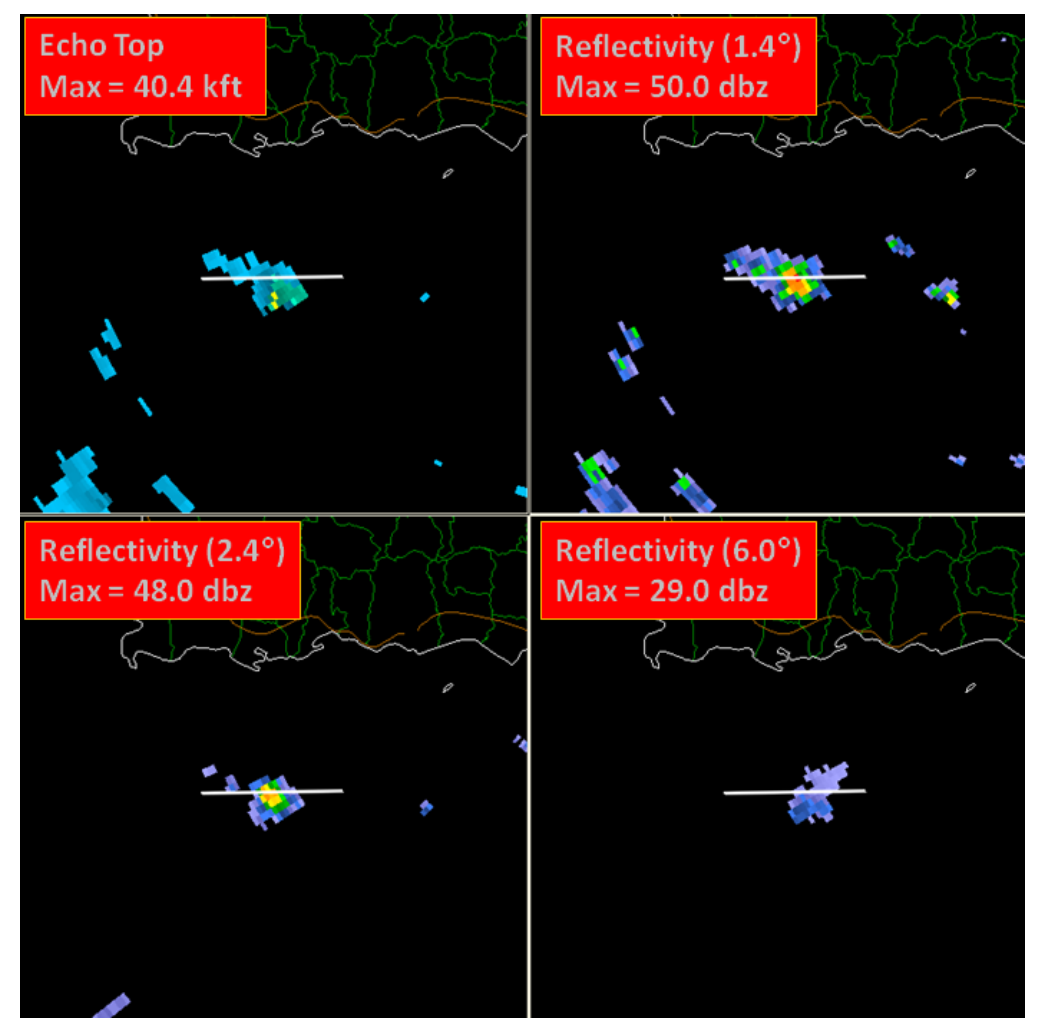

Figure 14. NEXRAD Level 2 data from the National Climate Data Center (NCDC). 3 August 2009 (0916UTC). Echo tops $(k f t)$ are shown in the top left panel and the radar reflectivity (dBZ) at different elevation angles is shown in the other three panels. The island of Puerto Rico is located to the north of the cell.

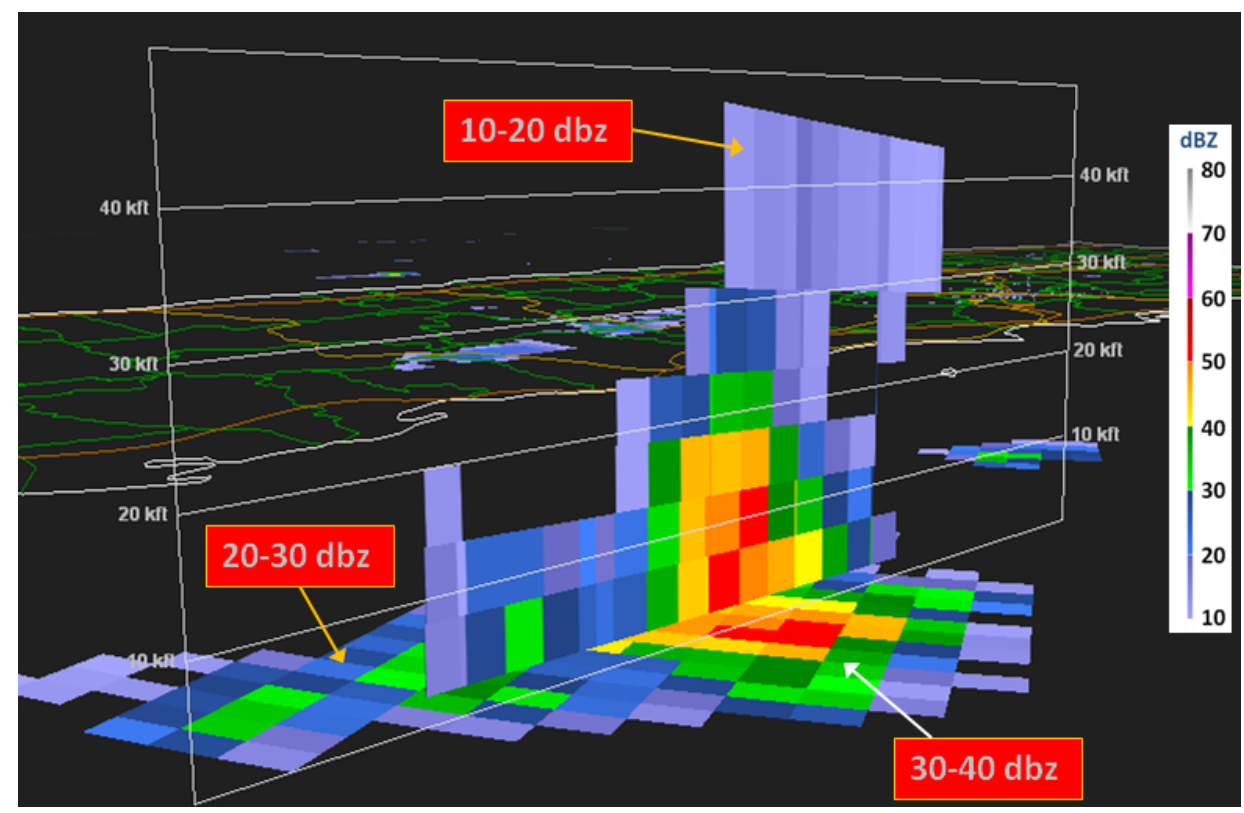

Figure 15. A vertical cross section of the radar reflectivity from the NEXRAD Level 2 data is shown in the figure. Source: National Climate Data Center (NCDC). 3 August 2009 (0916UTC). 
Table 4: NEXRAD Station Data

\begin{tabular}{|c|c|}
\hline Station ID & TJUA \\
\hline Location & San Juan, PR \\
\hline Latitude & $18^{\circ} 06^{\prime} 57^{\prime}$ ' N \\
\hline Longitude & $66^{\circ} 04^{\prime} 40^{\prime}$ ' W \\
\hline Elevation (MSL) & $902 \mathrm{~m}(2958 \mathrm{ft})$ \\
\hline
\end{tabular}

Table 5: Characteristics of the Storm - 3 August 2009

\begin{tabular}{|c|c|c|c|c|c|c|c|c|c|}
\hline $\begin{array}{c}\text { Time } \\
\text { (UTC) }\end{array}$ & $\begin{array}{c}\text { Lat } \\
\text { (deg) }\end{array}$ & $\begin{array}{c}\text { Lon } \\
\text { (deg) }\end{array}$ & $\begin{array}{c}\text { Range } \\
\text { (nmi) }\end{array}$ & $\begin{array}{c}\text { Azimuth } \\
\text { (deg) }\end{array}$ & $\begin{array}{c}\text { Echo Top } \\
\quad(\mathbf{k m})\end{array}$ & $\begin{array}{c}\text { VIL } \\
\left(\mathrm{kg} / \mathrm{m}^{2}\right)\end{array}$ & $\begin{array}{c}\text { Max } \\
\text { Reflectivity } \\
\text { (dBZ) }\end{array}$ & $\begin{array}{c}\text { One Hour } \\
\text { Precip } \\
\text { (mm) }\end{array}$ & $\begin{array}{c}\text { Storm } \\
\text { Movement } \\
(\operatorname{deg} \mid \mathbf{m} / \mathbf{s}) \\
\end{array}$ \\
\hline $09: 03$ & $17.659 \mathrm{~N}$ & $66.810 \mathrm{~W}$ & 50 & 237 & 8.6 & 12 & 50.5 & 50.8 & $93 \mid 4.6$ \\
\hline $09: 10$ & $17.666 \mathrm{~N}$ & $66.856 \mathrm{~W}$ & 52 & 239 & 11.6 & 13 & 50.5 & 50.8 & \begin{tabular}{l|l}
94 & 5.1
\end{tabular} \\
\hline $09: 16$ & $17.671 \mathrm{~N}$ & $66.879 \mathrm{~W}$ & 53 & 240 & 12.3 & 12 & 50.0 & 50.8 & \begin{tabular}{l|l}
95 & 5.6
\end{tabular} \\
\hline $09: 23$ & $17.682 \mathrm{~N}$ & $66.926 \mathrm{~W}$ & 55 & 242 & 12.3 & 10 & 50.0 & 50.8 & $96 \mid 6.1$ \\
\hline $09: 29$ & $17.681 \mathrm{~N}$ & $66.965 \mathrm{~W}$ & 57 & 243 & 11.6 & 6 & 48.0 & 50.8 & \begin{tabular}{l|l}
96 & 6.6
\end{tabular} \\
\hline $09: 35$ & $17.697 \mathrm{~N}$ & $67.012 \mathrm{~W}$ & 59 & 245 & 8.8 & 3 & 42.5 & 38.1 & \begin{tabular}{l|l}
96 & 6.6
\end{tabular} \\
\hline
\end{tabular}

\section{Simulation Setup}

The TASS computational domain was defined by a horizontal mesh of $18 \mathrm{~km} \times 18 \mathrm{~km}$, which extended vertically between the lower boundary representing the ocean's surface to the model top set at $16.5 \mathrm{~km}$. The grid resolution of the data set was $60 \mathrm{~m}$ in all coordinate directions ( $303 \times 303 \times 277$ points). The model domain was allowed to translate with the simulated convective cell, thus relaxing the requirement for a larger computational domain.

The environmental conditions for the TASS simulation were initialized using a forecast sounding from the WRF mesoscale weather prediction model. The WRF simulation domain consisted of an outer most domain bounded between $100.67^{\circ} \mathrm{W}$ and $31.43^{\circ} \mathrm{W}$ in the longitude and $5.21^{\circ} \mathrm{S}$ and $38.85^{\circ} \mathrm{N}$ with a mesh resolution of $66.5 \mathrm{~km}$. Two higher resolution nests were defined within the outermost domain. Domain 2 was bounded between $85.91^{\circ} \mathrm{W}$ and $46.21^{\circ} \mathrm{W}$ in the longitude and $3.81^{\circ} \mathrm{N}$ and $31.1^{\circ} \mathrm{N}$ in the latitude with a mesh resolution of $22.16 \mathrm{~km}$. The innermost domain was bounded between $76.37^{\circ} \mathrm{W}$ and $55.95^{\circ} \mathrm{W}$ in the longitude and $10.36^{\circ} \mathrm{N}$ and $25.05^{\circ} \mathrm{N}$ with a mesh resolution of $7.38 \mathrm{~km}$. The WRF computational domain and the terrain for the innermost domain are shown in Figure 16.

The WRF mesoscale simulation was initialized using Global Forecast System (GFS) data from the National Climate Data Center (NCDC) for 2 August 2009 at 1200 UTC. The simulation was run for 36 hours of forecast time. The output for the innermost domain was generated every $15 \mathrm{~min}$. The sounding forecast (see Figure 17) was extracted from the WRF simulation high-resolution nest for 3 August at 0915 UTC. The low levels of the sounding were modified to agree with observed cloud base heights. The sounding indicates a moist environment favorable for single-cell convection with relatively small diameters. The initial environment assumed in TASS varies only in the vertical condition in accordance with the sounding in Figure 17. Convection with cloud and precipitation development was triggered in TASS by imposing the artificial bubble of warm air. Three-dimensional fields evolved as convection interacted with the environmental fields. Figure 18 shows the vertical cross sections of temperature and relative humidity through the location of extracted sounding (from the WRF simulation). A deep convection layer in the region surrounding the sounding location was conducive for triggering intense tropical thunderstorms. 

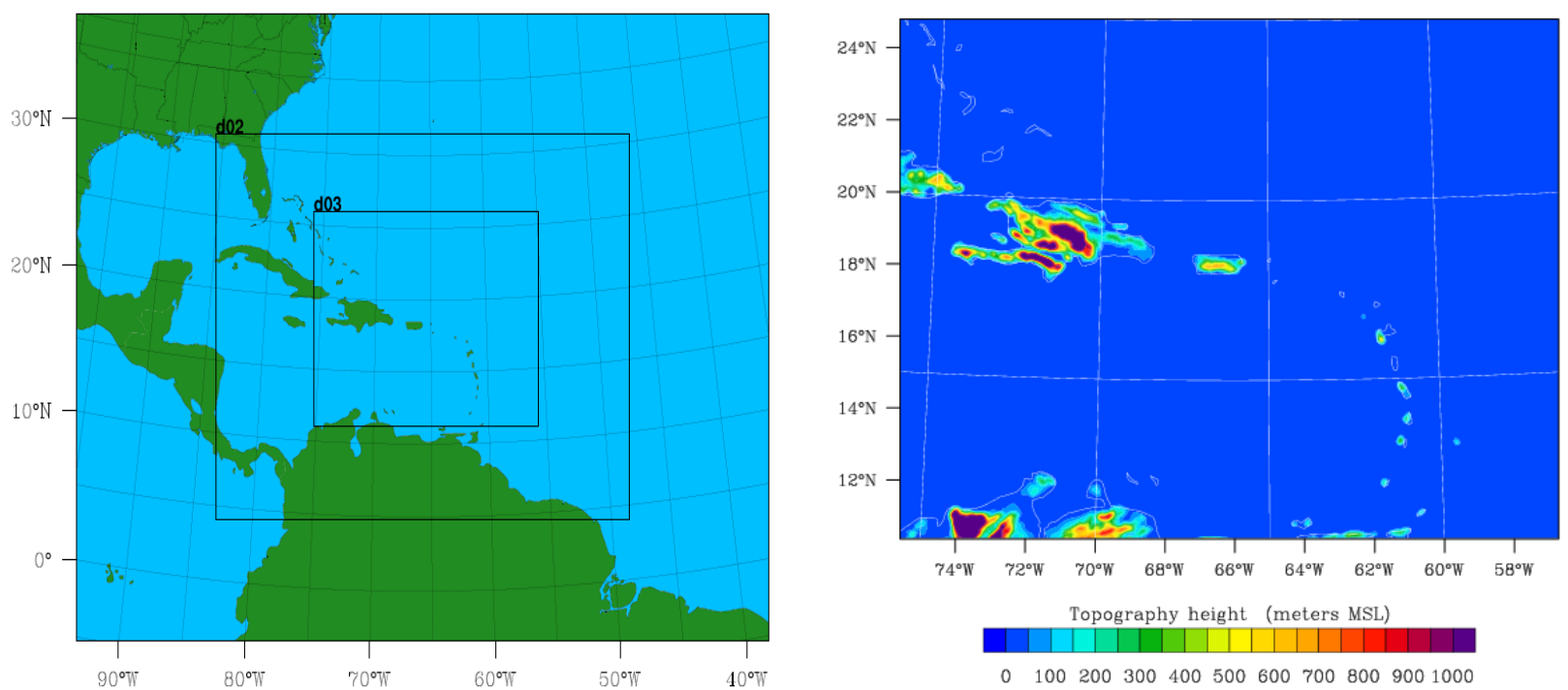

$0 \quad 1002003004005006007008009001000$

Figure 16. The left panel shows the WRF computational domain with higher resolution nests and the right panel shows the terrain contours for the inner most computational domain. The terrain maximum value in the plot is $4447.95 m$ and the minimum value is $0 m$.

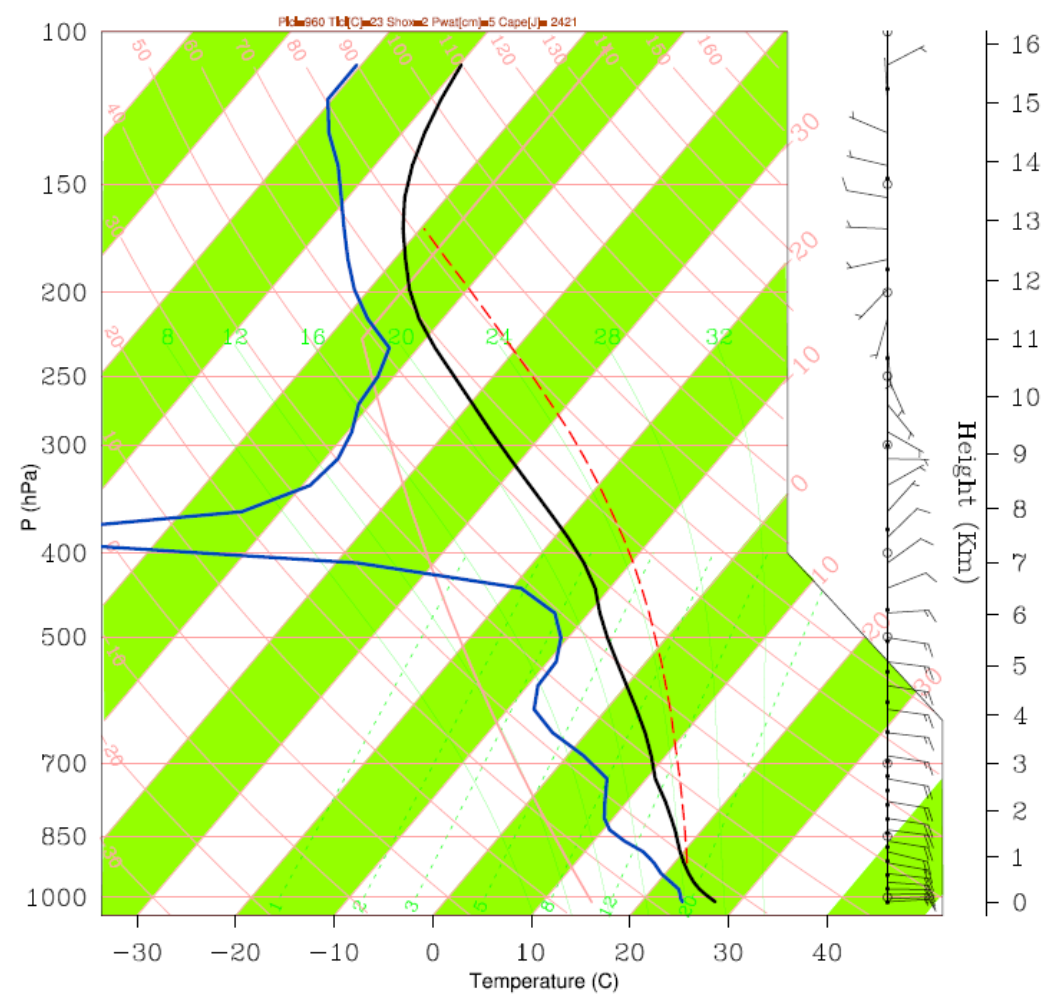

Figure 17. Skew-T chart of atmospheric sounding representing the environment for the location southwest of Puerto Rico. Shown are temperature, dewpoint, and horizontal wind velocity as a function of atmospheric pressure. 


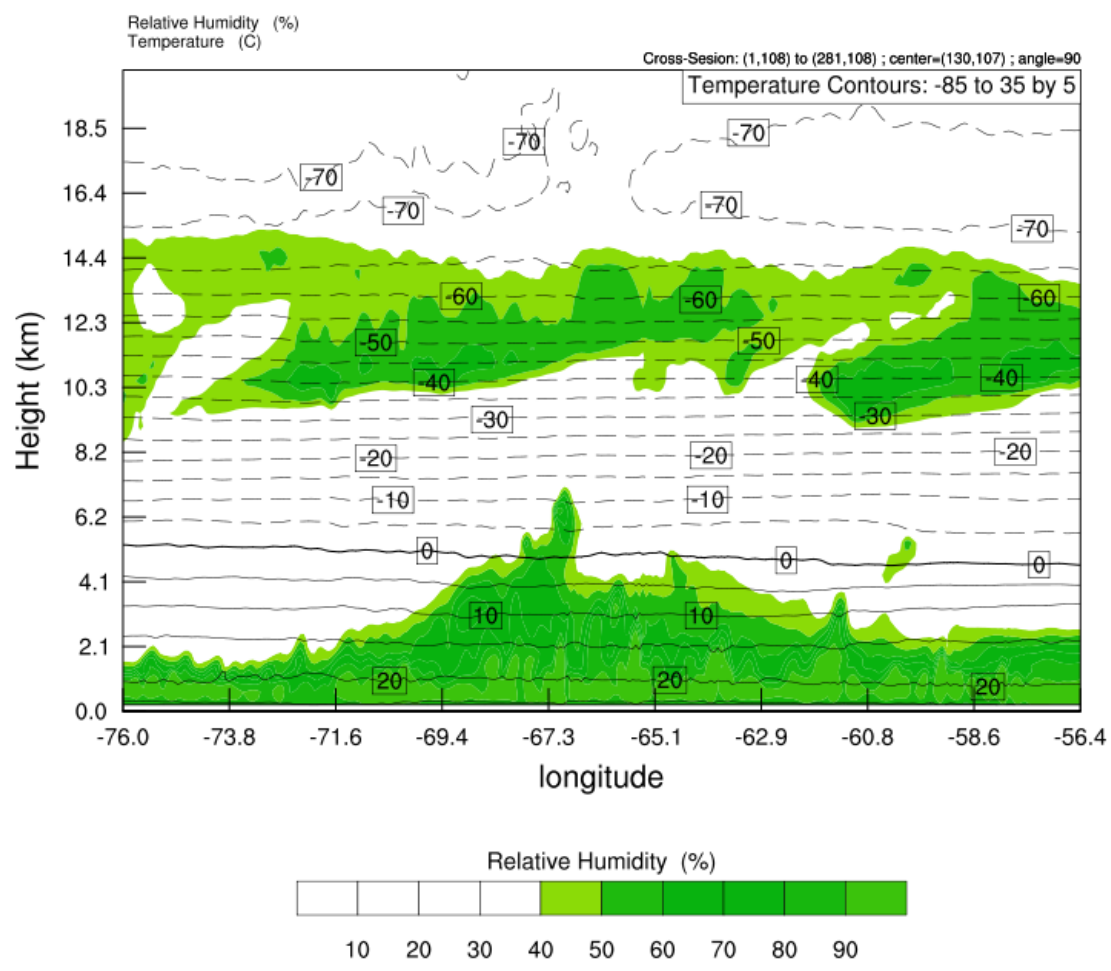

Figure 18. WRF simulation data for 3 August 2009 at 0915UTC. Vertical cross-section of relative humidity and temperature through the location of the storm (latitude $=17.67^{\circ} \mathrm{N}$ and longitude $=66.86^{\circ} \mathrm{W}$ ) are shown in the figure.

\section{Validation and Analysis of Simulation}

A matching of the model time with UTC time shows that the TASS simulation time $=28 \mathrm{~min}$ is best representative of the conditions at 0930UTC. This was done with the aid of NEXRAD Level 2 data. In space, the TASS $x$-coordinate of $x=-11,151 \mathrm{~m}$ is equivalent to $66.93^{\circ} \mathrm{W}$ longitude and, the $y$-coordinate of $y=1024 \mathrm{~m}$ is equivalent to $17.67^{\circ} \mathrm{N}$ latitude. The TASS simulation results are compared with observations in Table 6 . The simulated storm motion (both speed and direction) closely match the observed system. The simulated echo tops are also in good agreement with the observations. The computed radar reflectivity however is larger than observed from NEXRAD. In Figures 19-20, the TASS simulated cloud fields are shown at two different times (20min and 32min). The interaction of the convective system with the strong environmental shear at higher altitudes can be seen in Figure 20. Figure 21 shows a cross section of the TASS computed radar reflectivity in $x$-z plane for $y=2071 \mathrm{~m}$ at time $=30 \mathrm{~min}$.

Table 6: Model Comparison with Observations

\begin{tabular}{|l|c|c|}
\hline \multicolumn{1}{|c|}{ Variable } & TASS & Observed \\
\hline Orientation of Storm & East - West (slight tilt towards North) & East - West (slight tilt towards North) \\
\hline Peak Storm Tops (AGL) & $12.5 \mathrm{~km}$ & $12.3 \mathrm{~km}$ \\
\hline Storm Motion & $6.1 \mathrm{~m} / \mathrm{s} \mid 95$ degrees & $6.8 \mathrm{~m} / \mathrm{s} \mid 96$ degrees (average values) \\
\hline Max Radar Reflectivity & $60 \mathrm{dBZ}$ & $50.5 \mathrm{dBZ}$ \\
\hline
\end{tabular}




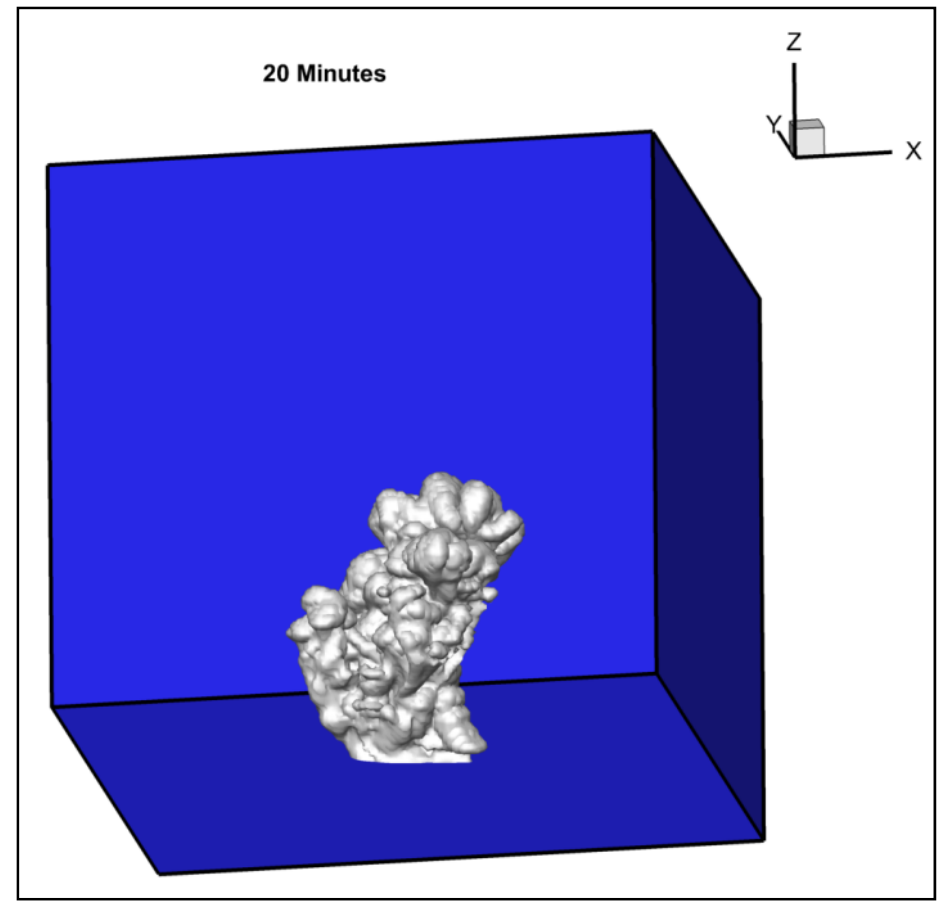

Figure 19. TASS simulated cloud field at time $=20 \mathrm{~min}$ into the simulation. View is from the southsouthwest. Every other point in $x$ - $y$ - and $z$-direction is plotted. The simulation domain was bounded within an $18 \mathrm{~km} \times 18 \mathrm{~km} \times 16.5 \mathrm{~km}$ domain. Mesh resolution was set to $\Delta x=\Delta y=\Delta z=60 \mathrm{~m}$.

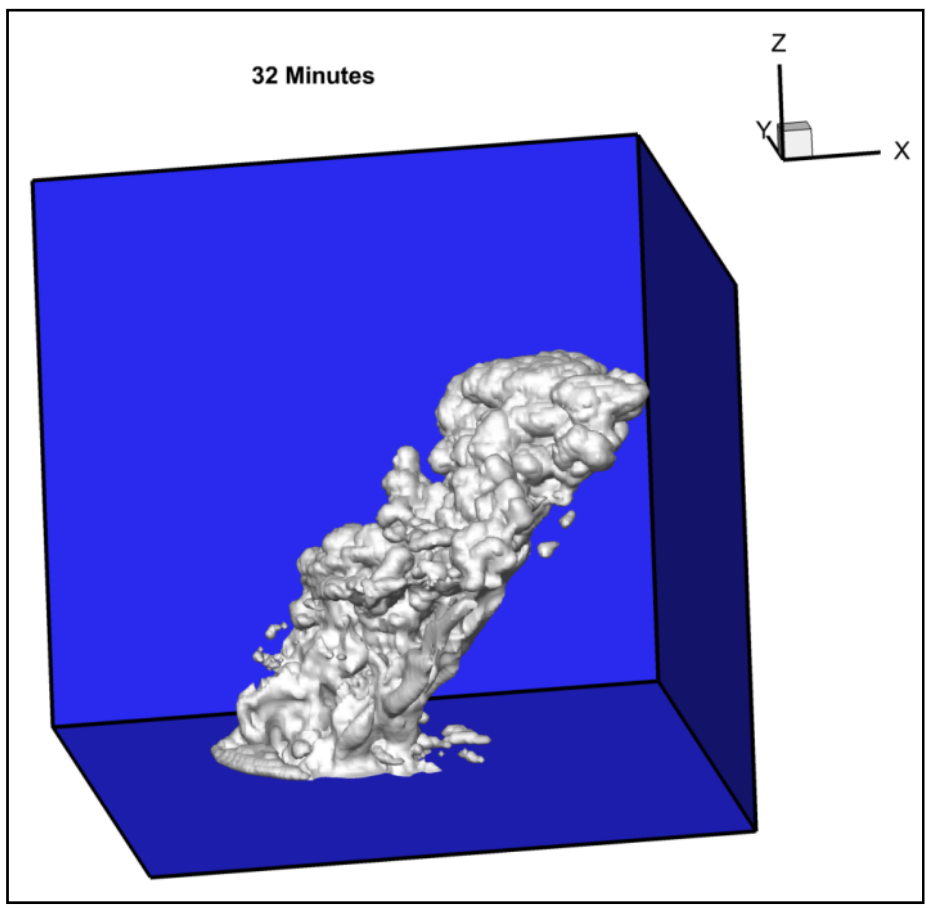

Figure 20. TASS simulated cloud field at time $=32 \mathrm{~min}$ into the simulation. View is from the southsouthwest. Every other point in $x$ - $y$ - and $z$-direction is plotted. The simulation domain was bounded within an $18 \mathrm{~km} \times 18 \mathrm{~km} \times 16.5 \mathrm{~km}$ domain. Mesh resolution was set to $\Delta x=\Delta y=\Delta z=60 \mathrm{~m}$. 


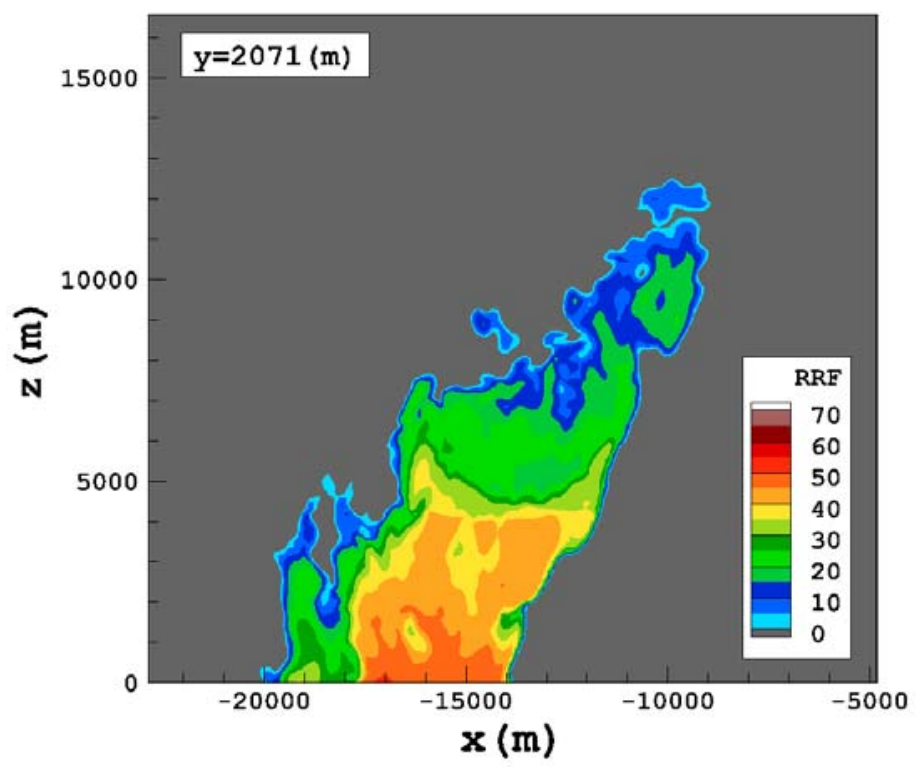

Figure 21. Vertical cross section $(x-z$ plane at $y=2071 \mathrm{~m})$ of the TASS simulated radar reflectivity field at time $=30 \mathrm{~min}$ into the simulation. Every other point in $x$ - $y$ - and z-direction is plotted. The simulation domain was bounded within an $18 \mathrm{~km} \times 18 \mathrm{~km} \times 16.5 \mathrm{~km}$ domain. Mesh resolution was set to $\Delta x=\Delta y=\Delta z=60 \mathrm{~m}$.

\section{Turbulence}

The turbulence characteristics for this case are shown in Figure 22 along with the radar reflectivity factor. The root mean square of the normal load acceleration is computed assuming an in-flight Boeing 767 with a weight of 300klbs. Light to moderate turbulence intensities occur within the top levels of this storm and coincide with low values of radar reflectivity. Convection induced turbulence was encountered by a Boeing 767 at an elevation of $10.97 \mathrm{~km}(36,000 \mathrm{ft})$ in a similar environment that was northeast of Puerto Rico on this date (3 August 2009).
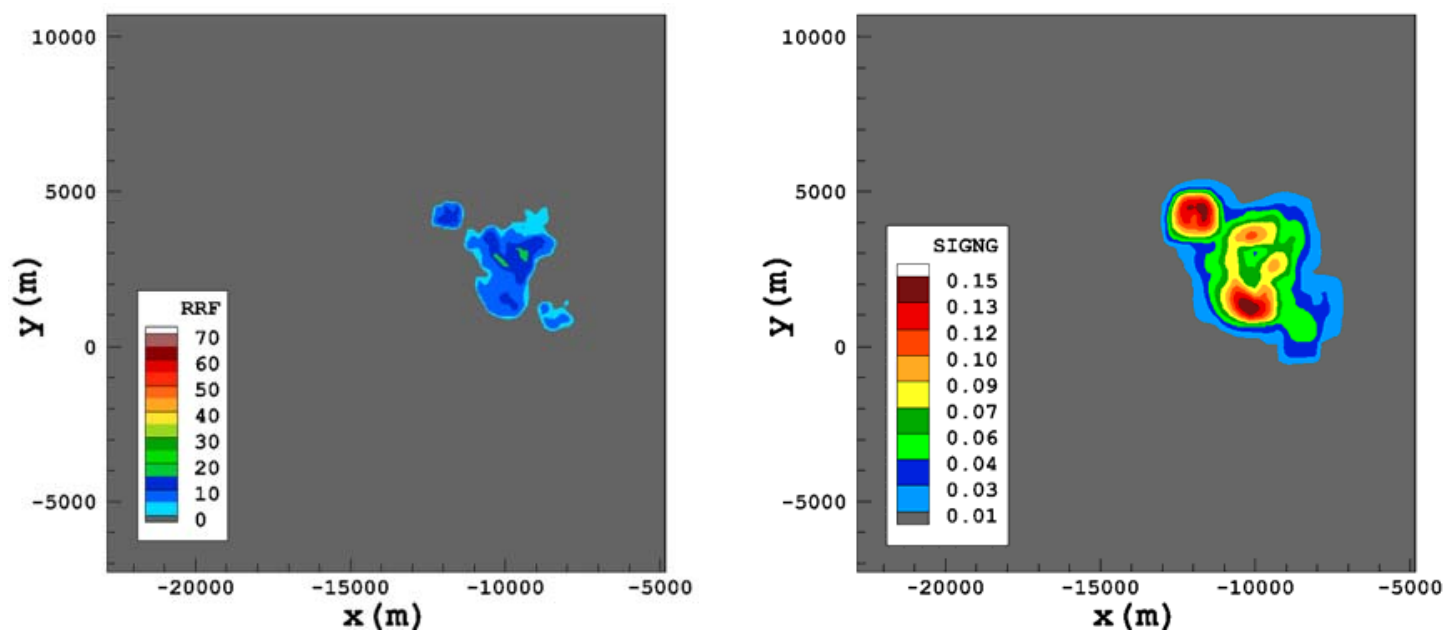

Figure 22. Radar reflectivity field and the root mean square of the normal load acceleration $\left(\sigma_{\Delta \mathrm{n}}\right)$ computed from simulation at time $=30 \mathrm{~min}$ for an altitude of $10.98 \mathrm{~km}$ AGL. Turbulence characteristics are based on data for an in-flight B-767 with a weight of $300 \mathrm{klbs}$. Every other point in $x$ - $y$-and z-direction is plotted. The simulation domain was bounded within an $18 \mathrm{~km} \times 18 \mathrm{~km} \times 16.5 \mathrm{~km}$ domain. Mesh resolution was set to $\Delta x=\Delta y=\Delta z=60 \mathrm{~m}$. 


\section{Indiana Hailstorm (19 June 2009)}

A supercell convective storm formed on the border of Fulton County and Marshall County on 19 June 2009 at approximately 2000UTC. The storm was located southwest of the NEXRAD radar site at Fort Wayne, Indiana. The prevalent synoptic conditions at 2100UTC on 19 June 2009 are shown in Figure 23 along with the infrared imagery from the GOES-E satellite. The storm persisted for a couple of hours and moved westnorthwest (278 degrees) at a speed of $10.7 \mathrm{~m} / \mathrm{s}(21 \mathrm{kts})$. Throughout its lifecycle the storm remained within $60 \mathrm{~km}$ of the NEXRAD radar site at Fort Wayne, Indiana (station ID KIWX). The NEXRAD station coordinates and elevation are given in Table 7. The storm characteristics (storm location, trajectory and strength) obtained from an analysis of the NEXRAD L2 and L3 data are summarized in Table 8.

The supercell resulted in a hailstorm that produced softball sized hail $(114.3 \mathrm{~mm})$ and generated a wall cloud. Observations of hail were reported from 2000UTC until 2206UTC. Hail ranging from pea to grapefruit size and lasting for 20min was reported in Fulton County at 2030UTC. Possibility of hail $(49.2 \mathrm{~mm})$ was reported by the NEXRAD data in the Marshall County at 2016UTC. Hail (possible size ranging from $54.6 \mathrm{~mm}$ to $60.9 \mathrm{~mm}$ ) was also reported in Kosciusko County at 2055UTC and again at 2118UTC, as the storm moved east. No substantial wind damage was reported for Fulton County and the storm in general had low shear in the lower $1 \mathrm{~km}$ of the boundary layer.

Analysis of the NEXRAD data indicated radar reflectivity in excess of $70 \mathrm{dBZ}$ and storm tops of $17 \mathrm{~km}$ $(>55,000 \mathrm{ft}$ ). The echo tops and the radar reflectivity values (from Level 2 data) at different elevation angles are shown in Figure 24 for 2044UTC. Radar reflectivity of $65 \mathrm{dBZ}$ at low levels was observed, indicating very heavy rainfall and the possibility of marble to golf ball sized hail at that time. The maximum echo tops recorded at this time were higher than $17.1 \mathrm{~km}(56,000 \mathrm{ft})$. A vertical cross section of the Level 2 NEXRAD data is shown in Figure 25. A region of reflectivity with values as high as $70 \mathrm{dBZ}$ can be seen in Figure 25. A detailed description of the storm is given by B. J. Simpson of the National Weather Service (NWS) in a presentation posted on the NWS website (Simpson 2009). Simpson also discusses the reasons why this particular supercell with sufficient energy (MLCAPE in excess of $4000 \mathrm{~J} / \mathrm{kg}$ ) did not produce tornados. One of the reasons for the failure of tornadogenesis is attributed to weak low level shear.

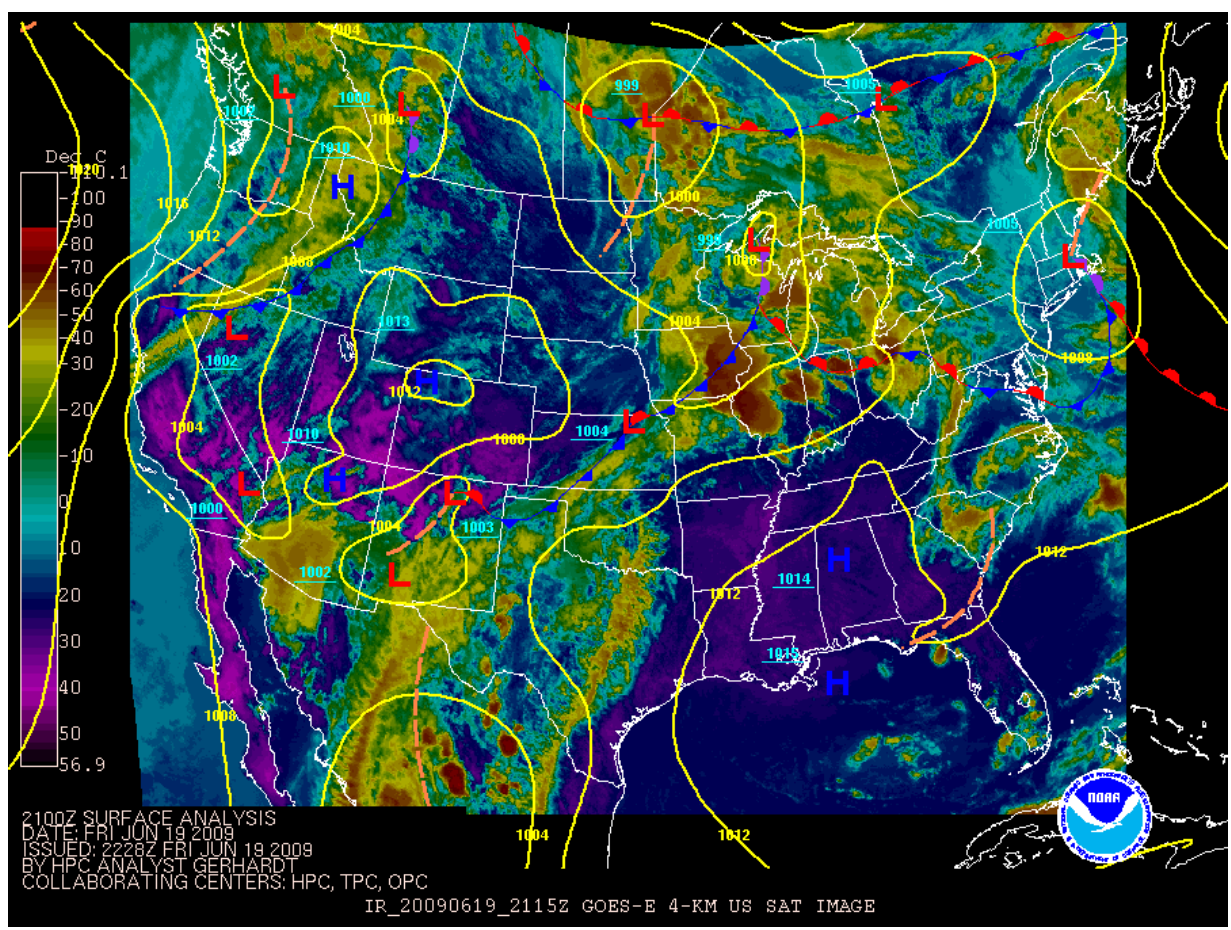

Figure 23. Surface weather map for the continental United States overlaid with GOES-E IR imagery at 2100UTC on 19 June 2009. Source: National Centers for Environmental Prediction (NCEP). 


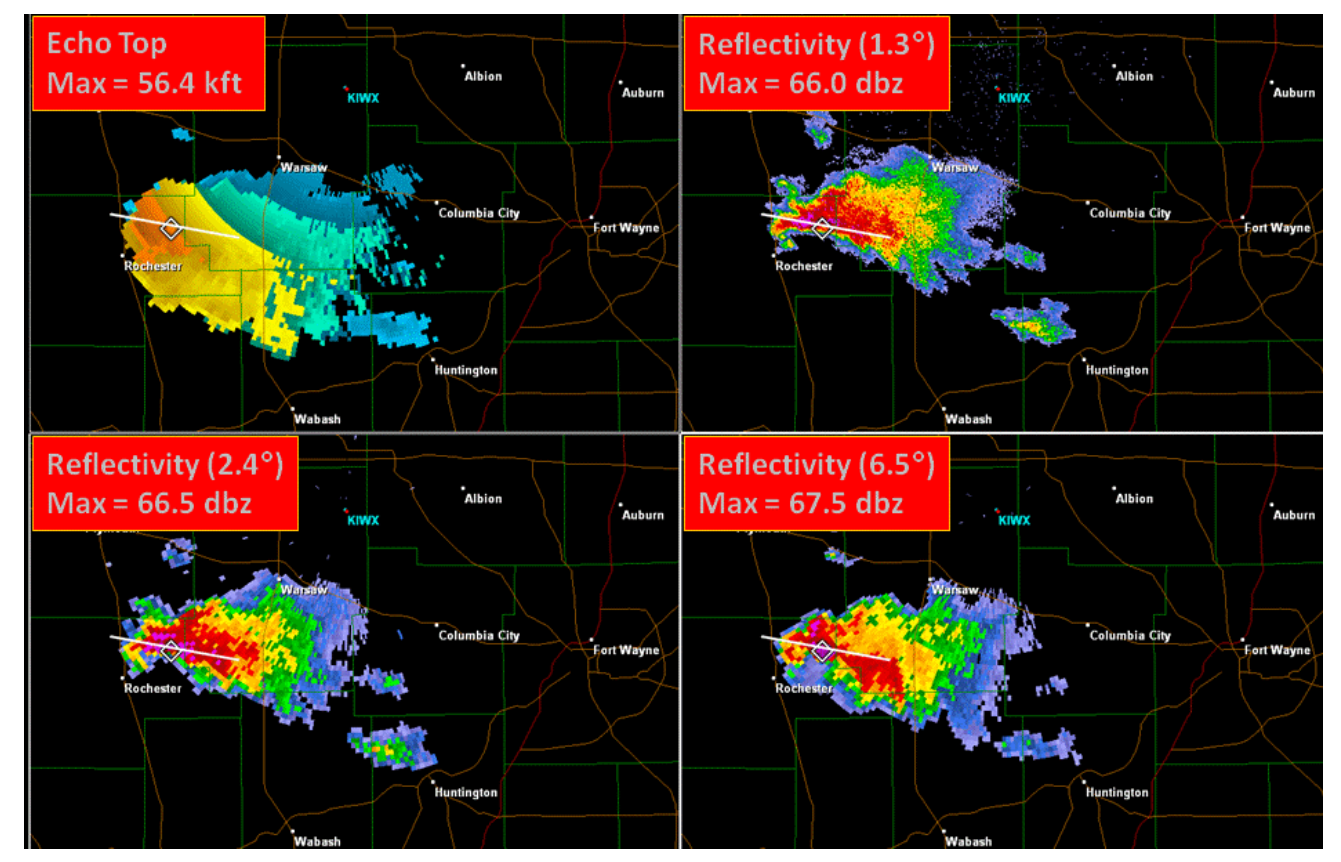

Figure 24. NEXRAD Level 2 data from the National Climate Data Center (NCDC). 19 June 2009 (2044UTC). Echo tops (kft) are shown in the top left panel and the radar reflectivity (dBZ) at different elevation angles is shown in the other three panels. The white diamond represents the observed hail size of 87.4mm.

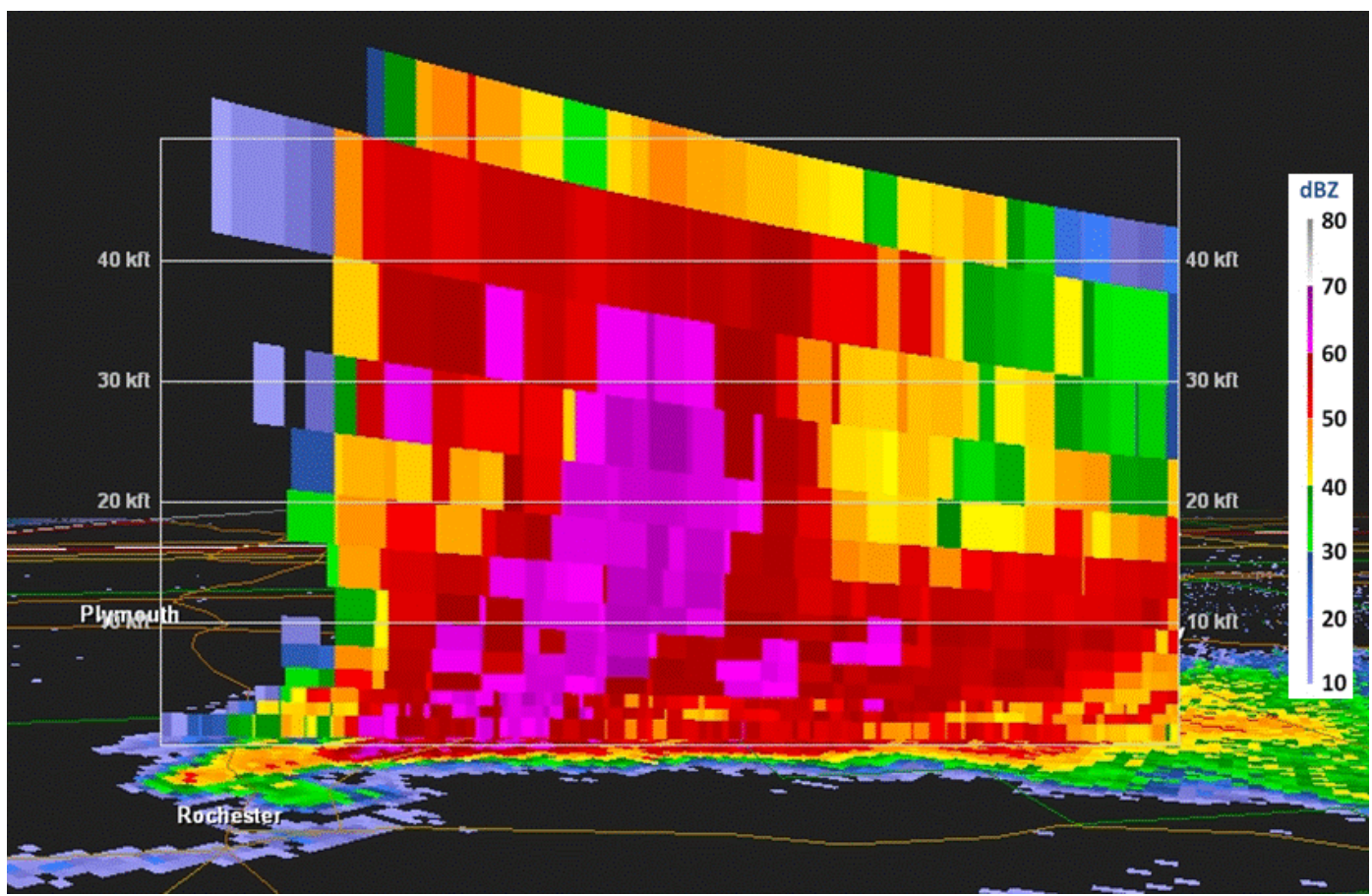

Figure 25. NEXRAD Level 2 data from the National Climate Data Center (NCDC). 19 June 2009 (2044UTC). A vertical cross section of the radar reflectivity is shown in the figure. 
Table 7: NEXRAD Station Data

\begin{tabular}{|c|c|}
\hline Station ID & KIWX \\
\hline Location & Fort Wayne, IN \\
\hline Latitude & $41^{\circ} 21^{\prime} 32^{\prime}$ N \\
\hline Longitude & $85^{\circ} 42^{\prime} 00^{\prime} \mathrm{W}$ \\
\hline Elevation (MSL) & $321.6 \mathrm{~m}(1055 \mathrm{ft})$ \\
\hline
\end{tabular}

Table 8: Characteristics of the Storm - 19 June 2009

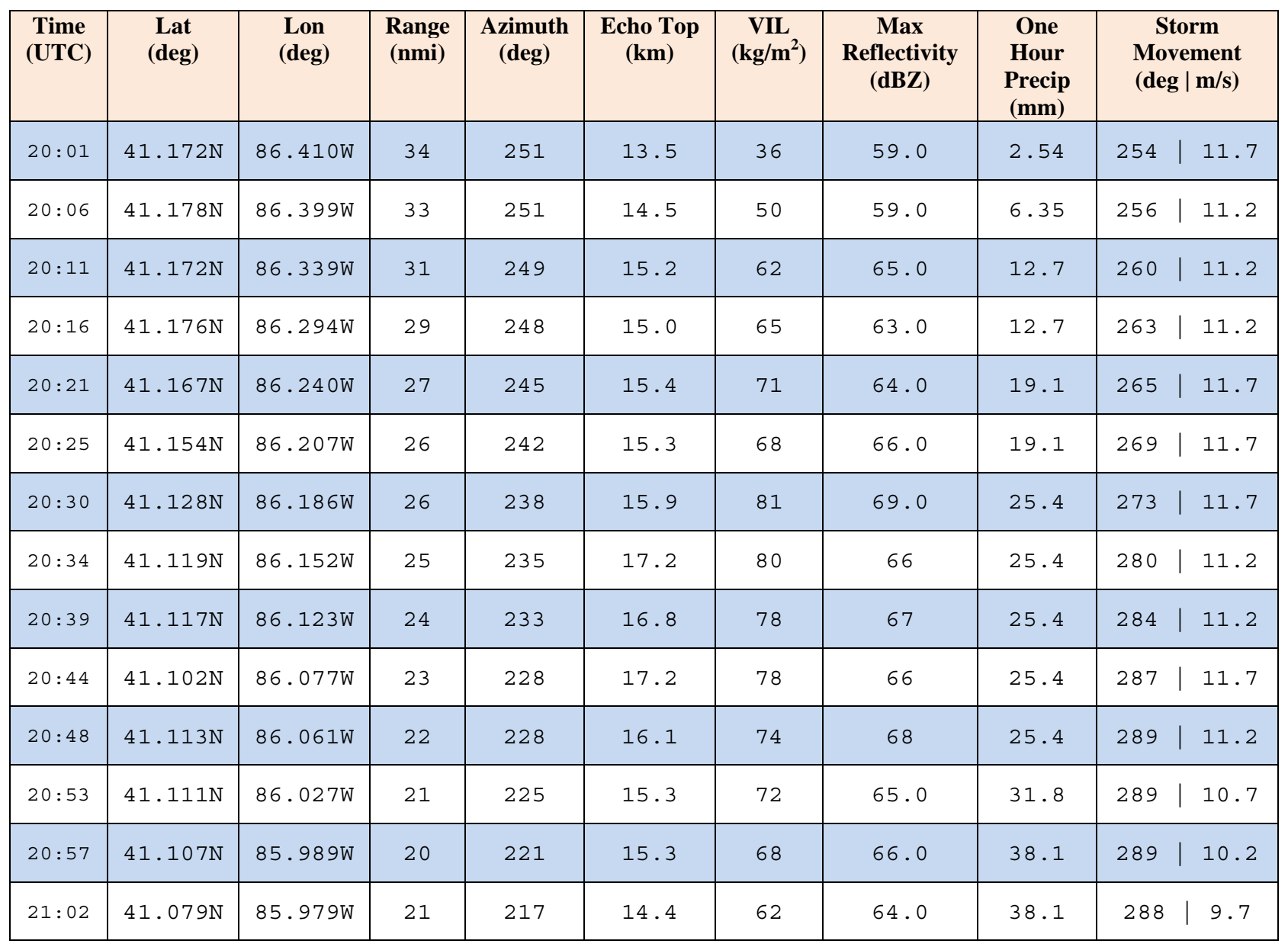

\section{Simulation Setup}

The TASS computational domain was bounded in the horizontal within a mesh of $70 \mathrm{~km} \times 70 \mathrm{~km}$. The vertical extant was set to $18.5 \mathrm{~km}$. The grid resolution of the data set was $100 \mathrm{~m}$ in all coordinate directions $(703 \times 703 \times 188$ points). The TASS simulation was initialized using a sounding from the Weather Research and Forecast model simulation. The WRF simulation domain consisted of an outer most domain bounded between $122.92^{\circ} \mathrm{W}$ and $46.07^{\circ} \mathrm{W}$ in the longitude and $20.79^{\circ} \mathrm{N}$ and $58.14^{\circ} \mathrm{N}$ with a mesh resolution of $18.0 \mathrm{~km}$. Two higher resolution nests were defined within the outermost domain. Domain 2 was bounded between $107.82^{\circ} \mathrm{W}$ and $65.03^{\circ} \mathrm{W}$ in the longitude and $28.82^{\circ} \mathrm{N}$ and $51.62^{\circ} \mathrm{N}$ in the latitude with a mesh resolution of $6.0 \mathrm{~km}$. The innermost domain was bounded between $95.95^{\circ} \mathrm{W}$ and $76.65^{\circ} \mathrm{W}$ in the longitude and $35.31^{\circ} \mathrm{N}$ and $46.19^{\circ} \mathrm{N}$ with a mesh resolution of $2.0 \mathrm{~km}$. High-resolution $(1 \mathrm{~km})$ terrain and land use datasets were used for the innermost domain and coarse resolution datasets were used for outer domains. The WRF computational domain and the terrain for the innermost domain are shown in Figure 26. The simulation was initialized using North American Regional Reanalysis (NARR) 
data from the National Climate Data Center (NCDC) for 19 June 2009 at 1200 UTC. The simulation was run for 24 hours. The output for the innermost domain was generated every $30 \mathrm{~min}$.

The sounding forecast (see Figure 27) was extracted from the WRF simulation high-resolution nest for 19 June at 2000UTC. The low levels of the sounding were modified to agree with observed cloud base heights. The initial environment assumed in TASS varies only in the vertical condition in accordance to the sounding in Figure 27. Convection with cloud and precipitation development was triggered in TASS by imposing an artificial bubble of warm air. Three-dimensional velocity and thermodynamic quantities evolved as convection interacted with the environmental fields.
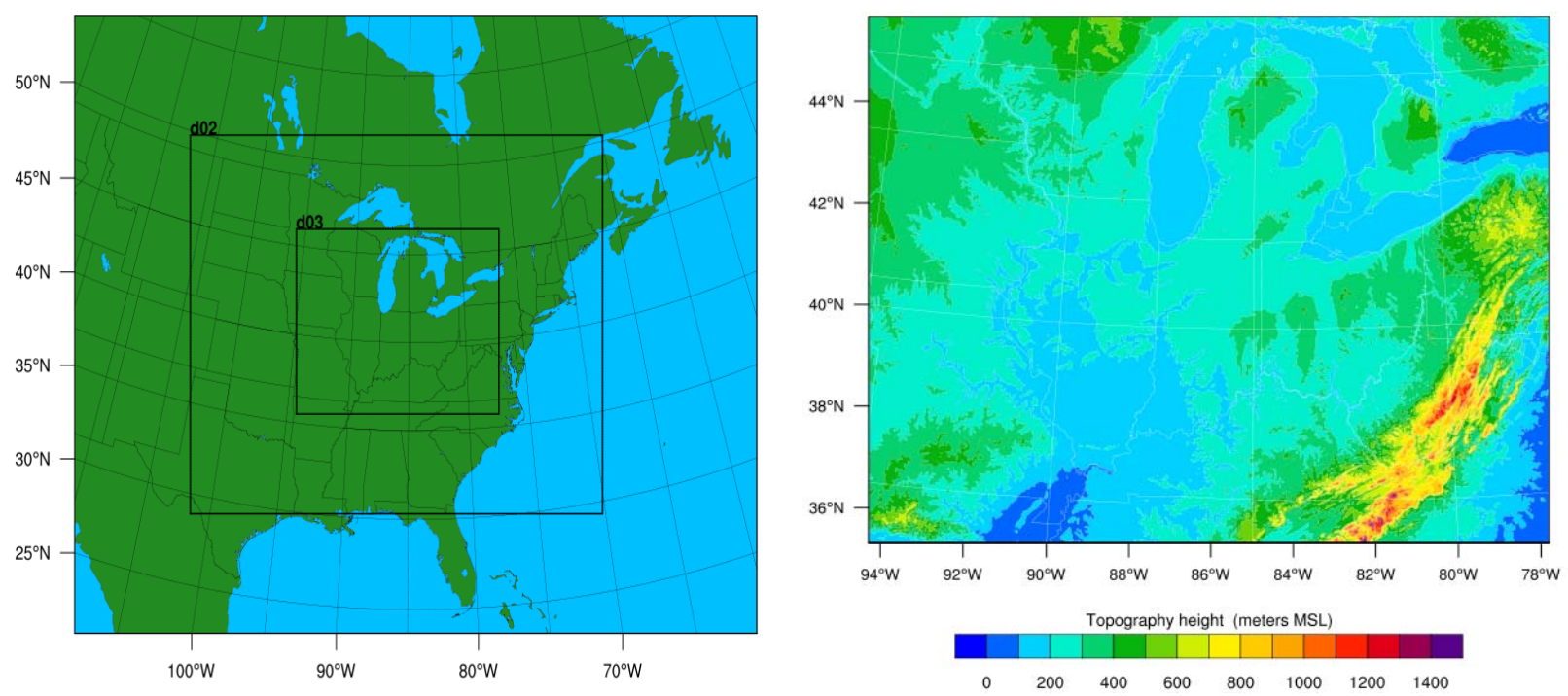

Figure 26. The left panel shows the WRF computational domain with higher resolution nests and the right panel shows the terrain contours for the inner most computational domain. The terrain maximum value in the plot is $1726.62 \mathrm{~m}$ and the minimum value is $15.47 \mathrm{~m}$.

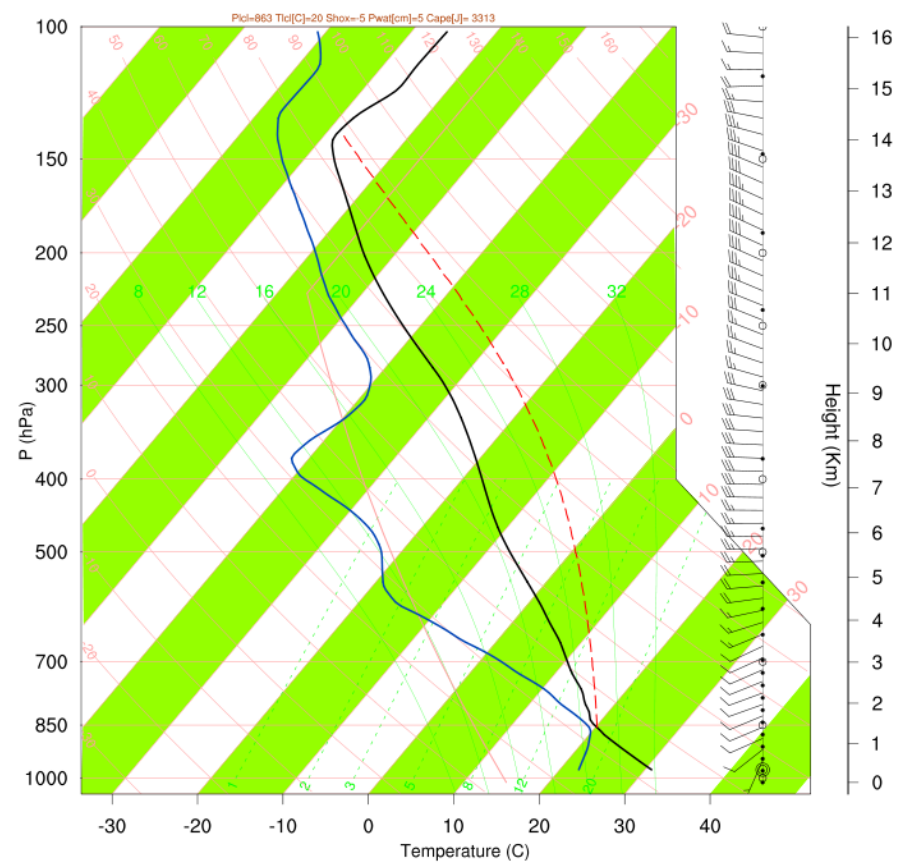

Figure 27. Skew-T chart of atmospheric sounding representing the ambient environment. Shown are temperature, dewpoint, and horizontal wind velocity as a function of atmospheric pressure. 


\section{Validation and Analysis of Simulation}

A matching of the model time with UTC time shows that the TASS simulation time $=53 \mathrm{~min}$ is best representative of the conditions at 2030UTC. In space, the TASS $x$-coordinate of $x=25 \mathrm{~km}$ corresponds to $86.178^{\circ} \mathrm{W}$ longitude and, the $y$-coordinate of $y=12.75 \mathrm{~km}$ corresponds to $41.09^{\circ} \mathrm{N}$ latitude. The temporal and spatial mapping between the TASS and the observed data was done with the help of NEXRAD radar data. The TASS simulation results are compared with observations in Table 9. In Figure 28, the TASS simulated cloud field is shown at time $=50 \mathrm{~min}$ and $15 \mathrm{~s}$ into the simulation. The TASS computed RRF fields at two different heights are shown in Figure 29. The formation of the hook echo and the gust front can be seen in the figure. These features were also observed in the actual hailstorm.

Table 9: Model Comparison with Observations

\begin{tabular}{|l|c|c|}
\hline \multicolumn{1}{|c|}{ Variable } & TASS & Observed \\
\hline Orientation of Storm & West - East & West - East (slight tilt to the south) \\
\hline Peak Storm Tops (AGL) & $16 \mathrm{~km}$ & $17.2 \mathrm{~km}$ \\
\hline Storm Motion & $11.7 \mathrm{~m} / \mathrm{s} \mid 255$ degrees & $10.7 \mathrm{~m} / \mathrm{s} \mid 278$ degrees (average values) \\
\hline Maximum Radar Reflectivity & $78.4 \mathrm{dBZ}$ & $69.0 \mathrm{dBZ}$ \\
\hline
\end{tabular}

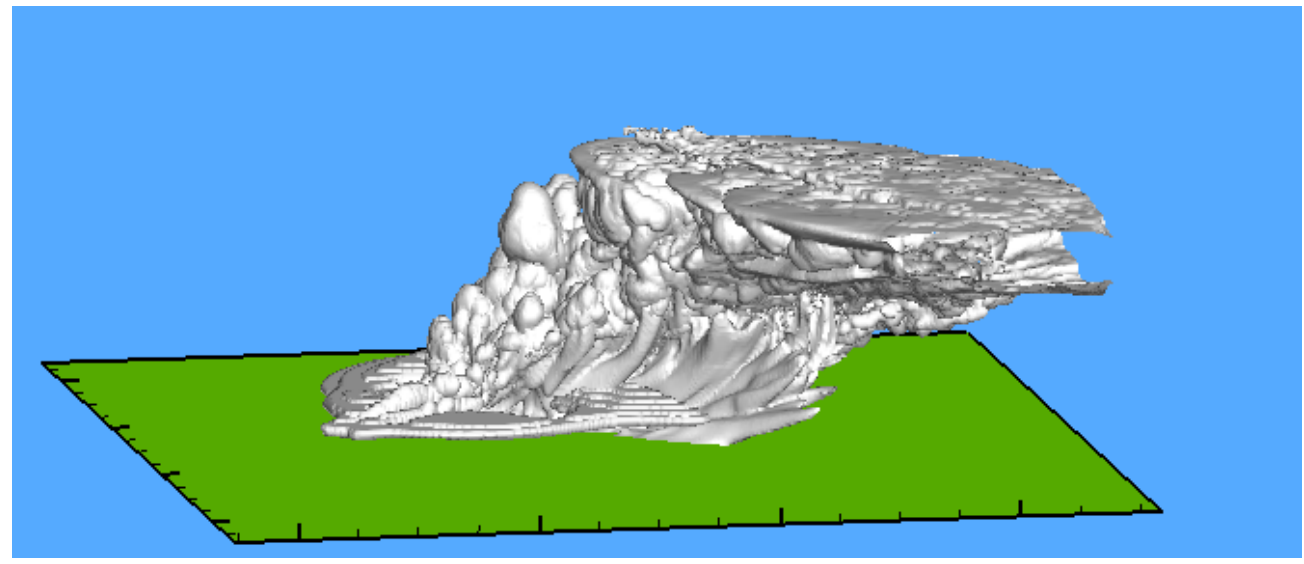

Figure 28. TASS simulated cloud field at time $=50 \mathrm{~min}: 15 \mathrm{~s}$. View is from the southwest. The simulation domain is bounded within a $70 \mathrm{~km} \times 70 \mathrm{~km} \times 18.5 \mathrm{~km}$ domain. Mesh resolution was set to $\Delta x=\Delta y=\Delta z=100 \mathrm{~m}$.
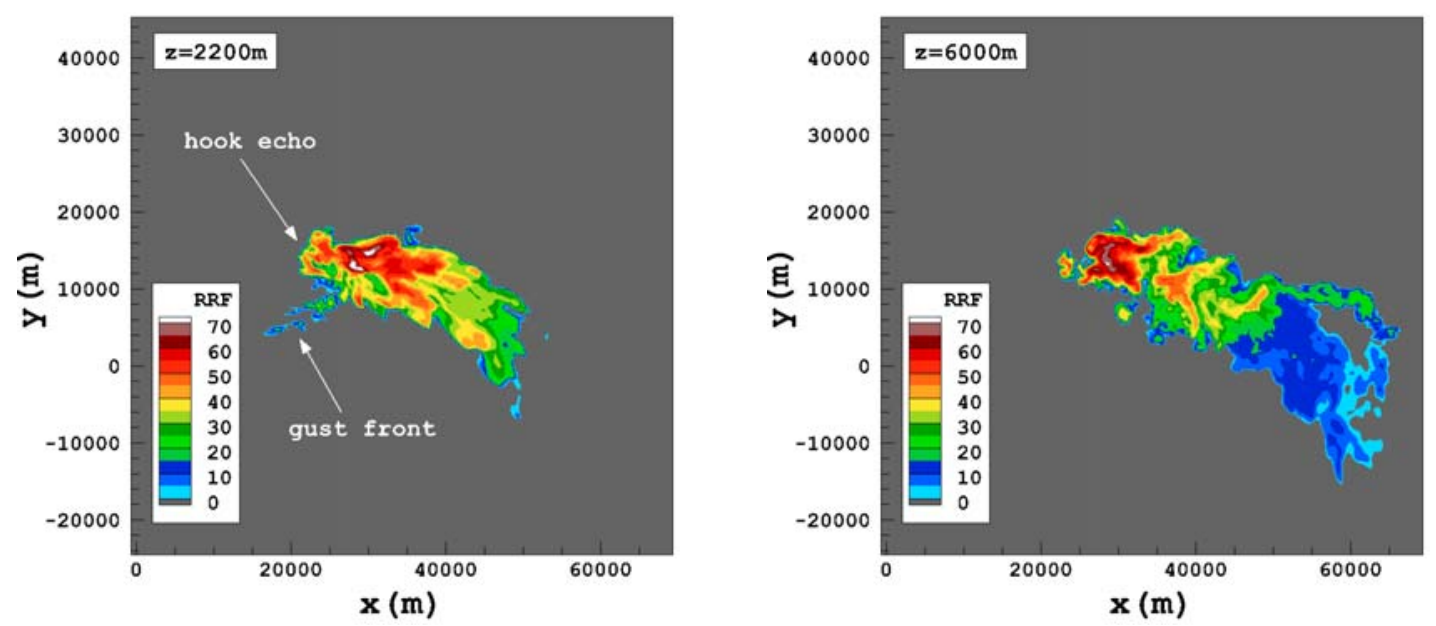

Figure 29. The TASS computed RRF field in the $x-y$ plane at an altitude of $2200 \mathrm{~m}$ is shown in the left panel and at an altitude of $6000 \mathrm{~m}$ is shown in the right panel. Time $=53 \mathrm{~min}$ into the simulation. 


\section{Turbulence}

The RMS of the normal load acceleration $\left(\sigma_{\Delta \mathrm{n}}\right)$ was computed from the TASS simulation data assuming an inflight Boeing B737-300 with a weight of 100klbs. Significant $\sigma_{\Delta \mathrm{n}}$ values $\left(\sigma_{\Delta \mathrm{n}} \geq 0.2 \mathrm{~g}\right)$ occur within the top levels of this storm and coincide with low values of radar reflectivity. These values correspond to peak normal loads $(|\Delta n|)$ greater than $0.5 \mathrm{~g}$. The $0.2 \mathrm{~g}$ isosurface of the RMS normal load acceleration from TASS simulation is shown in Figure 30 along with the $35 \mathrm{dBZ}$ radar reflectivity isosurface. The maximum $\sigma_{\Delta \mathrm{n}}$ value at this time was $0.77 \mathrm{~g}$. The TASS computed RRF and the $\sigma_{\Delta \mathrm{n}}$ fields in the $x-y$ plane at an altitude of $10 \mathrm{~km}$ are shown in Figure 31.

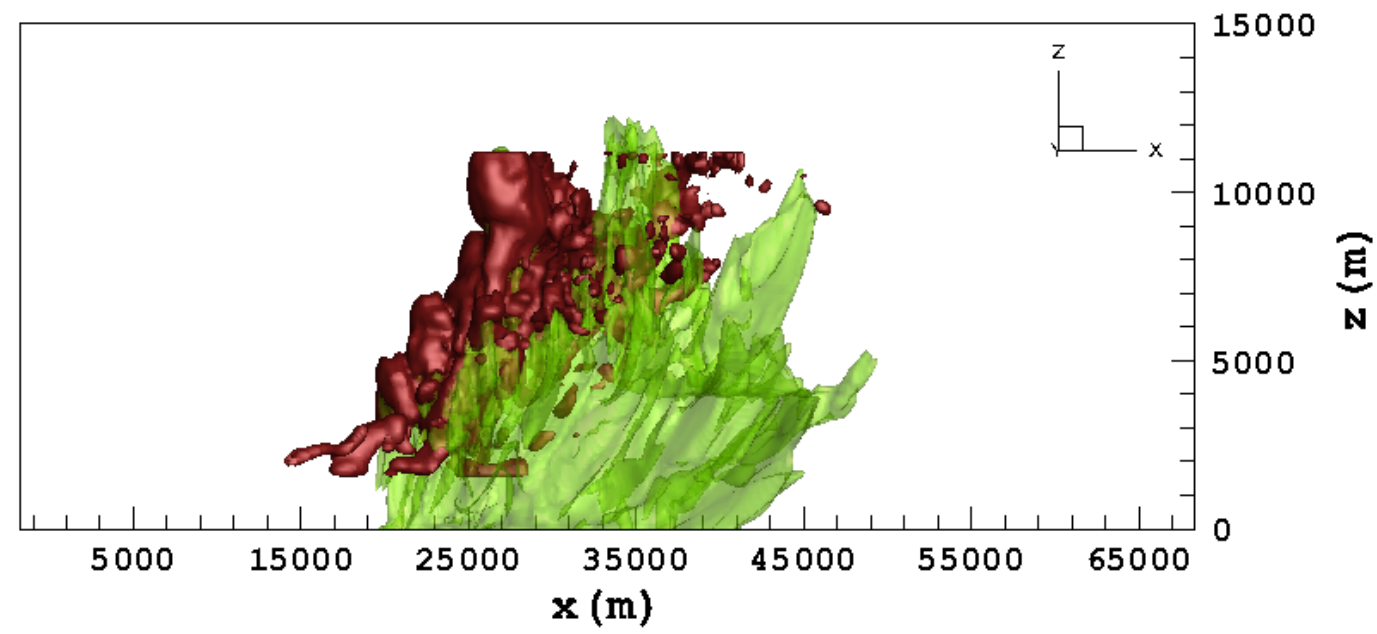

Figure 30. Radar Reflectivity Factor (RRF) isosurface (35dBZ) is shown in green and the $0.2 g \sigma_{\Delta \mathrm{n}}$ isosurface is shown in red. A Boeing 737-300 aircraft with a weight of $100 \mathrm{klbs}$ is assumed in $\sigma_{\Delta \mathrm{n}}$ calculation. Every point in $z$-direction is plotted and every other point in $x$ - and $y$-direction is plotted. The simulation domain was bounded within a $70 \mathrm{~km} \times 70 \mathrm{~km} \times 18.5 \mathrm{~km}$ domain. Mesh resolution was set to $\Delta x=\Delta y=\Delta z=$ $100 \mathrm{~m}$. The TASS simulation time $=53 \mathrm{~min}$.
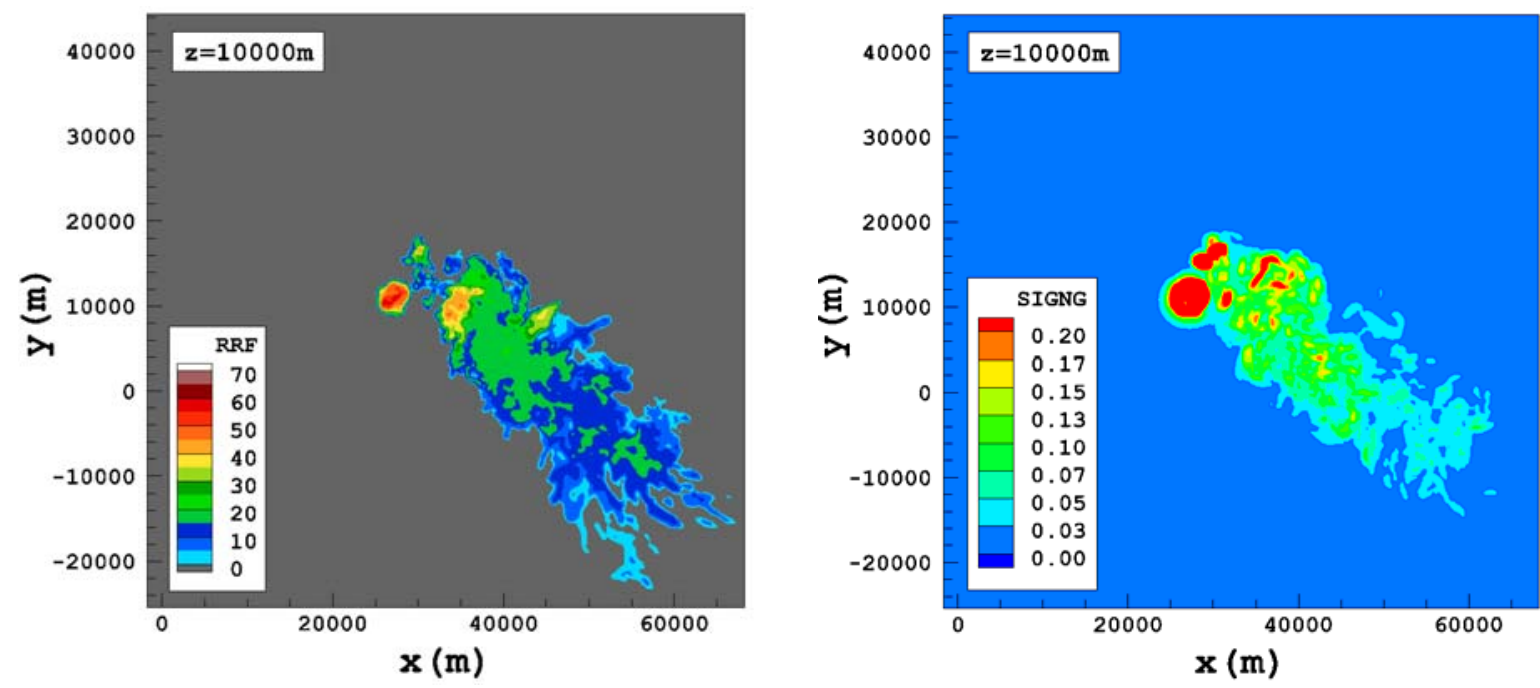

Figure 31. The TASS computed Radar Reflectivity Factor field in the $x-y$ plane at an altitude of $10000 \mathrm{~m}$ is shown in the left panel and the $\sigma_{\Delta \mathrm{n}}$ field on the same plane is shown in the right panel. Every other point in $x$ and $y$-direction is plotted. A Boeing 737-300 aircraft with a weight of $100 \mathrm{klbs}$ is assumed in the $\sigma_{\Delta \mathrm{n}}$ calculation. Time $=53 \mathrm{~min}$ into the simulation. 


\section{Puerto Rico (17 July 2010)}

On 17 July 2010, a strong gust front formed on the eastern shore of Puerto Rico and started moving westnorthwest. The $1 \mathrm{~km}$ resolution visible imagery (Figure 32) from GOES-13 shows the outflow boundary as the front propagated westwards. The Intertropical Convergence Zone (ITCZ) is normally south of Puerto Rico in July and it is possible that the initial forcing for the gust front may have been provided by convection due to the convergence in the ITCZ. There were unconfirmed reports of a waterspout/tornado near Mayaguez around 1645UTC along with reports of damage to trees and structures. Multiple injuries were also reported and surface wind gusts in excess of $22.35 \mathrm{~m} / \mathrm{s}(50 \mathrm{mph})$ were recorded at various locations in the path of the gust front. An enhanced-V signature $\left(\Delta T \sim-10^{\circ} \mathrm{C}\right)$ can be seen in the MODIS infrared imagery (Figure 32). The enhanced-V signature is formed due to winds going around overshooting tops and is indicative of severe thunderstorms (McCann 1983).

The thunderstorm event over northwestern Puerto Rico was detected at 1630UTC by the NEXRAD radar site near San Juan, Puerto Rico (NEXRAD station ID TJUA). Several convective storms with multiple cells formed in the region. These cells split and merged into each other as the gust front moved over northwest Puerto Rico. The storm moved briskly at approximately $11.82 \mathrm{~m} / \mathrm{s}$ towards the westnorthwest. The storm was later observed to move out over the ocean and dissipate by $1800 \mathrm{UTC}$. Hail (size ranging from $21.6 \mathrm{~mm}$ to $24.1 \mathrm{~mm}$ ) was estimated from the NEXRAD at 1706UTC. Maximum radar reflectivity of $57 \mathrm{dBZ}$ and echo tops as high as $14.3 \mathrm{~km}(47 \mathrm{kft}$ ) were observed during the storm lifetime. The radar reflectivity (Level 2 data) and echo tops at 1706UTC at different elevation angles is shown in Figure 33. A vertical cross section of the Level 2 NEXRAD data is shown in Figure 34. The details on storm trajectory, strength and precipitation are given in Table 10.
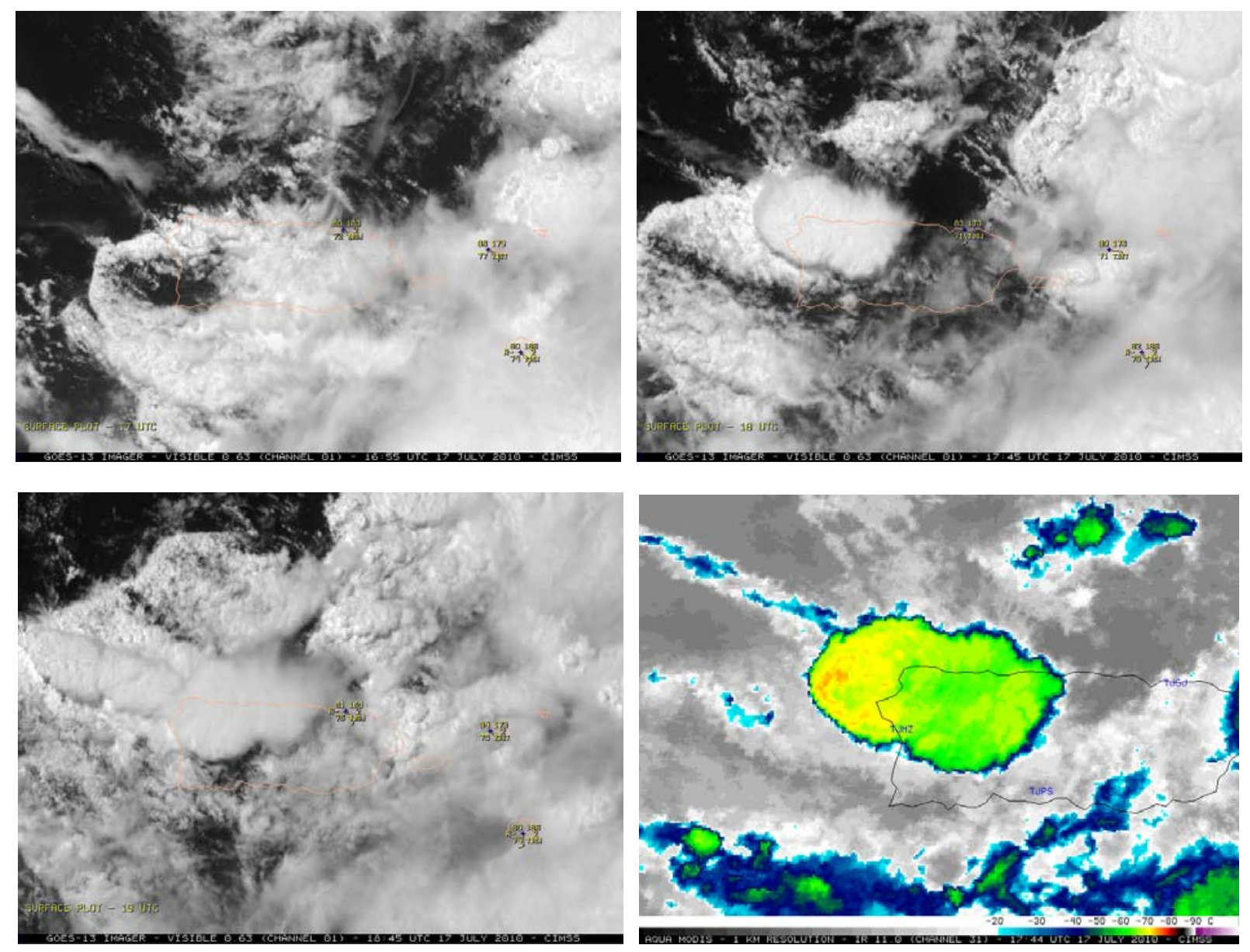

Figure 32. Visible imagery from NOAA's GOES-13 satellite for 17 July 2010. 1655UC (top left), 1745UTC (top right), 1845UTC (bottom left). The Aqua MODIS IR imagery at 1744UTC is shown in the bottom right panel. Source: Cooperative Institute for Meteorological Satellite Studies (CIMSS). 


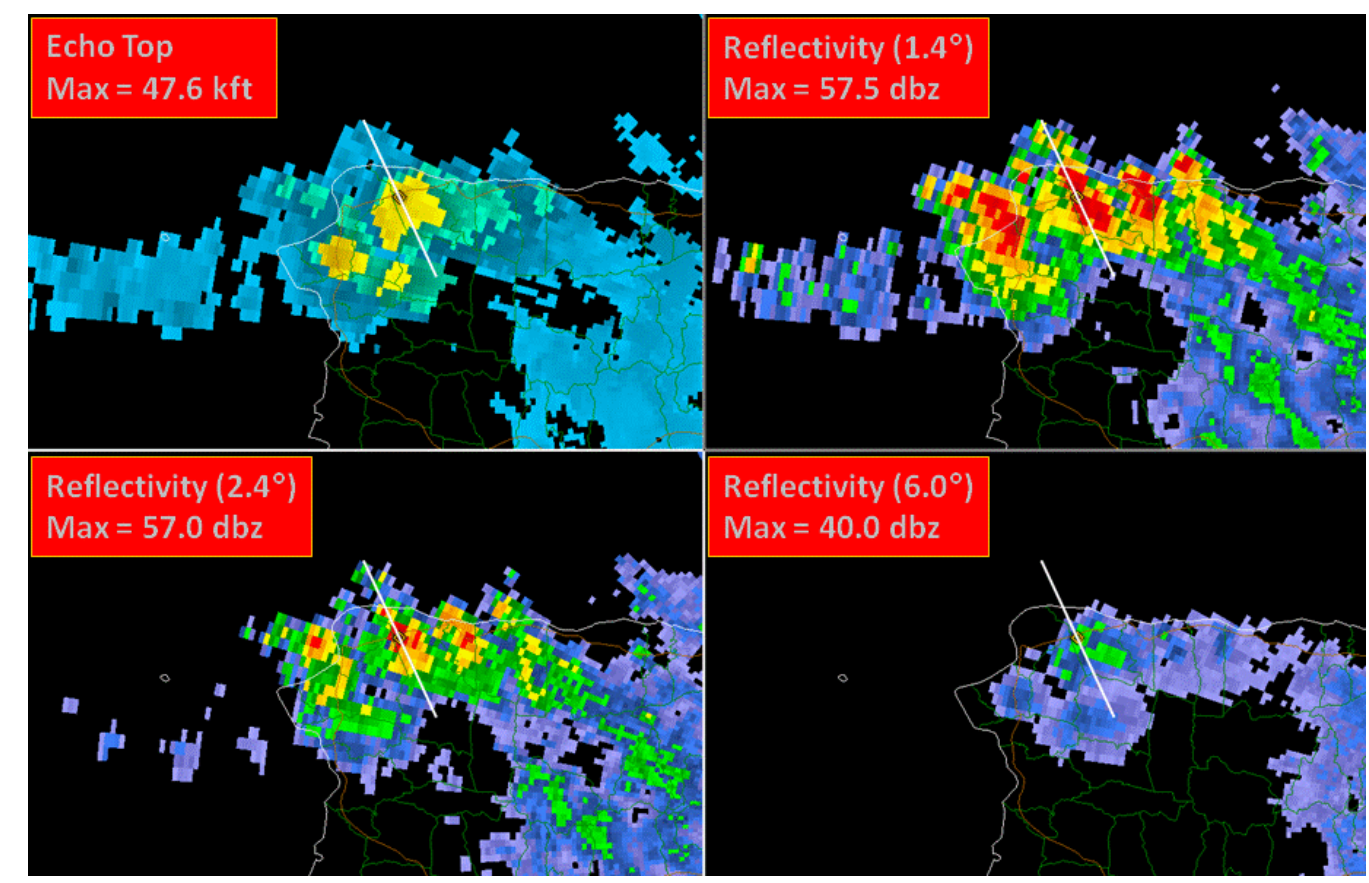

Figure 33. NEXRAD Level 2 data from the National Climate Data Center (NCDC). 17 July 2010 (1706UTC). Echo tops $(k f t)$ are shown in the top left panel and the radar reflectivity $(\mathrm{dBZ})$ at different elevation angles is shown in the other three panels.

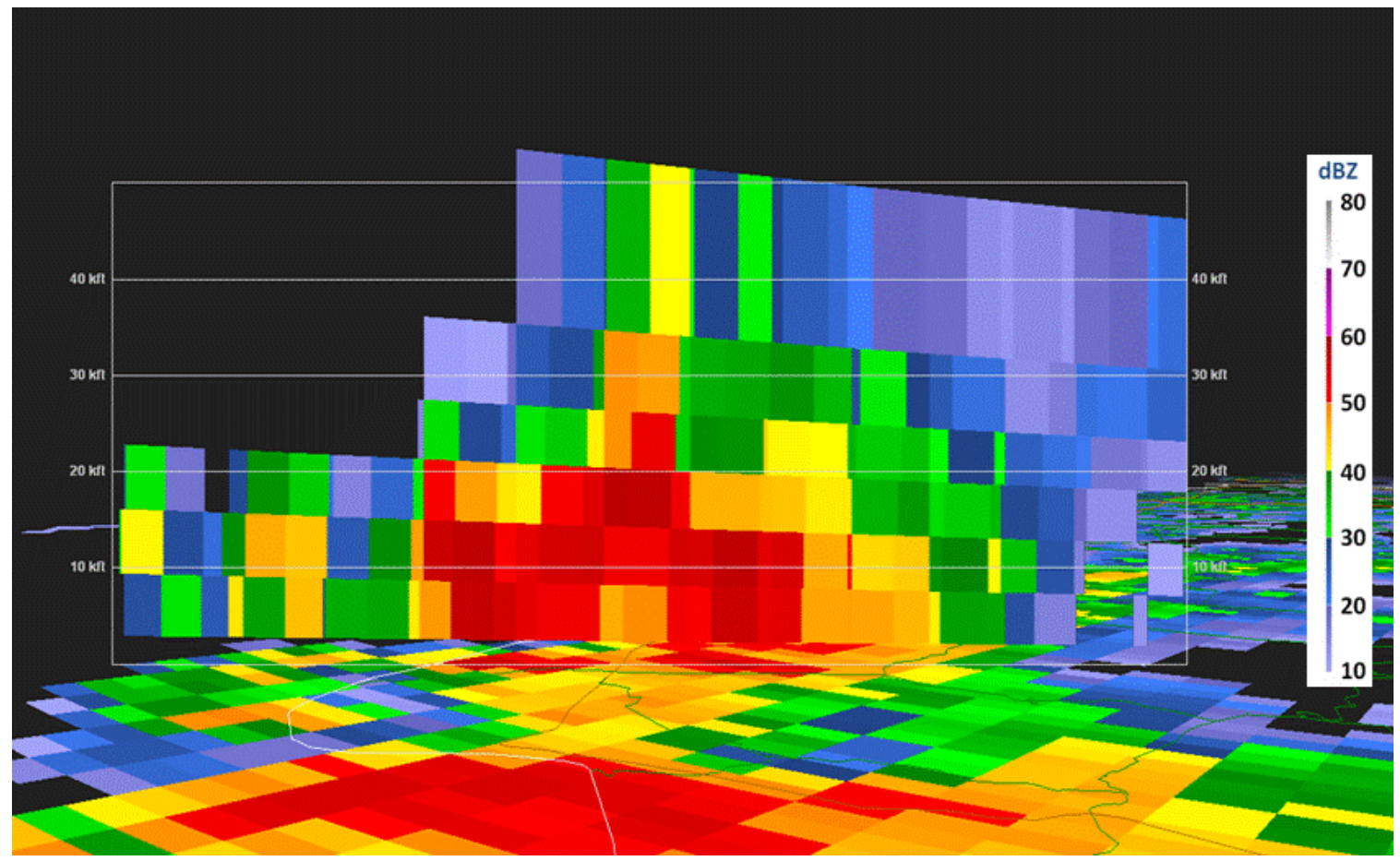

Figure 34. NEXRAD Level 2 data from the National Climate Data Center (NCDC). 17 July 2010 (1706UTC). A vertical cross section of the radar reflectivity is shown in the figure. 
Table 10: Characteristics of the Storm - 17 July 2010

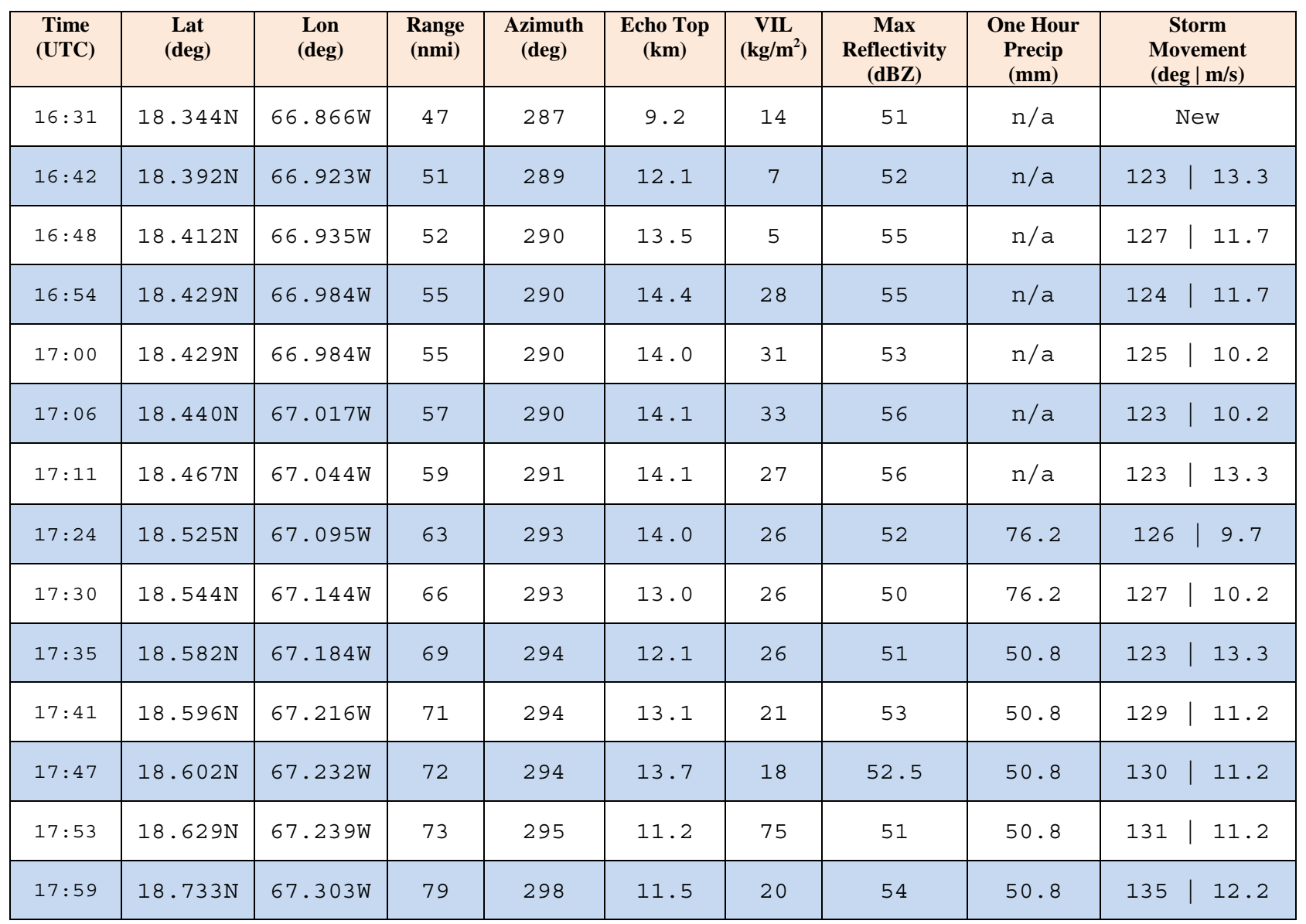

\section{Simulation Setup}

The TASS computational domain was bounded in the horizontal within a mesh of $45 \mathrm{~km} \times 45 \mathrm{~km}$. The model top was set to $17.2 \mathrm{~km}$. The grid resolution was set to $80 \mathrm{~m}$ in all coordinate directions (566 x $566 \times 216$ points). The model domain was allowed to translate with simulated convective cell, thus relaxing the requirement for a larger computational domain. The TASS simulation was initialized from a sounding obtained from a WRF simulation.

The WRF simulation domain consisted of an outer most domain bounded between $108.98^{\circ} \mathrm{W}$ and $23.13^{\circ} \mathrm{W}$ in the longitude and $9.86^{\circ} \mathrm{S}$ and $43.04^{\circ} \mathrm{N}$ with a mesh resolution of $36 \mathrm{~km}$. Two higher resolution nests were defined within the outermost domain. Domain 2 was bounded between $86.54^{\circ} \mathrm{W}$ and $45.57^{\circ} \mathrm{W}$ in the longitude and $3.90^{\circ} \mathrm{N}$ and $31.27^{\circ} \mathrm{N}$ in the latitude with a mesh resolution of $12 \mathrm{~km}$. The innermost domain was bounded between $75.56^{\circ} \mathrm{W}$ and $56.54^{\circ} \mathrm{W}$ in the longitude and $11.52^{\circ} \mathrm{N}$ and $24.39^{\circ} \mathrm{N}$ with a mesh resolution of $4 \mathrm{~km}$. High-resolution $(1 \mathrm{~km})$ terrain and land use datasets were used for the innermost domain. The WRF computational domain and the terrain for the innermost domain are shown in Figure 35. The simulation was initialized using Global Forecast System (GFS) data from the National Climate Data Center (NCDC) for 17 July 2010 at 1200UTC. The simulation was run for 12 hours. The output for the innermost domain was generated every $15 \mathrm{~min}$. The sounding forecast (see Figure 36) was extracted from the WRF high-resolution nest for 17 July at 1530UTC. The initial environment assumed in TASS varies only in the vertical condition in accordance to the sounding in Figure 36. Convection with cloud and precipitation development was triggered in TASS by imposing an artificial bubble of warm air. Three-dimensional velocity and thermodynamic quantities evolved as convection interacted with the environmental fields. 

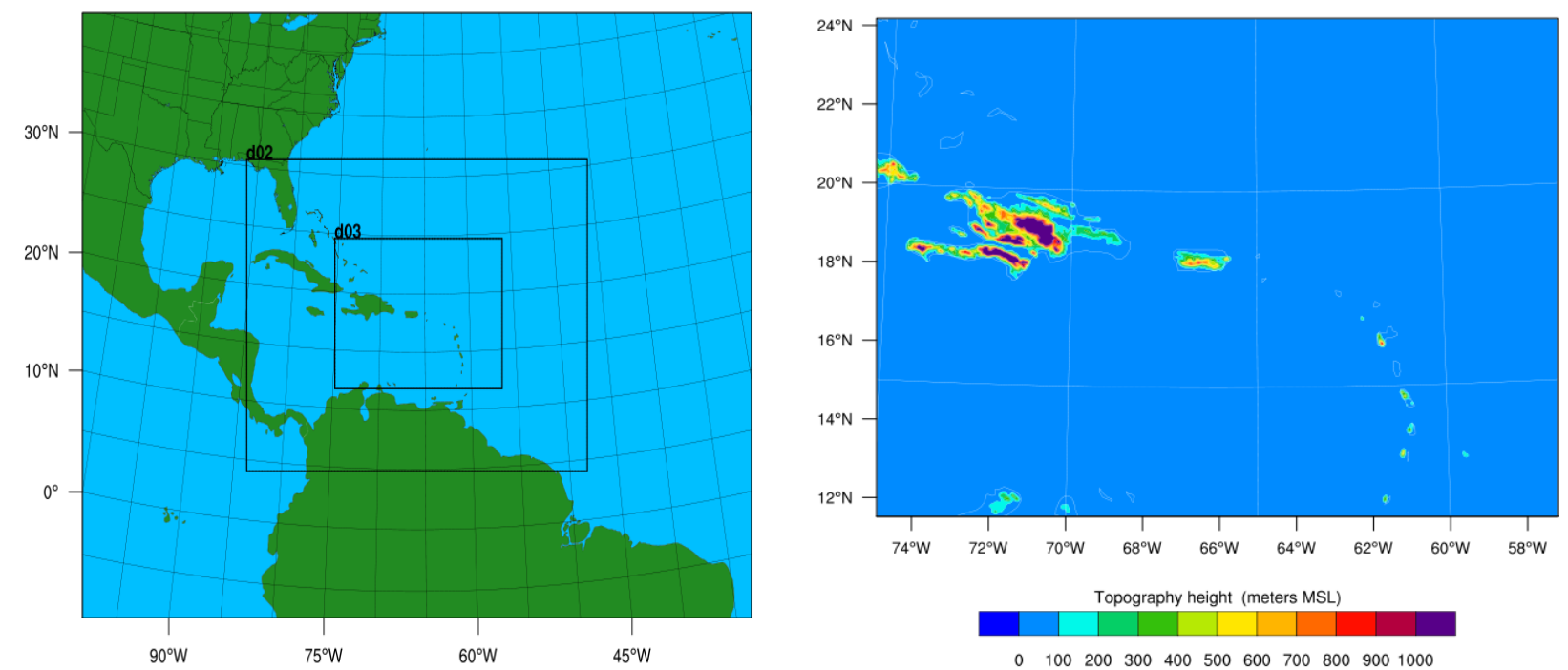

Figure 35. The left panel shows the WRF computational domain with higher resolution nests and the right panel shows the terrain contours for the inner most computational domain. The terrain maximum value in the plot is $2400.94 m$ and the minimum value is $0 \mathrm{~m}$.

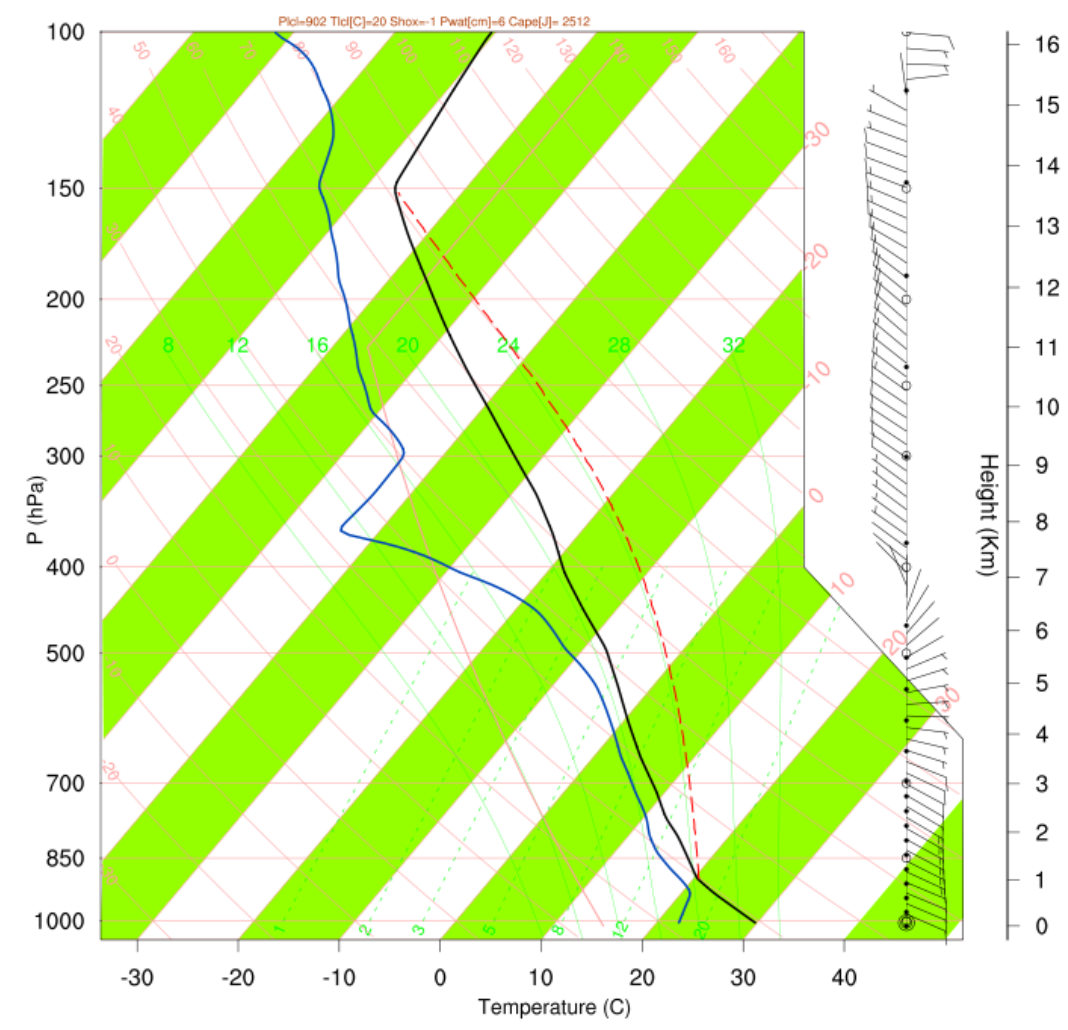

Figure 36. Skew-T chart of atmospheric sounding representing the ambient environment at the time of TASS initialization. Shown are temperature, dewpoint, and horizontal wind velocity as a function of atmospheric pressure. 


\section{Validation and Analysis of Simulation}

A matching of the model time with the UTC time shows that the TASS simulation at time $=40 \mathrm{~min}$ is best representative of conditions at 1712UTC. This was done with the aid of NEXRAD Level 2 data. The TASS coordinates of $x=-23201 \mathrm{~m}$ and $y=10698 \mathrm{~m}$ are equivalent to $67.065^{\circ} \mathrm{W}$ longitude and $18.482^{\circ} \mathrm{N}$ latitude. The TASS simulation captured one of the 3 or 4 storms that stretched from the southeast to the northwest. Simulation results are compared with the observations in Table 11. The model is able to capture the salient features of the storm such as peak echo tops and the storm motion and direction, as well as the shearing of the cloud system from the northwest to southeast. The angle of the shearing is more southward in the NEXRAD data. Also, the peak radar reflectivity is higher in the computations compared to the NEXRAD data.

The TASS simulated cloud field at time $=43 \mathrm{~min}$ and $15 \mathrm{~s}$ is shown in Figure 37. The tilt of the cloud at higher altitudes due to shear in the environment is apparent in the figure. The TASS computed radar reflectivity is compared with the San Juan NEXRAD $0.47^{\circ}$ scan in Figure 38.

Table 11: Model Comparison with Observations

\begin{tabular}{|l|c|c|}
\hline \multicolumn{1}{|c|}{ Variable } & TASS & Observed \\
\hline Orientation of Storm & Southeast - Northwest & Southeast - Northwest \\
\hline Peak Storm Tops (AGL) & $13.72 \mathrm{~km}$ & $14.38 \mathrm{~km}$ \\
\hline Storm Motion & $12.4 \mathrm{~m} / \mathrm{s} \mid 115.14$ degrees & $11.5 \mathrm{~m} / \mathrm{s} \mid 127$ degrees (average values) \\
\hline Maximum Radar Reflectivity & $64.26 \mathrm{dBZ}$ & $56.0 \mathrm{dBZ}$ \\
\hline
\end{tabular}

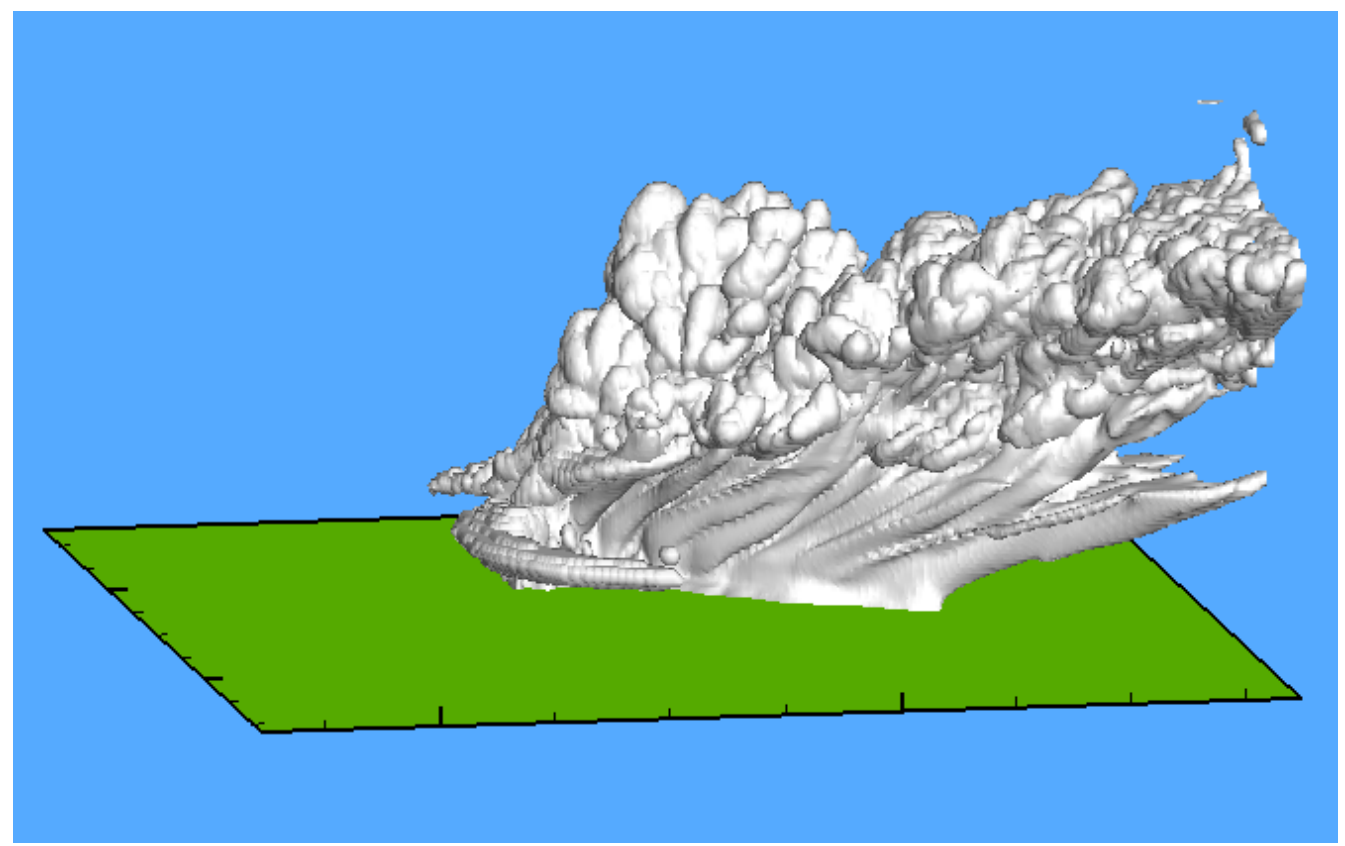

Figure 37. TASS simulated cloud field at time $=43 \mathrm{~min}$ and $15 \mathrm{~s}$. View is from the south. This is around the time of maximum storm intensity. Every other point in $x$-, $y$ - and $z$-direction is plotted. The simulation domain was bounded within a $45 \mathrm{~km} \times 45 \mathrm{~km} \times 17.2 \mathrm{~km}$ domain. Mesh resolution was set to $\Delta x=\Delta y=\Delta z=80 \mathrm{~m}$. 

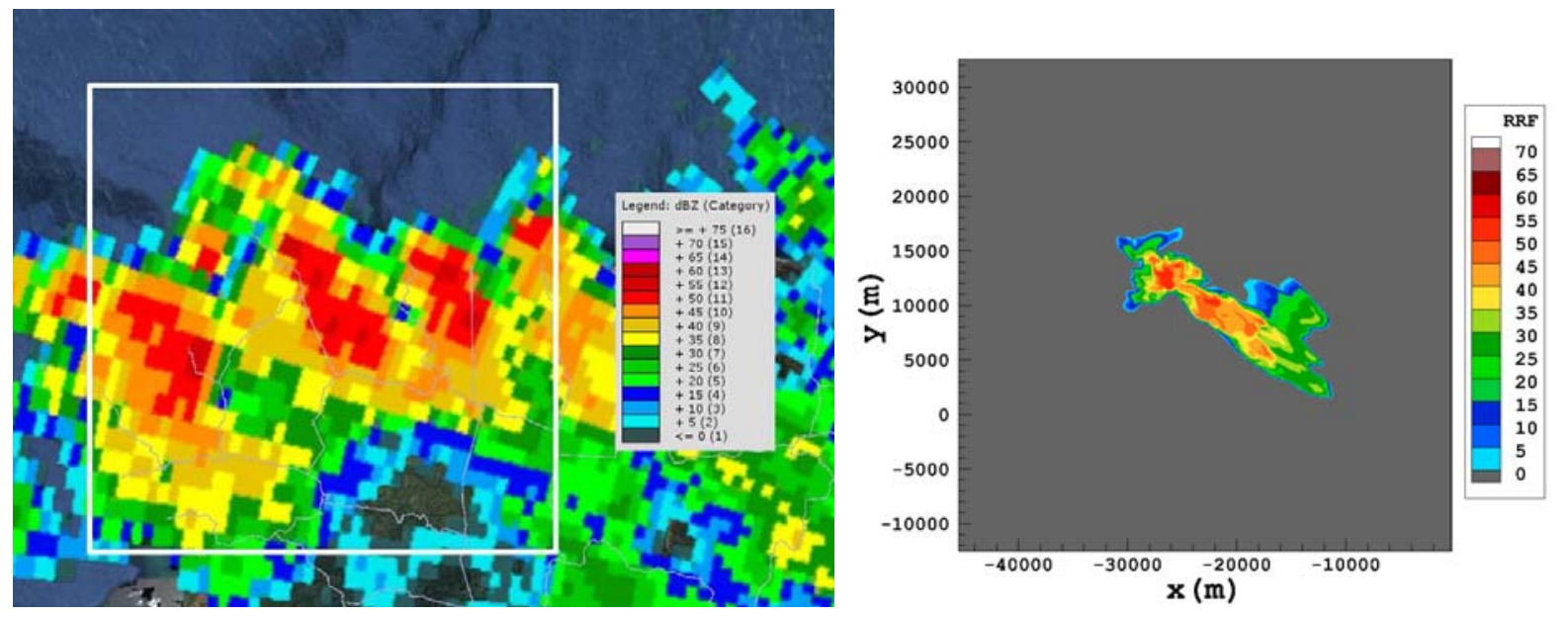

Figure 38. Comparison of the TJUA NEXRAD $0.47^{\circ}$ scan (left) with TASS RRF (right) at an altitude of $1600 \mathrm{~m}$. The white box has an area of $45 \mathrm{~km} \times 45 \mathrm{~km}$ which is the size of the TASS computational domain. NEXRAD is at 1712UTC and TASS data is at 40min into the simulation.

\section{Turbulence}

The RMS of the normal load acceleration $\left(\sigma_{\Delta \mathrm{n}}\right)$ was computed from the TASS simulation data assuming an inflight Boeing B737-300 with a weight of 100klbs. Significant $\sigma_{\Delta \mathrm{n}}$ values $\left(\sigma_{\Delta \mathrm{n}} \geq 0.2 \mathrm{~g}\right)$ occur within the top levels of this storm and coincide with low values of radar reflectivity. These values correspond to peak normal loads greater than $0.5 \mathrm{~g}$ (see Figure 1). The maximum $\sigma_{\Delta \mathrm{n}}$ value at this time in simulation was $0.46 \mathrm{~g}$. The $0.2 \mathrm{~g} \sigma_{\Delta \mathrm{n}}$ isosurface from TASS simulation is shown in Figure 39 along with the $35 \mathrm{dBZ}$ radar reflectivity isosurface. A portion of the vertical velocity slice in the $x$-z plane coinciding with the $0.2 g \sigma_{\Delta \mathrm{n}}$ isosurface is also shown in the figure.

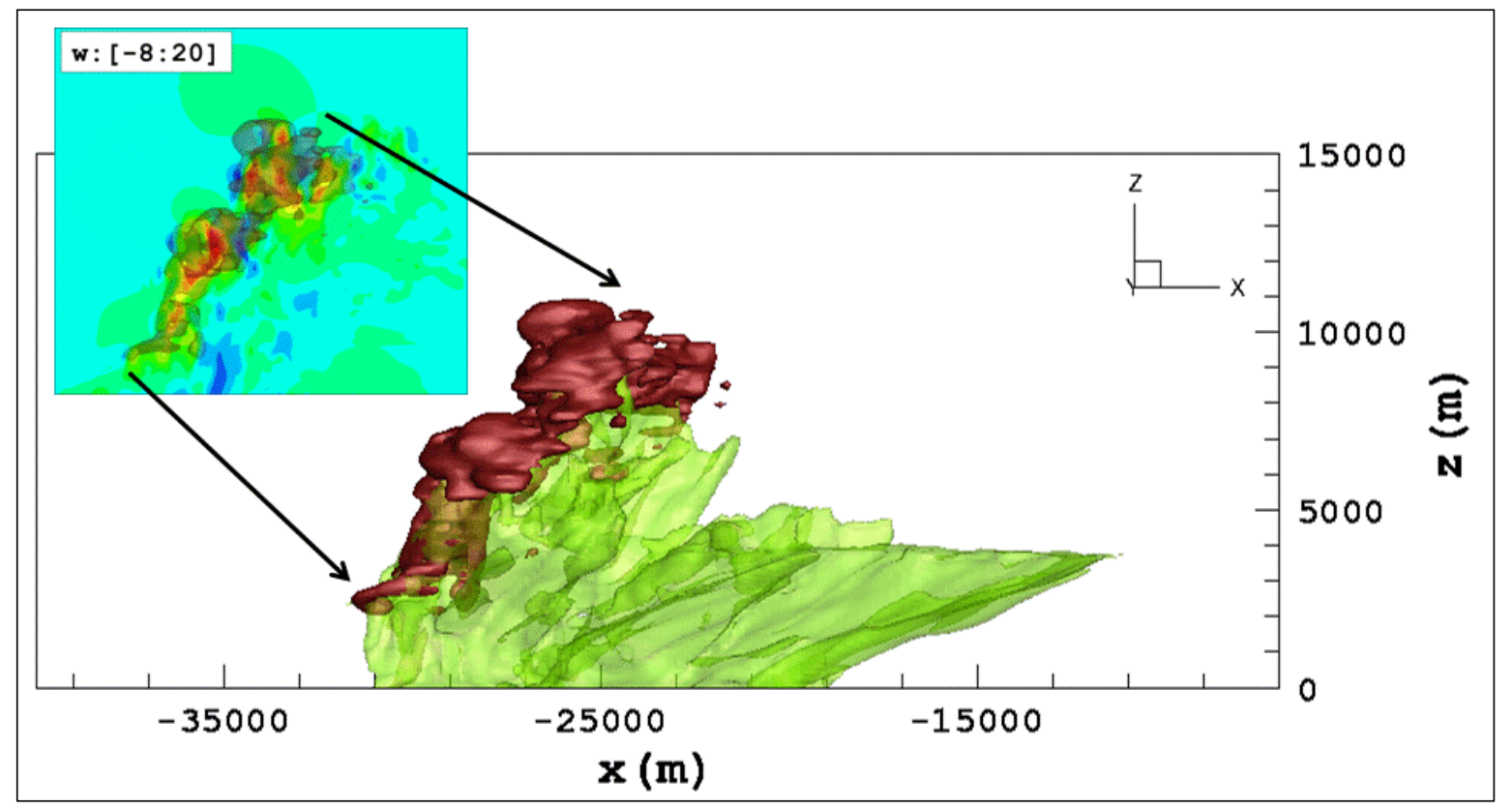

Figure 39. Radar Reflectivity Factor (RRF) isosurface (35dBZ) is shown in green and the $0.2 g \sigma_{\Delta \mathrm{n}}$ isosurface is shown in red. A portion of the vertical velocity $(\mathrm{m} / \mathrm{s})$ slice through the $x$-z plane at $y=12260 \mathrm{~m}$ is also shown in the figure. A Boeing 737-300 aircraft with a weight of $100 \mathrm{klbs}$ is assumed in $\sigma_{\Delta \mathrm{n}}$ calculation. The TASS simulation time $=43 \mathrm{~min}$ and $15 \mathrm{~s}$. 


\section{E. Lincoln, Illinois (10 August 2010)}

An isolated storm was identified by the Lincoln, Illinois NEXRAD station (station ID KILX) at 2117UTC on 10 August 2010. The NEXRAD station data is given in Table 12. The storm was assigned the identifier B2. The storm was re-assigned the identifier O0 at $2150 \mathrm{UTC}$. The storm O0 dissipated by $2245 \mathrm{UTC}$. The storm remained north of a front that stretched through the middle of Illinois (Figure 40). It meandered in the region at a slow speed ( $\sim 6 k t s)$ towards the east and remained in the Ford County. Throughout its evolution it remained within a 60 nautical miles radius around the radar site at Lincoln. The storm reached its maximum intensity around 2217UTC. The storm split into two cells and started to weaken and dissipate around 2245UTC. The cell completely dissipated by 2308UTC.

Probability of hail (possible sizes ranging from $19.1 \mathrm{~mm}$ to $38.1 \mathrm{~mm}$ ) was reported for both the storms B2 and O0 in the NEXRAD Level 2 data and the Level 3 hail index. The radar reflectivity (Level 2 data) at 2150UTC at different elevation angles are shown in Figure 41. Radar reflectivity of $52.5 \mathrm{dBZ}$ at low levels was observed which is indicative of heavy rainfall at that time. The maximum echo top at this time was $12.6 \mathrm{~km}(41.3 \mathrm{kft})$. A vertical cross section of the Level 2 NEXRAD data is shown in Figure 42. A region of reflectivity with values in the range of $56 d B Z$ can be seen in Figure 42.

The details on storm trajectory, strength and precipitation are given in Table 13. All of the data in Table 13 was obtained from NEXRAD Level 3 output except the echo tops which, were estimated by analyzing the Level 2 NEXRAD data. The actual event, as detected by NEXRAD radar, lasted for about 2 hours, had storm tops upwards of $12.9 \mathrm{~km}(42.3 \mathrm{kft})$, and moved relatively slowly $(\sim 3 \mathrm{~m} / \mathrm{s})$ towards the east.

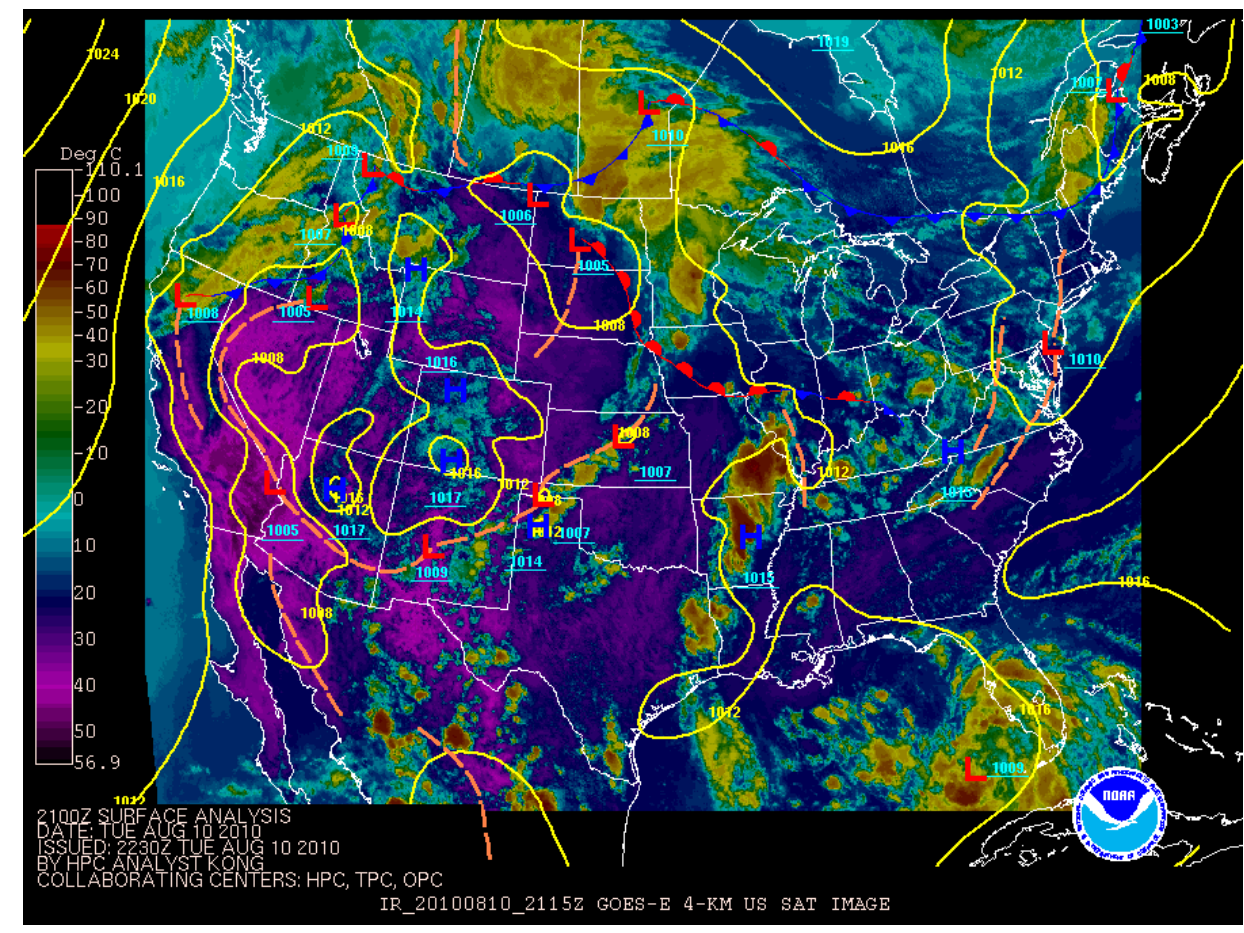

Figure 40. Surface weather map for the continental United States overlaid with GOES-E IR imagery at 2115UTC on 10 August 2010. Source: National Centers for Environmental Prediction (NCEP). 


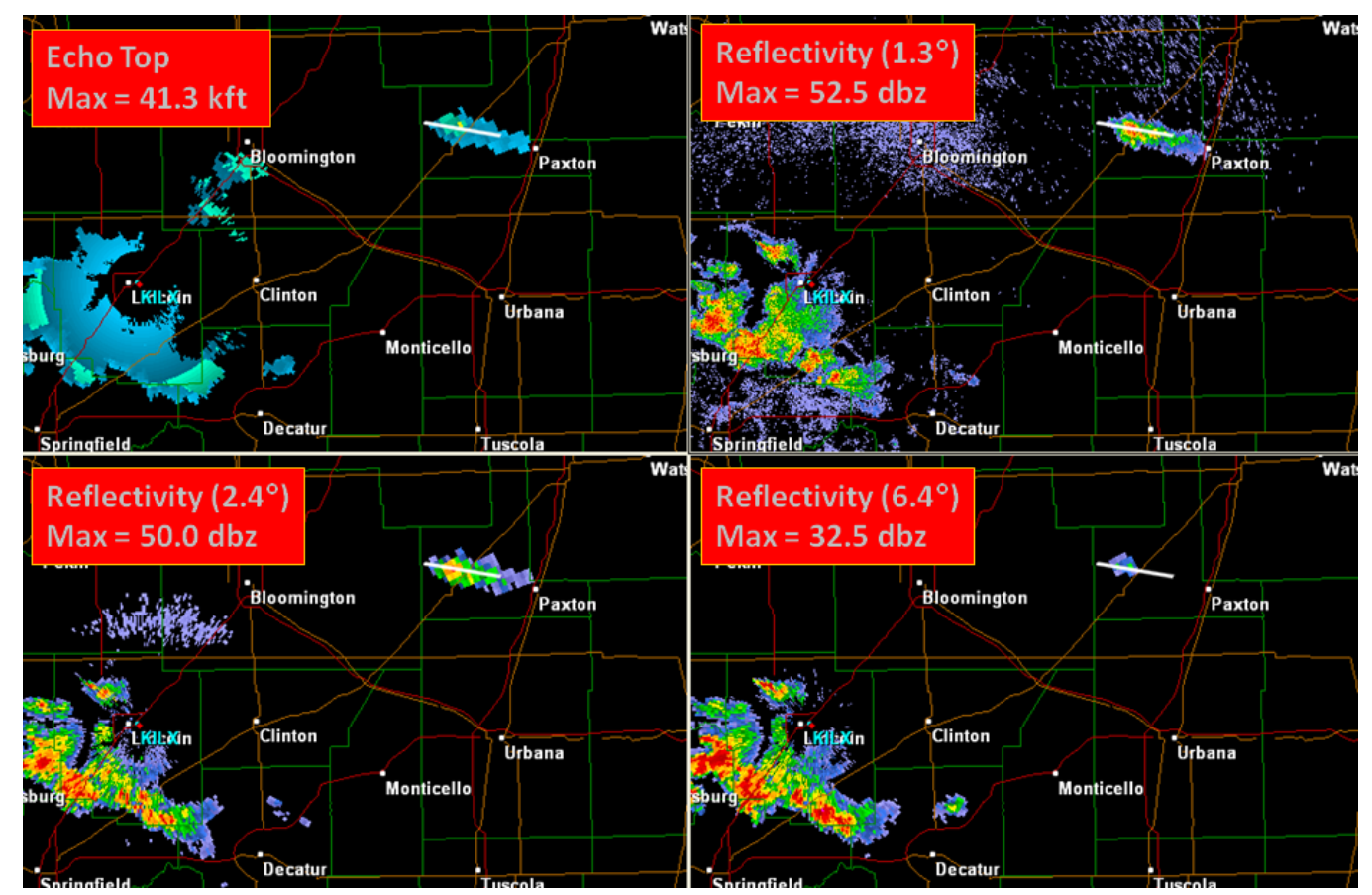

Figure 41. NEXRAD Level 2 data from the National Climate Data Center (NCDC). 10 August 2010 (2150UTC). Echo tops $(k f t)$ are shown in the top left panel and the radar reflectivity $(\mathrm{dBZ})$ at different elevation angles is shown in the other three panels. The storm of interest is near Paxton, Illinois.

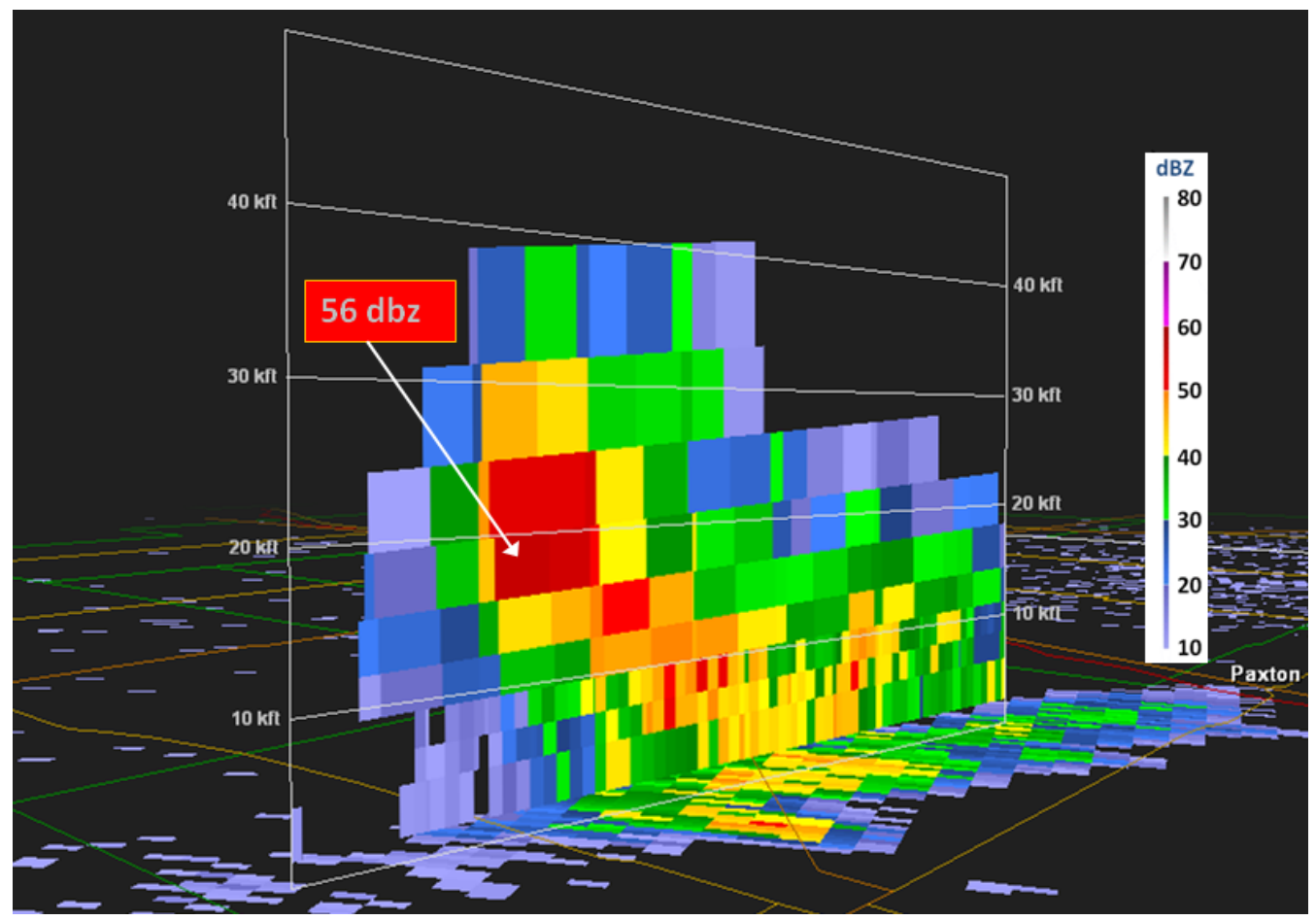

Figure 42. A vertical cross section of the NEXRAD Level 2 data radar reflectivity is shown. 10 August 2010 (2150UTC). Source: National Climate Data Center (NCDC). 
Table 12: NEXRAD Station Data

\begin{tabular}{|c|c|}
\hline Station ID & KILX \\
\hline Location & Lincoln, IL \\
\hline Latitude & $40^{\circ} 08^{\prime} 59^{\prime} \mathrm{N}$ \\
\hline Longitude & $89^{\circ} 20^{\prime} 13^{\prime} \mathrm{W}$ \\
\hline Elevation (MSL) & $222.5 \mathrm{~m}(730 \mathrm{ft})$ \\
\hline
\end{tabular}

Table 13: Characteristics of the Storm - 10 August 2010

\begin{tabular}{|c|c|c|c|c|c|c|c|c|c|}
\hline $\begin{array}{c}\text { Time } \\
\text { (UTC) }\end{array}$ & $\begin{array}{c}\text { Lat } \\
\text { (deg) }\end{array}$ & $\begin{array}{c}\text { Lon } \\
\text { (deg) }\end{array}$ & $\begin{array}{c}\text { Range } \\
\text { (nmi) }\end{array}$ & $\begin{array}{l}\text { Azimuth } \\
\text { (deg) }\end{array}$ & $\begin{array}{c}\text { Echo } \\
\text { Top } \\
(\mathbf{k m}) \\
\end{array}$ & $\begin{array}{c}\text { VIL } \\
\left(\mathrm{kg} / \mathrm{m}^{2}\right)\end{array}$ & $\begin{array}{c}\text { Max } \\
\text { Reflectivity } \\
\text { (dBZ) } \\
\end{array}$ & $\begin{array}{c}\text { One Hour } \\
\text { Precip } \\
\text { (mm) }\end{array}$ & $\begin{array}{c}\text { Storm } \\
\text { Movement } \\
\text { (deg } \mid \mathrm{m} / \mathbf{s}) \\
\end{array}$ \\
\hline B2 / $21: 22$ & $40.512 \mathrm{~N}$ & $88.307 \mathrm{~W}$ & 52 & 65 & 8.1 & 6 & 54.0 & 2.5 & 312 \\
\hline B2 / $21: 27$ & $40.505 \mathrm{~N}$ & $88.279 W$ & 53 & 66 & 8.4 & 9 & 52.5 & 6.3 & \begin{tabular}{l|l}
296 & 5.6
\end{tabular} \\
\hline $\mathrm{B} 2 / 21: 36$ & $40.512 \mathrm{~N}$ & $88.307 \mathrm{~W}$ & 52 & 65 & $\mathrm{n} / \mathrm{a}$ & 16 & 50.5 & 6.3 & 1.0 \\
\hline $00 / 21: 50$ & $40.524 \mathrm{~N}$ & $88.363 \mathrm{~W}$ & 50 & 63 & 12.6 & 22 & 50.5 & 12.7 & New \\
\hline $00 / 21: 55$ & $40.524 \mathrm{~N}$ & $88.363 \mathrm{~W}$ & 50 & 63 & 12.2 & 34 & 53.0 & 12.7 & 163 \\
\hline $00 / 22: 00$ & $40.537 \mathrm{~N}$ & $88.372 W$ & 50 & 62 & 12.6 & 46 & 58.5 & 12.7 & \begin{tabular}{l|l}
160 & 2.6
\end{tabular} \\
\hline $00 / 22: 06$ & $40.545 \mathrm{~N}$ & $88.352 W$ & 51 & 62 & 12.8 & 46 & 58.5 & 25.4 & 181 \\
\hline $00 / 22: 12$ & $40.532 \mathrm{~N}$ & $88.344 \mathrm{~W}$ & 51 & 63 & 12.9 & 31 & 59.0 & 31.8 & 2.6 \\
\hline $00 / 22: 17$ & $40.532 \mathrm{~N}$ & $88.344 \mathrm{~W}$ & 51 & 63 & 12.5 & 34 & 57.5 & 38.1 & 206 \\
\hline $00 / 22: 23$ & $40.532 \mathrm{~N}$ & $88.344 W$ & 51 & 63 & 12.4 & 27 & 56.5 & 38.1 & $\mathrm{n} / \mathrm{a}$ \\
\hline $00 / 22: 34$ & $40.526 \mathrm{~N}$ & $88.315 \mathrm{~W}$ & 52 & 64 & 11.6 & 12 & 53.5 & $\mathrm{n} / \mathrm{a}$ & $\mathrm{n} / \mathrm{a}$ \\
\hline $00 / 22: 40$ & $40.519 \mathrm{~N}$ & $88.287 W$ & 53 & 65 & 9.1 & 16 & 51.0 & 44.5 & 1.5 \\
\hline
\end{tabular}

\section{Simulation Setup}

The TASS computational domain was bounded in the horizontal within a mesh of $42 \mathrm{~km} \times 42 \mathrm{~km}$. The vertical extant was set to $18 \mathrm{~km}$. The grid resolution was set to $80 \mathrm{~m}$ in all coordinate directions ( $528 \times 528 \times 229$ points). The model domain translates with simulated convective cell, thus relaxing the requirement for a larger computational domain. The TASS simulation was initialized from the WRF sounding.

The WRF simulation domain consisted of an outer most domain bounded between $130.01^{\circ} \mathrm{W}$ and $50.81^{\circ} \mathrm{W}$ in the longitude and $20.33^{\circ} \mathrm{N}$ and $58.44^{\circ} \mathrm{N}$ with a mesh resolution of $60.0 \mathrm{~km}$. Two higher resolution nests were defined within the outermost domain. Domain 2 was bounded between $109.12^{\circ} \mathrm{W}$ and $71.69^{\circ} \mathrm{W}$ in the longitude and $30.63^{\circ} \mathrm{N}$ and $50.25^{\circ} \mathrm{N}$ in the latitude with a mesh resolution of $20.0 \mathrm{~km}$. The innermost domain was bounded between $99.01^{\circ} \mathrm{W}$ and $81.55^{\circ} \mathrm{W}$ in the longitude and $36.28^{\circ} \mathrm{N}$ and $45.31^{\circ} \mathrm{N}$ with a mesh resolution of $6.66 \mathrm{~km}$. Highresolution $(1 \mathrm{~km})$ terrain and land use datasets were used for the innermost domain. The WRF computational domain and the terrain for the innermost domain are shown in Figure 43. The simulation was initialized using Global Forecast System (GFS) data from the National Climate Data Center (NCDC) for 10 August 2010 at 1200UTC. The 
simulation was run for 24 hours. The output for the innermost domain was generated every $15 \mathrm{~min}$. The sounding forecast (see Figure 44) was extracted from the WRF simulation high-resolution nest for 10 August at 2130UTC. The low levels of the sounding were modified to agree with observed cloud base heights. The initial conditions in TASS vary only in the vertical direction in accordance to the sounding in Figure 44. Convection with cloud and precipitation development was triggered in TASS by imposing an artificial bubble of warm air. Three-dimensional fields evolved as convection interacted with the environmental fields.
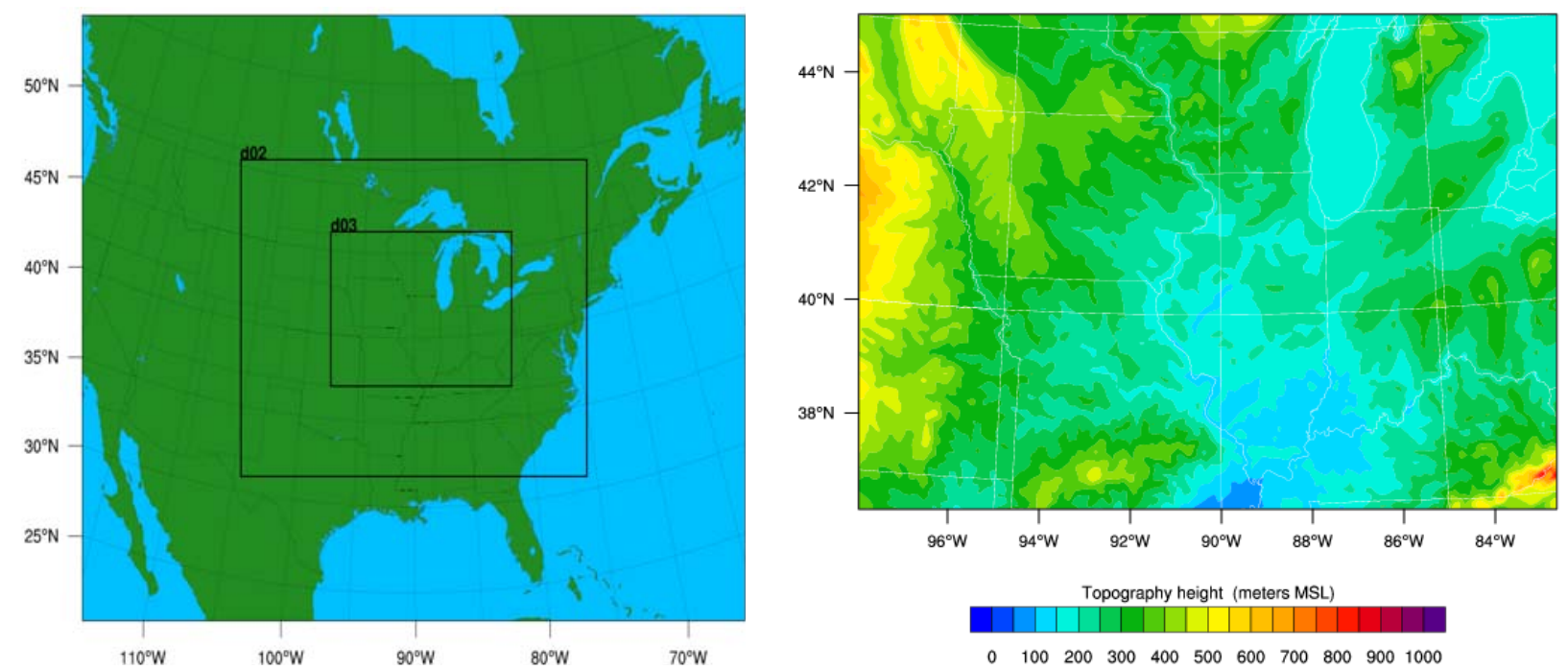

Figure 43. The left panel shows the WRF computational domain with higher resolution nests and the right panel shows the terrain contours for the inner most computational domain. The terrain maximum value in the plot is $869.96 \mathrm{~m}$ and the minimum value is $82.98 \mathrm{~m}$.



Figure 44. Skew-T chart of atmospheric sounding representing the ambient environment used for TASS initialization. Shown are temperature, dewpoint, and horizontal wind velocity as a function of atmospheric pressure. 


\section{Validation and Analysis of Simulation}

A matching of the model time with the UTC time shows that the TASS simulation at time $=37 \mathrm{~min}$ is best representative of conditions at 2217UTC. This was done with the aid of NEXRAD Level 2 data. The TASS coordinates of $x=8521.83 \mathrm{~m}$ and $y=501.51 \mathrm{~m}$ are equivalent to $88.34^{\circ} \mathrm{W}$ longitude and $40.536^{\circ} \mathrm{N}$ latitude. The TASS simulation results are compared with observations in Table 14. The TASS computed radar reflectivity is over-predicted but other measures such as, storm orientation, storm motion and peak echo tops are in good agreement with observations.

In Figure 45, the TASS simulated cloud field is shown at time $=37 \mathrm{~min}$ into the simulation. In Figures $46-47$, the cross sections of the TASS computed radar reflectivity in $x-y$ plane at two different heights are compared with NEXRAD data at time $=37 \mathrm{~min}$ into the simulation.

Table 14: Model Comparison with Observations

\begin{tabular}{|l|c|c|}
\hline \multicolumn{1}{|c|}{ Variable } & TASS & Observed \\
\hline Orientation of Storm & East - West & East - West \\
\hline Peak Storm Tops (AGL) & $14.5 \mathrm{~km}$ & $12.9 \mathrm{~km}$ \\
\hline Storm Motion & $3.8 \mathrm{~m} / \mathrm{s}$ & $2.8 \mathrm{~m} / \mathrm{s}$ \\
\hline Maximum Radar Reflectivity & $76.3 \mathrm{dBZ}$ & $59.0 \mathrm{dBZ}$ \\
\hline
\end{tabular}

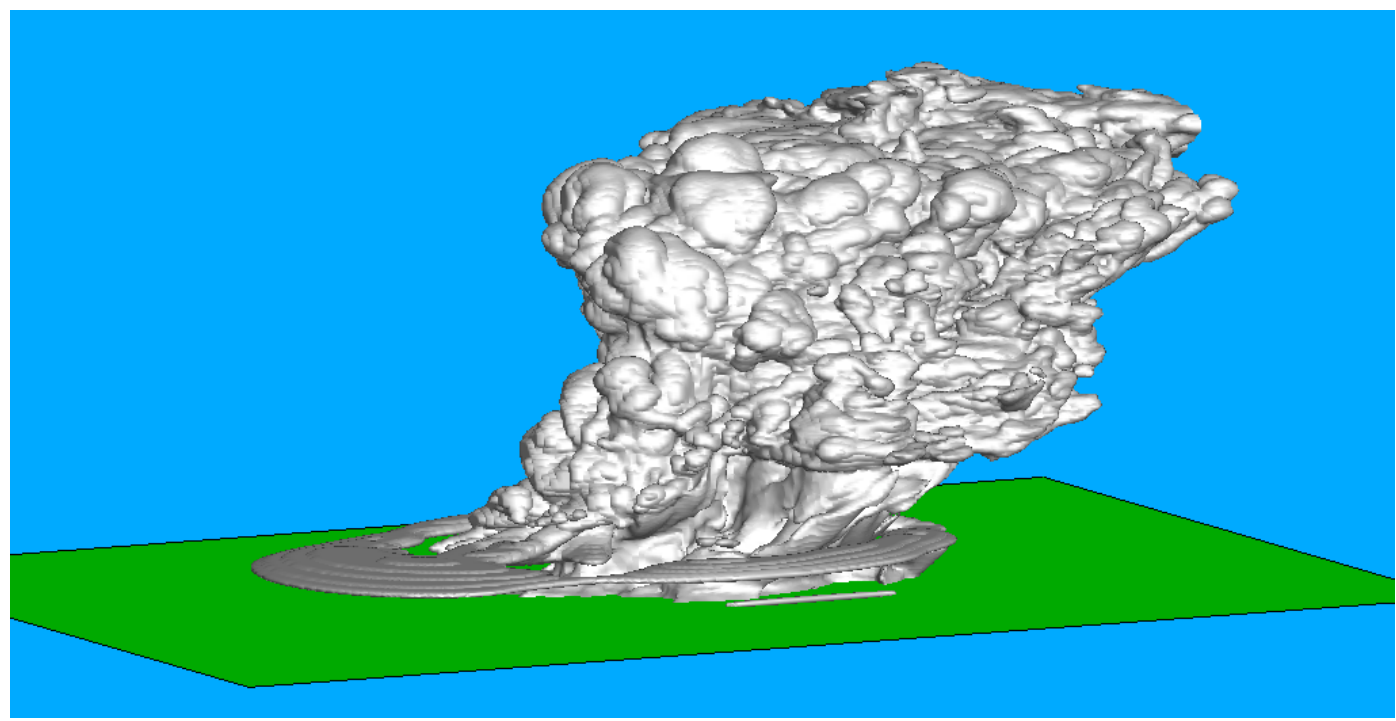

Figure 45. TASS simulated cloud field at time $=37 \mathrm{~min}$ is shown. The view is from the south. Every point in $z$-direction is plotted and every other point in $x$ - and $y$-direction is plotted. The simulation domain was bounded within a $42 \mathrm{~km} \times 42 \mathrm{~km} \times 18 \mathrm{~km}$ domain. Mesh resolution was set to $\Delta x=\Delta y=\Delta z=80 \mathrm{~m}$. 

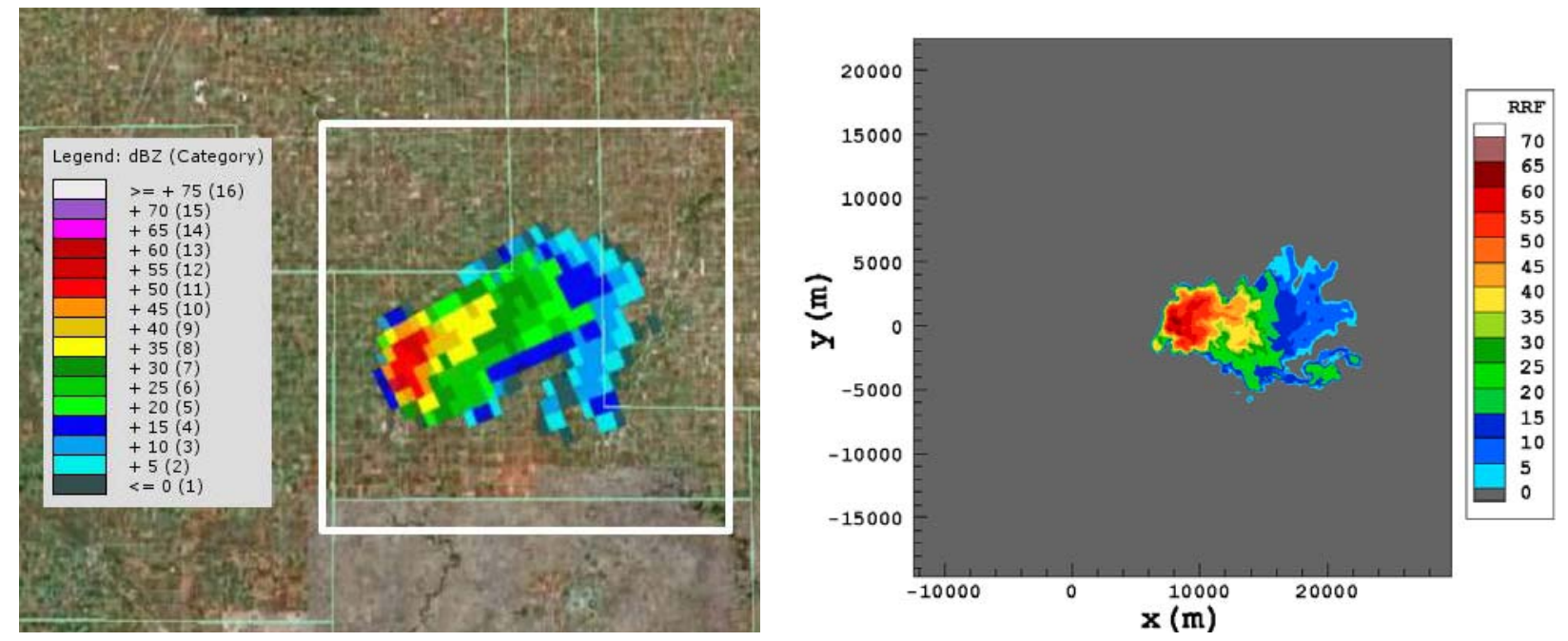

Figure 46. Comparison of the KILX NEXRAD $3.37^{\circ}$ scan (left) with TASS RRF (right). The white box is $42 \mathrm{~km} \times 42 \mathrm{~km}$ in area and represents the size of TASS simulation domain. TASS $x-y$ plane at an altitude of $6720 \mathrm{~m}$ is shown in the figure. NEXRAD is at 2217UTC and TASS data is at 37min into the simulation. Every other point in $x$ - and $y$-direction is plotted. The simulation domain was bounded within a $42 \mathrm{~km} \times 42 \mathrm{~km} \mathrm{x}$ $18 \mathrm{~km}$ domain. Mesh resolution is set to $\Delta x=\Delta y=\Delta z=80 \mathrm{~m}$.
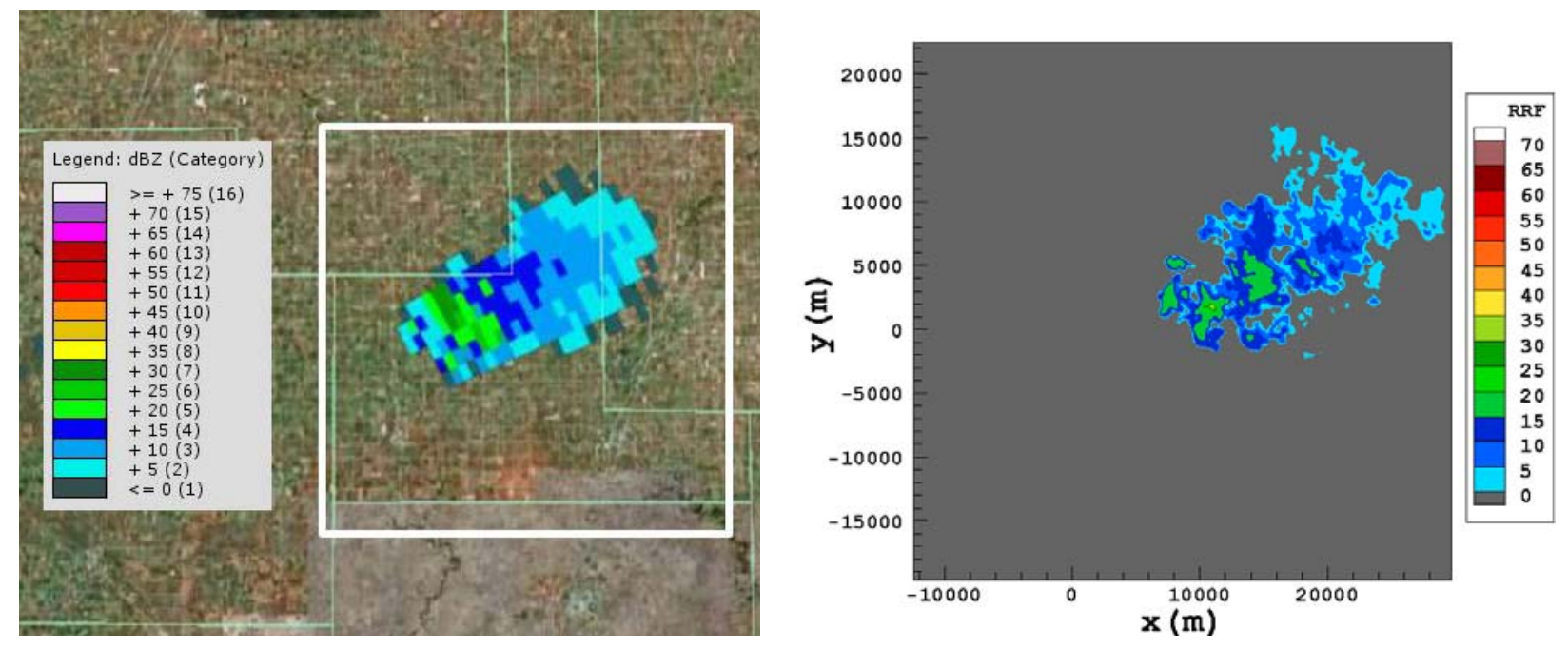

Figure 47. Comparison of the KILX NEXRAD 5.99 scan (left) with TASS RRF (right). The white box is $42 \mathrm{~km} \times 42 \mathrm{~km}$ in area and represents the size of TASS simulation domain. TASS $x-y$ plane at an altitude of $12000 \mathrm{~m}$ is shown in the figure. NEXRAD is at 2217UTC and TASS data is at 37min into the simulation. Every other point in $x$ - and $y$-direction is plotted. The simulation domain was bounded within a $42 \mathrm{~km} \times 42 \mathrm{~km}$ $x 18 \mathrm{~km}$ domain. Mesh resolution is set to $\Delta x=\Delta y=\Delta z=80 \mathrm{~m}$. 


\section{Turbulence}

The RMS of the normal load acceleration $\left(\sigma_{\Delta \mathrm{n}}\right)$ was computed from the TASS simulation data assuming an inflight Boeing B737-300 with a weight of 100klbs. Significant $\sigma_{\Delta \mathrm{n}}$ values $\left(\sigma_{\Delta \mathrm{n}} \geq 0.2 \mathrm{~g}\right)$ occur within the top levels of this storm and coincide with low values of radar reflectivity. These values correspond to peak normal loads greater than $0.5 \mathrm{~g}$. The $0.2 \mathrm{~g}$ isosurface of the RMS normal load acceleration from TASS simulation is shown in Figure 48 along with $35 \mathrm{dBZ}$ radar reflectivity isosurface. The maximum $\sigma_{\triangle \mathrm{n}}$ value at this time was $0.6 \mathrm{~g}$. The TASS computed $\mathrm{RRF}$ and the $\sigma_{\Delta \mathrm{n}}$ fields in the $x-y$ plane at an altitude of $11120 \mathrm{~m}$ are shown in Figure 49.

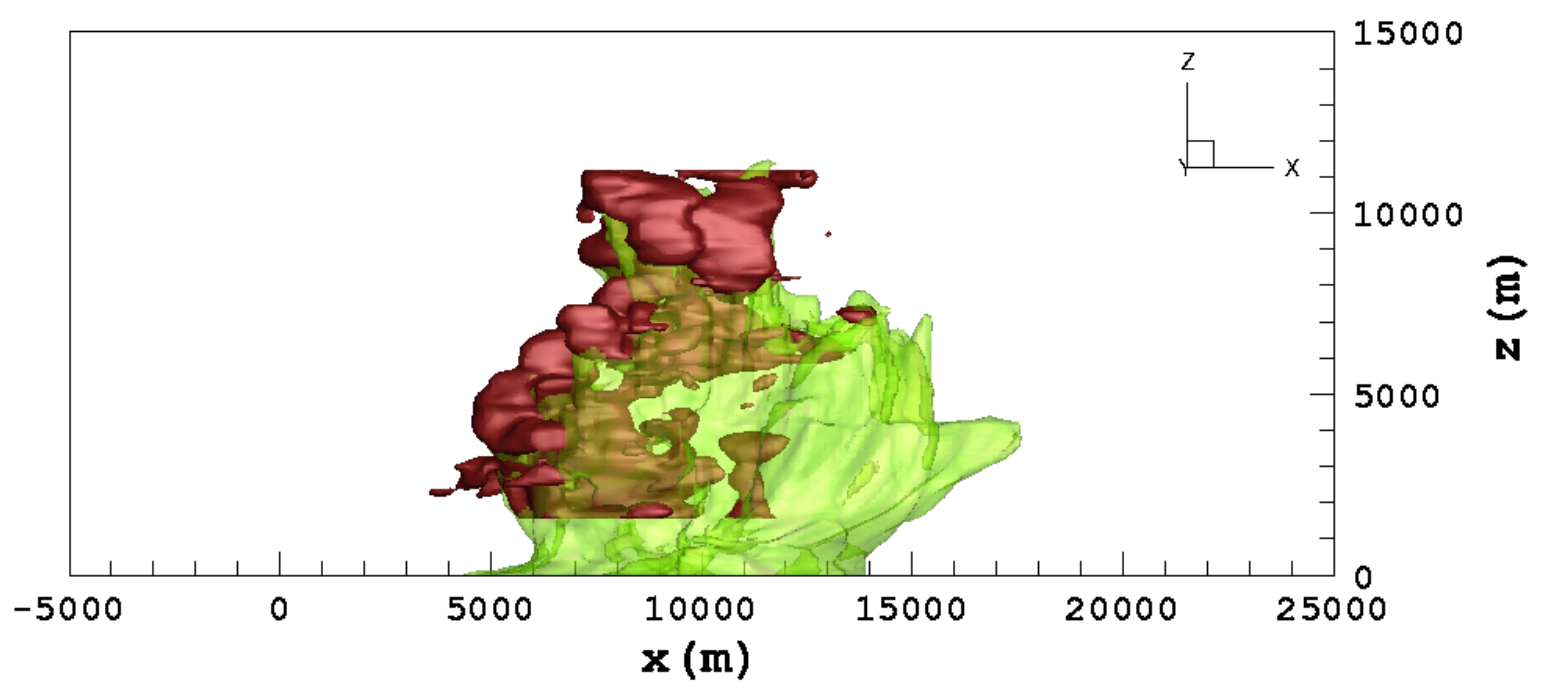

Figure 48. TASS computed Radar Reflectivity Factor isosurface of $35 d B Z$ is shown in green and the $0.2 \mathrm{~g}$ $\sigma_{\Delta \mathrm{n}}$ isosurface is shown in red. A Boeing 737-300 aircraft with a weight of 100klbs is assumed in $\sigma_{\Delta \mathrm{n}}$ calculation. Every point in $z$-direction is plotted and every other point in $x$ - and $y$-direction is plotted. The simulation domain was bounded within a $42 \mathrm{~km} \times 42 \mathrm{~km} \times 18 \mathrm{~km}$ domain. Mesh resolution was set to $\Delta x=\Delta y=$ $\Delta z=80 \mathrm{~m}$. Time $=37 \mathrm{~min}$ into the simulation.
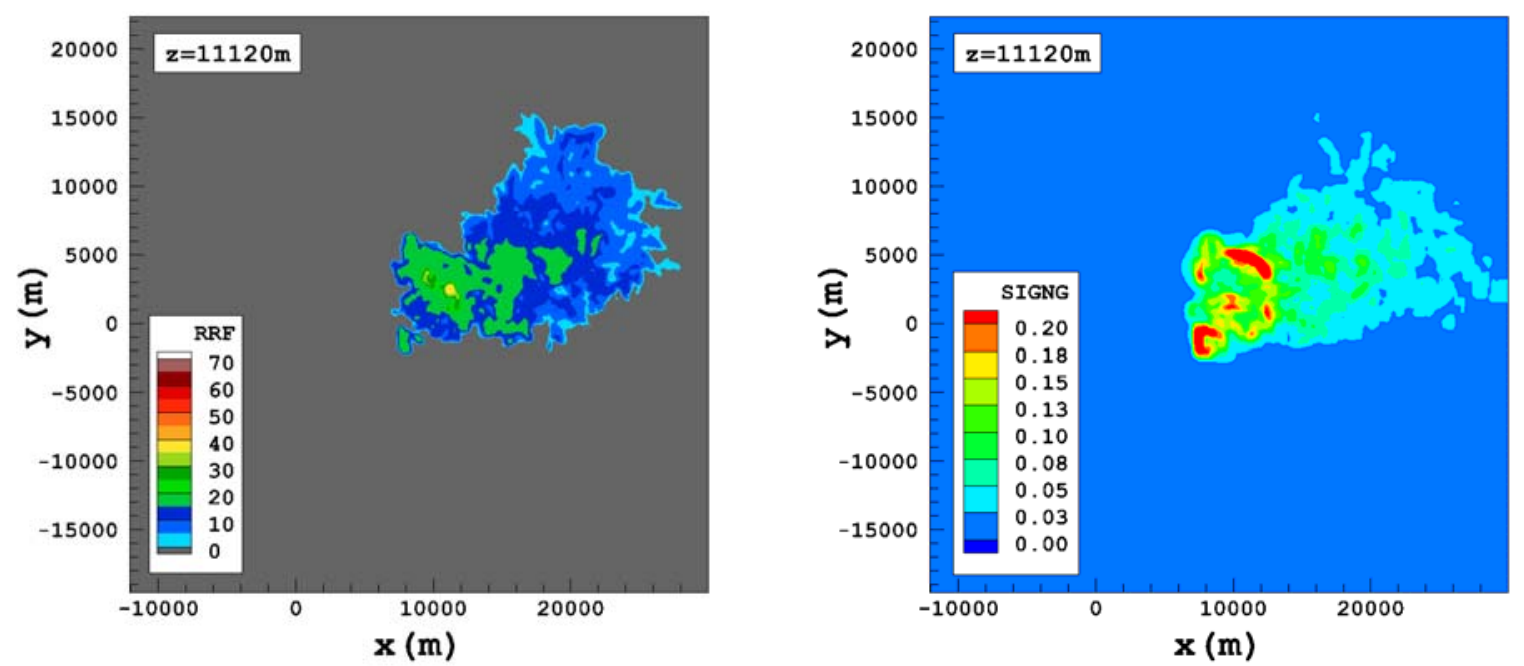

Figure 49. The TASS computed Radar Reflectivity Factor field in the $x-y$ plane at an altitude of $11120 \mathrm{~m}$ is shown in the left panel and the $\sigma_{\Delta \mathrm{n}}$ field on the same plane is shown in the right panel. Every other point in $x$ and $y$-direction is plotted. A Boeing 737-300 aircraft with a weight of $100 \mathrm{klbs}$ is assumed in the $\sigma_{\Delta \mathrm{n}}$ calculation. Time $=37 \mathrm{~min}$ into the simulation. 


\section{Summary}

Simulations of five severe convective induced turbulence events were performed using TASS. The events ranged from a large mesoscale convective system to isolated severe thunderstorms. The initial environments for TASS simulations were obtained from WRF predictions. Convection in TASS was initialized by an artificial impulse. A comparison of the model results with NEXRAD and other surface observations showed that it was able to simulate the evolution of storms in detail and with a good degree of accuracy. In most cases the model computed storm motion, storm orientation, peak echo tops, size of the radar echo, and the duration of the event agreed well with the observations but the peak radar reflectivity was generally over estimated. Some of the discrepancy in radar reflectivity is expected, since the model does not take into account the radar beam size and geometry in RRF calculation.

Aircraft-centric turbulence characteristics were analyzed for each case. The turbulence analysis was consistent with previous studies (Proctor et al. 2002; Hamilton and Proctor 2002; Hamilton and Proctor 2003) and showed that large pockets of significant turbulence hazard can be found in regions of low radar reflectivity. Moderate and severe turbulence often was found in building cumulus turrets and overshooting tops, especially on the upwind side of the convective system. Data sets such as these can be very useful in radar simulation studies (e.g., Hamilton and Proctor 2006) for testing and developing algorithms for hazard avoidance, as well as in the understanding of turbulence in relation to convective storms.

\section{Appendix A}

The Weather Surveillance Radar - 1988 Doppler (WSR-88D) is more commonly known as the NEXt Generation RADar or NEXRAD. The National Weather Service (NWS) operates the NEXRAD sites that cover the entire continental United States, Hawaii, Puerto Rico and Guam (http://www.roc.noaa.gov/WSR88D/). The NEXRAD data is archived by NCDC and is available for download from their website (http://www.ncdc.noaa.gov/nexradinv/). The NEXRAD base reflectivity data has a resolution of $1 \mathrm{~km}$ in range and $1^{\circ}$ in azimuth. The data frequency in time is every $6 \mathrm{~min}$. The Level 2 (L2) data has $256 \mathrm{dBZ}$ levels and the Level 3 (L3) data has $16 \mathrm{dBZ}$ levels. The L2 base velocity is at a resolution of $250 \mathrm{~m} \times 1^{\circ}$ compared to L3 base velocity which is at $1 \mathrm{~km} \times 1^{\circ}$. The number of radar tilt angles is also larger in the L2 data (14 angles compared to 4 angles in L3).

The NEXRAD Level 2 data is comprised of reflectivity, mean radial velocity and spectrum width, whereas the Level 3 data has 41 products which include base reflectivity, base velocity, base spectrum width, composite reflectivity at different levels, vertical integrated liquid, echo tops and wind profiles. The Level 3 products also include precipitation estimates such as one hour cumulative precipitation and total storm precipitation, etc. In addition, the Level 3 data contains derived information on storm structure and storm tracks, etc. The NEXRAD Level 2 and Level 3 products were used in the analysis and validation of TASS simulations presented in this paper. A brief description of the NEXRAD Level 3 products which were used in the analysis is given in Table A-1 for reference.

Table A-1: Description of Storm Characteristics Variables

\begin{tabular}{|c|l|}
\hline Variable & \multicolumn{1}{|c|}{ Description } \\
\hline Range & Distance from radar in nautical miles. Maximum range $=124 \mathrm{nmi}(\mathrm{nmi}=1.852 \mathrm{~km})$ \\
\hline Azimuth & Azimuth angle from radar in degrees $(0=$ north; $90=$ east; $180=$ south; $270=$ west $)$ \\
\hline Echo Top & Elevation of storm in $\mathbf{k f t}(\mathrm{ft}=0.3048 \mathrm{~m})$ \\
\hline VIL & Cell based vertically integrated liquid in $\mathbf{k g} / \mathbf{m}^{2}$ \\
\hline Max Reflectivity & Maximum reflectivity of the storm cell in $\mathbf{~} \mathbf{}$ \\
\hline Storm Movement $0.5^{\circ}$ elevation angle scan \\
\hline One Hour Precipitation & Storm movement in degrees and $\mathbf{k t s}(\mathrm{kt}=0.514 \mathrm{~m} / \mathrm{s})$ \\
\hline
\end{tabular}




\section{Acknowledgements}

This work was completed under a Reimbursable Space Act Agreement (SAA1-1017) between Rockwell Collins, Inc. and the National Aeronautics and Space Administration. The authors would like to acknowledge assistance in data processing by George Switzer (Analytical Services and Materials) and Fanny Limon-Duparcmeur (Metis Technical Solutions). The Weather Research and Forecast (WRF) model simulations were conducted on NASA Langley's K-cluster.

\section{References}

Ahmad, N.N., F.H. Proctor, "Advection of Microphysical Scalars in Terminal Area Simulation System (TASS),” AIAA 2011-1004.

Arakawa, A., V. R. Lamb, "Computational Design of the Basic Dynamical Process of the UCLA General Circulation Model," Methods in Computational Physics, Vol. 17, 1977, pp. 173-265.

Ashley, W. S., T. L. Mote, P. G. Dixon, S. L. Trotter, E. J. Powell, J. D. Durkee, A. J. Grundstein, "Distribution of Mesoscale Convective Complex Rainfall in the United States,” Monthly Weather Review, Vol. 131, 2003, pp. 3003-3017.

Bowles, R.L., B. Buck, “A Methodology for Determining Statistical Performance Compliance for Airborne Doppler Radar with Forward-Looking Turbulence Detection Capability,” NASA CR 2009-215769.

Clark, T. L., and R. D. Farley, "Severe Downslope Windstorm Calculations in Two and Three Spatial Dimensions using Anelastic Interactive Grid Nesting: A Possible Mechanism for Gustiness," Journal of Atmospheric Science, Vol. 41, 1984, pp. $329-350$.

Doviak, R. J., and J. T. Lee, "Radar for Storm Forecasting and Weather Hazard Warning,” Journal of Aircraft, Vol. 22, 1985, pp. 1059-1064.

Hamilton, D.W., and F.H. Proctor, "Convectively-Induced Turbulence Encountered during NASA's Fall-2000 Flight Experiments," $10^{\text {th }}$ Conference on Aviation, Range and Aerospace Meteorology, American Meteorological Society, 2002, pp. 371-374.

Hamilton, D.W., and F.H. Proctor, “An Aircraft Encounter with Turbulence in the Vicinity of a Thunderstorm,” AIAA 20034075 .

Hamilton, D.W., and F.H. Proctor, "Progress in the Development of an Airborne Turbulence Detection System," $12^{\text {th }}$ Aviation, Range, and Aerospace Meteorology Conference, Paper 6.5, American Meteorological Society, January 2006.

Hamilton, D.W., and F.H. Proctor, “Airborne Turbulence Detection System Certification Tool Set,” AIAA 2006-75.

Kaplan, M.L., A.W. Huffman, K.M. Lux, J.J. Charney, A.J. Riordan, and Y.-L. Lin, "Characterizing the Severe Turbulence Environments Associated with Commercial Aviation Accidents," Meteorology and Atmospheric Physics, Vol. 88, 2005, pp. 129152.

Klemp, J. B., W. C. Skamarock, and J. Dudhia, "Conservative Split-Explicit Time Integration Methods for the Compressible Nonhydrostatic Equations," Monthly Weather Review, Vol. 135, August 2007, pp. 2897-2913.

Klemp, J. B., and R. Wilhelmson, "The Simulation of Three-Dimensional Convective Storm Dynamics," Journal of Atmospheric Sciences, Vol. 35, 1978, pp. 1070-1096.

Leonard, B. P., M. K. MacVean and A. P. Lock, "The Flux-Integral Method for Multidimensional Convection and Diffusion,” Applied Mathematical Modeling, Vol. 19, 1995, pp. 333-342.

Lin, Y-L., Farley, R. D., and Orville, H. D., "Bulk Parameterization of the Snow Field in a Cloud Model," Journal of Climate and Applied Meteorology, Vol. 22, 1983, pp. 1065-1092.

Maddox, R. A., “Mesoscale Convective Complexes,” Bulletin of American Meteorological Society, Vol. 61, 1980, pp. 13741387. 
McCann, D. W., "The Enhanced-V: A Satellite Observable Severe Storm Signature," Monthly Weather Review, Vol. 111, 1983, pp. 887-894.

Mesinger, F., G. DiMego, E. Kalnay, K. Mitchell, P. C. Shafran, W. Ebisuzaki, D. Jović, J. Woollen, E. Rogers, E. H. Berbery, M. B. Ek, Y. Fan, R. Grumbine, W. Higgins, H. Li, Y. Lin, G. Manikin, D. Parrish, W. Shi,’North American Regional Reanalysis," Bulletin of the American Meteorological Society, Vol. 87, 2006, pp. 343-360.

Orlanski, I., "A Simple Boundary Condition for Unbounded Hyperbolic Flows," Journal of Computational Physics, Vol. 21. 1976, pp. 251-269.

Perkey, D.J., and C.W. Kreitzberg, "A Time-Dependent Lateral Boundary Scheme for Limited-Area Primitive Equation Models," Monthly Weather Review, Vol. 104, 1976, pp.744-755.

Prince, J. B., B. K. Buck, P. A. Robinson, "In-Service Evaluation of the Turbulence Auto-PIREP System and Enhanced Turbulence Radar Technologies," NASA CR 2007-214887.

Proctor, F. H., "The Terminal Area Simulation System / Volume 1: Theoretical Formulation," NASA CR 1987-4046.

Proctor, F. H., "The Terminal Area Simulation System / Volume 2: Verification Cases," NASA CR 1987-4047.

Proctor, F. H., D. W. Hamilton, and R. L. Bowles, "Numerical Study of a Convective Turbulence Encounter," AIAA 20020944.

Proctor, F.H., D.W. Hamilton and R.L. Bowles, "Numerical Simulation of a Convective Turbulence Encounter," Preprints $10^{\text {th }}$ Conference on Aviation, Range, and Aerospace Meteorology, May 2002, Amer. Meteor. Soc., pp. 41-44.

Proctor, F. H., "Interaction of Aircraft Wakes from Laterally Spaced Aircraft," AIAA 2009-343.

Proctor, F. H., "Numerical Simulation of Wake Vortices Measured During the Idaho Falls and Memphis Field Programs," AIAA 1996-2496.

Proctor, F. H., and D. W. Hamilton, "Hazard Metric Unification," NASA WxAP Annual Review, Williamsburg, Virginia, Powerpoint Presentation, 20 pp. 2005.

Smagorinsky, J., “General Circulation Experiments with the Primitive Equations,” Monthly Weather Review, Vol. 91, 1963, pp. 99-164.

Tvaryanas, A.P., "Epidemiology of Turbulence-Related Injuries in Airline Cabin Crew, 1992-2001," Aviation and Space Environmental Medicine, Vol. 74, 2003, pp. 970-976.

Siebesma, A.P., C. R. Bretherton, A. Brown, A. Chlond, J. Cuxart, P.G. Duynkerke, H. Jiang, M. Khairoutdinov, D. Lewellen, C. Moeng, E. Sanchez, B. Stevens, D. Stevens, “A Large Eddy Simulation Intercomparison Study of Shallow Cumulus Convection,” Journal of the Atmospheric Sciences, Vol. 60, 2003, pp. 1201-1219.

Simpson, B. J., “A Review of a Rare Classic Supercell in Northern Indiana and Possible Explanations for Tornadogenesis Failure," Presentation posted at: http://www.crh.noaa.gov/iwx/?n=isolatedsupercellinnorthernindiana6/19, 2009.

Stull, R., An Introduction to Boundary-Layer Meteorology, Kluwer Academic Publishers, 1997.

van Leer, B., "Towards the Ultimate Conservative Difference Scheme: V, A Second-Order Sequel to Godunov's Method," Journal of Computational Physics, Vol. 32, 1979, pp. 101-136.

Williams, J. K., R. Sharman, C. Kessinger, W. Feltz, A. Wimmers, K. Bedka, "Developing a Global Turbulence and Convection Nowcast and Forecast System," AIAA 2009-3634.

Zhang, D.-L., and J. M. Fritsch, "Numerical Sensitivity Experiments of Varying Model Physics on the Structure, Evolution, and Dynamics of Two Mesoscale Convective Systems,” Journal of Atmospheric Science, Vol. 45, 1988, pp. 261-293. 